ANL-6954

ANL-6954

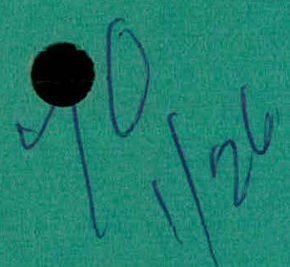

Argonne Rational Iabaratoru

LIQUID MHD POWER CYCLE STUDIES

by

Michael Petrick and Kung-You Lee 


\section{DISCLAIMER}

This report was prepared as an account of work sponsored by an agency of the United States Government. Neither the United States Government nor any agency Thereof, nor any of their employees, makes any warranty, express or implied, or assumes any legal liability or responsibility for the accuracy, completeness, or usefulness of any information, apparatus, product, or process disclosed, or represents that its use would not infringe privately owned rights. Reference herein to any specific commercial product, process, or service by trade name, trademark, manufacturer, or otherwise does not necessarily constitute or imply its endorsement, recommendation, or favoring by the United States Government or any agency thereof. The views and opinions of authors expressed herein do not necessarily state or reflect those of the United States Government or any agency thereof. 


\section{DISCLAIMER}

Portions of this document may be illegible in electronic image products. Images are produced from the best available original document. 


\section{LEGAL NOTICE}

This report was prepared as an account of Government sponsored work. Neither the United States, nor the Commission, nor any person acting on belialf of the Commission.

A. Makes any warranty or representation, expressed or implied, with respect to the accuracy, completeness, or usefulness of the information contained in this report, or that the use of any information, apparatus, methur, un procese diseloged in this report may not infringe privately owned rights; or

B. Assumes any liabilities with respect to the use of, or for damages resulting from the use of any information, apparatus, method, or process disclosed in this report.

As used in the above, "person acting on behalf of the Commission" includes any employee or contractor of the Commission, or employee of such contractor, to the extent that such employee or contractor of the Commission, or employee of such contractor prepares, disseminates, or provides access to, any information pursuant to his employment or contract with the Commission, or his employment with such contractor.

Printed in USA. Price $\$ 3,00$. Available from the Clearinghouse for Federal Scientific and Technical Information, National Bureau of Standards, U. S. Department of Commerce, Springfield, Virginia 
Propulsion Systems and Energy Conversion (TID-4500, 46th Ed.)

AEC Research and

Development Report

\section{ARGONNE NATIONAL LABORATORY Y700 South Cass Avenue Argonne, Illinois 60440}

LIQUID MHD POWER CYCLE STUDIES by

Michael Petrick and Kung-You Lee

Reactor Engineering Division

June 1965

Operated by The University of Chicago under

Contract W-31-109-eng-38

with the

U.S. Atomic Energy Cómmission 


\section{THIS PAGE \\ WAS INTENTIONALLY \\ A LEFT BLANK}


TABLE OF CONTENTS

$\underline{\text { Page }}$

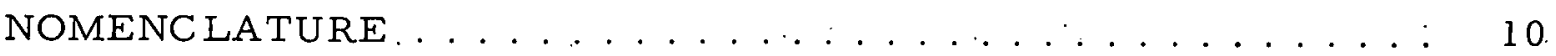

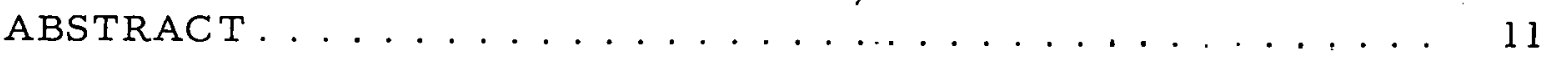

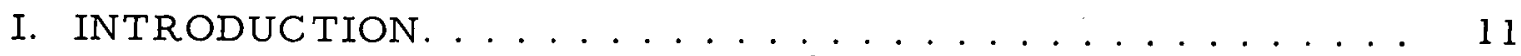

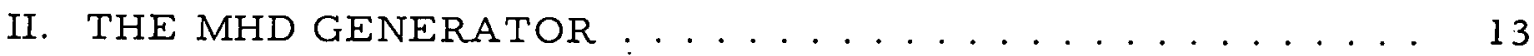

A. General Consideration. . . . . ............ 13

B. The Constant-area Generator for Incompressible Fluid. . . 15

C. The Variable-area Generator for Incompressible Fluid. . . 16

1. Induced $\operatorname{Emf} \ldots \ldots \ldots \ldots \ldots \ldots \ldots$

2. Internal Resistance. . . . . . . . . . . 17

3. Current Equation ................... 18

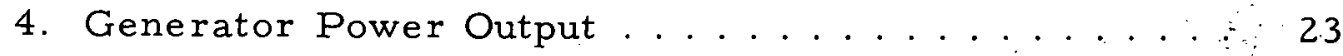

5. Pressure Drop. . . . . . . . . . . . . 23

6. Generator Efficiency. ............... 26

7. Divergent Angle. . . . . . . . . . . . 27

D. Geometry Performance Characteristics . . . . . . . . 28

1. The Constant-area Generator........... 28

2. The Variable-area Generator............ 32

III. THE TWO-COMPONENT, TWO-PHASE MHD CYCLE . . . . . 36

A. Cycle Analysis. . . . . . . . . . . . . . . . 36

1. Two-phase Nozzle . . . . . . . . . . . . . . 37

2. Separator and Diffuser .............. 39

3. Constant-area Nonideal Generator. . . . . . . . . 40

4. Diffuser after Generator . . . . . . . . . . . . 40

5. Reactor .................... . . 40

6. Mixer...................... 40

7. Heat Exchanger . ...................... 41

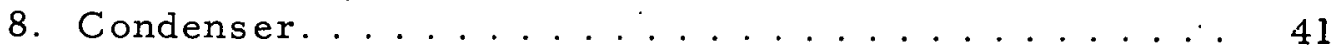

9. EM Pump ..................... 41

10. Cycle Efficiency. . . . . . . . . . . . . . . 41

11. Specified Component and Cycle Parameters . . . . . 42

B. Discussion of Results . . . . . . . . . . . . . . . 43 
$\underline{\text { Page }}$

IV. THE ONE-COMPONENT; TWO-PHASE MHD CYCLE . . . . . 49

A. Cycle Analysis . . . . . . . . . . . . . . . . $51 \%$

1. Two-phase Nozzle ................. 51

2. Variable-area Generator. . . . . . . . . . 52

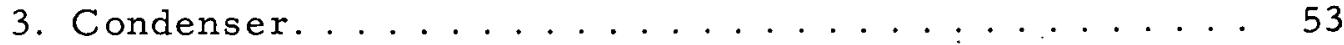

4. Diffuser..................... . . 53

5. Reactor ......................... . . . . .

6. Cyele Efflclency. ................. . . 54

B. Specified Components and Cycle Parameters. . . . . . . . 54

C. Discussion of Results . . . . . . . . . . . . . . . . . 54

V. THE CONDENSING-INJECTOR CYCLE .......... 60

A. Cycle Analysis. . . . . . . . . . . . . . . . 62

1. Condensing Injector . .............. 62

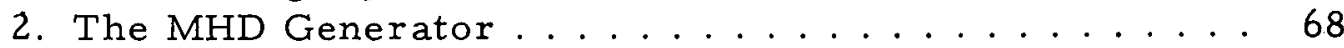

3. The Heat Exchanger . . . . . . . . . . . . 68

4. The Heat Source. . . . . . . . . . . . . 6.9

5. The Cycle Efficiency. . . . . . . . . . . . . . 69

B. Discussion of Results ................... . 70

VI. POTENTIAL OF LIQUID METAL MHD CYCLES FOR

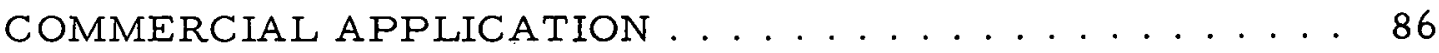

A. Overall Efficiencies of Binary Cycles . . . . . . . . . 87

B. Economic Considerations. . . . . . . . . . . . 89

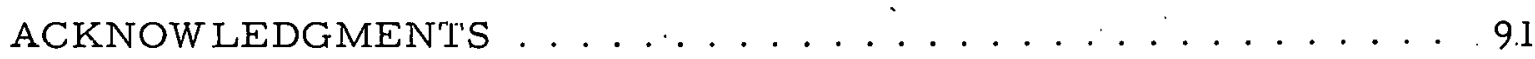

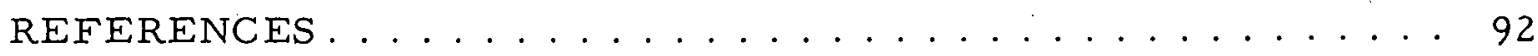




\section{LIST OF FIGURES}

No.

Title

Page

II- 1 Schematic of Nozzle and Generatór Component ....... I 15

II- 2 Schematic of MHD Generalur . . . . . . . . . . . . 16

II- 3 Circuit Diagram for a MHD Generator . . . . . . . . . . 19

II-4 Conformed Map of MHD Generator ..............21

II-5 Diagram Depicting Performance of Variable-area

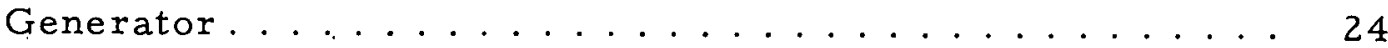

II- 6 Diagram Showing Relationship between Performance

Parameters of Variable-area Generator. . . . . . . . 26

II-7 Schematic Showing Relationship among Pressure Drop,

Power, and Velocities in Variable-area Generator...... 26

II- 8 Generalized Performance Parameter $\mathrm{P}_{0} \mathrm{~B}_{0}^{2} / \mathrm{fa}$ for the

Constant-area Generator ................ 30

II- 9 Generalized Performance Parameter V/a $\bar{U}_{7} B_{0}$ for the Constant-area Generator ........................... 31

II- $10 \quad F_{1}\left(x_{1}, \theta\right)$ vs $x_{1}$ for Cesium and Potassium ......... 33

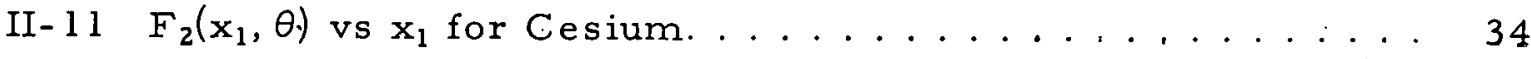

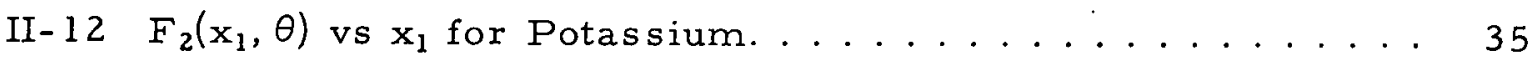

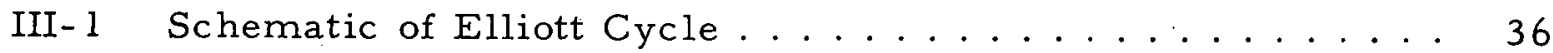

III- 2 Calculated Cycle Efficiency as a Function of System

Parameters for the Elliott Cycle............. 43

III- 3 Detailed Cycle Parameter for $P_{2}=16$ psia........ 45

III-4 Detailed Cycle Parameter for $P_{2}=25$ psia........ 45

III-5 Detáiled Cycle Parameter for $\mathrm{P}_{2}=35 \mathrm{psia} \ldots \ldots 46$

III- 6 Effect of Varying Generator Velocity on Cycle

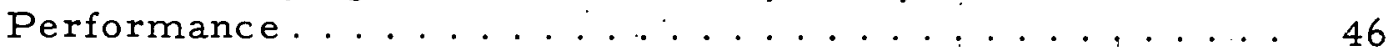

III-7 Performance Parameter for a Potassium-Lithium System. . 47

IV-1. Schematic of the One-component, Two-phase MHD Cycle. . 49

IV-2 Schematic of the Two Types of Generators.Being Studied

$a \& b$ for the One-component, Two-phase MHD Cycle, (a). When

$\mathrm{x}_{1}<10 \%$ and $(\mathrm{b})$ When $\mathrm{x}_{1}>10 \% \ldots \ldots \ldots$

IV-3 Electrical Conductivity Data for Air-Water Mixture.... 50 


\section{LIST OF FIGURES}

No.

Title

Page

IV-4 Cycle Efficiency vs Mixture Qualities for Potassium,

Cesium, and Sodium $\left(\mathrm{T}_{1}=2700^{\circ} \mathrm{R}, \mathrm{T}_{4}=1800^{\circ} \mathrm{R}, \theta=7.5^{\circ}\right) \ldots$

IV-5 Effect of Generator Efficiency and Half-angle $\theta$ on Cycle

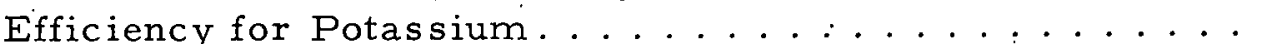

IV-6 Effect of Heat-source and Sink Temperature on Cycle Efficiency for Potassium. . . . . . . . . . . . . bb

IV-7 Fiffect of Cundenser Temperature on Cycle Efficiency

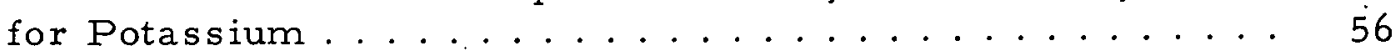

IV-8 Cycle Efficiency as a Function of Mixture Quality and Source and Sink Temperature for Mercury ..........

IV-9 Cycle Efficiency as a Function of Mixture Quality and Source and Sink Temperature for $40 \mathrm{~m} / \mathrm{o}$ Mercury-

Potas sium Eutectic. . . . . . . . . . . . . . . .

V-1 Schematic of Condensing Injector Power Cycle . . . . . . 60

V-2 Performance Parameter of Condensing Injector

Determined by Rose . . . . . . . . . . . . . .

V-3 Calculated Performance Data for the Condensing-injector

Cycle Operating with Cesium for $\mathrm{T}_{1}=2400^{\circ} \mathrm{R}$,

$\mathrm{T}_{\mathrm{S}}=1060^{\circ} \mathrm{R}$, and $\mathrm{R}=3.00 \ldots \ldots \ldots \ldots \ldots \ldots \ldots \ldots \ldots \ldots \ldots$

V-4 Calculated Performance Data for the Condensing-injector Cycle Operating with Cesium for $\mathrm{T}_{1}=2400^{\circ} \mathrm{R}$,

$\mathrm{T}_{\mathrm{S}}=1060^{\circ} \mathrm{R}$, and $\mathrm{R}=5.00 \ldots \ldots \ldots$

V-5 Calculated Performance Data for the Condensing-injector Cycle Operating with Cesium for $\mathrm{T}_{1}=2400^{\circ} \mathrm{R}$, $\mathrm{T}_{\mathrm{S}}=1060^{\circ} \mathrm{R}$, and $\mathrm{R}=7.00 \ldots \ldots \ldots \ldots$

V-6 Calculated Performance Data for the Condensing-injector Cycle Operating with Cesium for $\mathrm{T}_{1}=2700^{\circ} \mathrm{R}$,

$\mathrm{T}_{\mathrm{S}}=1060^{\circ} \mathrm{R}$, and $\mathrm{R}=10.0 \ldots \ldots \ldots \ldots \ldots \ldots \ldots \ldots \ldots \ldots \ldots \ldots \ldots . \ldots \ldots$

V-7 Calculated Performance Data for the Condensing-injector Cycle Operating with Cesium for $T_{1}=2700^{\circ} \mathrm{R}$,

$\mathrm{T}_{\mathrm{S}}=1060^{\circ} \mathrm{R}$, and $\mathrm{R}=3.00 \ldots \ldots \ldots \ldots \ldots \ldots \ldots \ldots \ldots \ldots \ldots$

V-8 Calculated Performance Data for the Condensing-injector Cycle Operating with Cesium for $\mathrm{T}_{1}=2700^{\circ} \mathrm{R}$, $\mathrm{T}_{\mathrm{S}}=1060^{\circ} \mathrm{R}$, and $\mathrm{R}=5.0 \ldots \ldots \ldots$

V-9 Calculated Performance Data for the Condensing-injector Cycle Operating with Cesium for $\mathrm{T}_{1}=2700^{\circ} \mathrm{R}$,

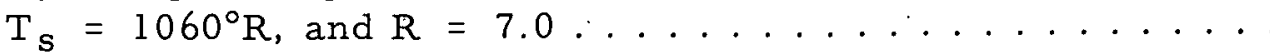




\section{LIST OF FIGURES}

No. Title

Page

V-10 Calculated Performance Data for the Condensing-injector Cycle. Operating. with Cesium for $\mathrm{T}_{1}=2700^{\circ} \mathrm{R}$, $\mathrm{T}_{\mathrm{S}}=1510^{\circ} \mathrm{R}$, and $\mathrm{R}=3.00 \ldots \ldots \ldots$

V-11 Calculated Performance Data for the Condensing-injector Cycle Operating with Cesium for $\mathrm{T}_{1}=2700^{\circ} \mathrm{R}$, $\mathrm{T}_{\mathrm{S}}=1510^{\circ} \mathrm{R}$, and $\mathrm{R}=5.00 \ldots \ldots \ldots$

V-12 Calculated Performance Data for the Condensing-injector Cycle Operating with Cesium for $\mathrm{T}_{1}=2700^{\circ} \mathrm{R}$, $\mathrm{T}_{\mathrm{S}}=1510^{\circ} \mathrm{R}$, and $\mathrm{R}=7.00 \ldots \ldots \ldots$

V-13 Calculated Performance Data for the Condensing-injector Cycle Operating, with Cesium for $\mathrm{T}_{1}=2700^{\circ} \mathrm{R}$, $\mathrm{T}_{\mathrm{S}}=1860^{\circ} \mathrm{R}$, and $\mathrm{R} \doteq 3.00 \ldots \ldots \ldots \ldots \ldots \ldots \ldots \ldots \ldots \ldots \ldots \ldots$

V-14 Calculated Performance Data for the Condensing-injector Cycle Operating with Potassium for $\mathrm{T}_{1}=2700^{\circ} \mathrm{R}$, $\mathrm{T}_{\mathrm{S}}=1860^{\circ} \mathrm{R}$, and $\mathrm{R}=3.00 \ldots \ldots \ldots$

V-15 Calculated Performance Data for the Condensing-injector Cycle Operating with Potassium for $T_{1}=2700^{\circ} \mathrm{R}$, $\mathrm{T}_{\mathrm{S}}-1860^{\circ} \mathrm{R}$, and $\mathrm{R}=5.00 \ldots \ldots \ldots$

V-16 Calculated Performance Data for the Condensing-injector Cycle Operating, with Potassium for $\mathrm{T}_{1}=2700^{\circ} \mathrm{R}$, $\mathrm{T}_{\mathrm{S}}=1860^{\circ} \mathrm{R}$, and $\mathrm{R}=7.00 \ldots \ldots \ldots$

V-17 Calculated Performance Data for the Condensing-injector Cycle Operating with Mercury for $\mathrm{T}_{1}=1860^{\circ} \mathrm{R}$, $\mathrm{T}_{\mathrm{S}}=1060^{\circ} \mathrm{R}$, and $\mathrm{R}=3.00 \ldots \ldots \ldots$

V-18 Calculated Performance Data for the Condensing-injector Cycle Operating with Mercury for $\mathrm{T}_{1}=1860^{\circ} \mathrm{R}$,

$\mathrm{T}_{\mathrm{s}}=1060^{\circ} \mathrm{R}$, and $\mathrm{R}=5.00 \ldots \ldots \ldots$

V-19 Calculated Performance Data for the Condensing-injector Cycle Operating. with Mercury for $\mathrm{T}_{1}=1860^{\circ} \mathrm{R}$,

$\mathrm{T}_{\mathrm{S}}=1060^{\circ} \mathrm{R}$, and $\mathrm{R}=7.0 \ldots \ldots \ldots$

V-20 Calculated Performance Data for the Condensing-injector Cycle Operating with Sodium for $T_{1}=2400^{\circ} \mathrm{R}$, $\mathrm{T}_{\mathrm{S}}=1060^{\circ} \mathrm{R}$, and $\mathrm{R}=7.0 \ldots \ldots \ldots$

V-21 Calculated Performance Data for the Condensing-injector Cycle Operating with Sodium for $\mathrm{T}_{1}=2400^{\circ} \mathrm{R}$, $\mathrm{T}_{\mathrm{S}}=1060^{\circ} \mathrm{R}$, and $\mathrm{R}=5.0 \ldots \ldots$

V-22 Calculated Performance Data for the Condensing-injector Cycle Operating, with Sodium for $T_{1}=2400^{\circ} \mathrm{R}$, $\mathrm{T}_{\mathrm{S}}=1060^{\circ} \mathrm{R}$, and $\mathrm{R}=3.0 \ldots \ldots \ldots$ 


\section{LIST OF FIGURES}

No.

Title

Page

V-23 Variation of Cycle Efficiency vs Flowrate Ratio ( $R$ ) at

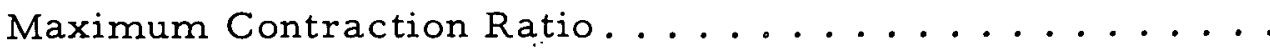

VI-1 Lifetime of Power Equipment vs Maximum Operating

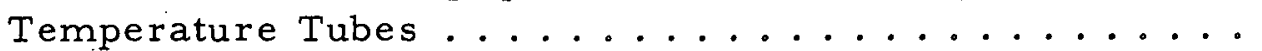

VI-2 Overall Cycle Efficiency, Percentage Increase of Cycle Efficiency, and Pcrcent of Total Power Generated by MID Topping. Cycle vs Topping Cycle Efficiency and Steam Plant Efficiency .................

VI-3 Dollar Differential Resulting from Reduced Fuel Costs as a Function of Increase in Cycle Efficiency. . . . . . . 90

VI-4 Dollar Differential Resulting from Reduced Steam-plant Size as a Function of Increase in Cycle Efficiency . . . . . : 90

VI-5 Total Dollar Differential as a Function of Perc̈ent Increase in Cycle Efficiency. ..............

\section{TABLE}

No. Title Page

$\mathrm{V}-1$ Maximum Cycle Efficiencies .............. 


\begin{tabular}{|c|c|c|c|}
\hline Symbol & Description & Symbol & Description \\
\hline A & Cross-sectional area of generator flow channel & $Q^{\prime}$ & Heat absorbed by the fllowing flluid from the surroundings \\
\hline$A_{r}$ & Area ratio & $Q_{f}$ & Friction loss \\
\hline$a$ & Width of the generator flow channel & $Q_{0}$ & Generator ohmic heat loss \\
\hline$a_{1}$ & Height of the generator flow channel & R & Perfect gas constant \\
\hline$a_{2}$ & Width of the generator flow channel at exit & $\mathrm{R}_{\mathrm{e}}$ & End loss resistance : \\
\hline$a_{3}$ & Width of the generator flow channel at exit & $R_{i}$ & Generator internal resistance \\
\hline aiv & Average width of the variable-area generator & $R_{0}$ & Generator external load resistance \\
\hline $\mathrm{am}_{\mathrm{m}}$ & Log mean of $a_{3}$ and $a_{2}=\left(a_{3}-a_{2}\right) / \ln \left(a_{3} / a_{2}\right)$ & $R_{t}$ & Total load resistance \\
\hline$B_{0}$ & Applied magnetic field & s & Entropy per unit mass \\
\hline B & Magnetic field intensity & $s_{n, f}$ & Entropy of liquid at position $n ; n=1,2, \ldots$ \\
\hline & Aspect ratio $=L / a$ & $s_{11,9}$ & Entropy of vapor at position $n ; n-1,2, \ldots$ \\
\hline$c_{f}$ & Liquid specific heat in two-component system (BTU/OR/DG) & r & Temperature \\
\hline$c_{g}$ & Vapor specific heat in two-component system $\left(B T U /{ }^{\circ} R / \mathrm{Lb}\right)$ & $\mathrm{T}_{\mathrm{b}}$ & Reterence temperature \\
\hline & Condensate specific heat in two-component system (BTU/OR/b) & $T_{n}$ & Temperature at position $n ; n=1,2, \ldots$ \\
\hline$c_{p}$ & Gas specific heat at constant pressure (BTU/OR/1b) & u & Velocity \\
\hline$c_{v}$ & Gas specific heat at constant volume (BTU/\%R/lb) & $\underset{\nu}{\underline{\nu}}$ & Velocily vector \\
\hline$\varepsilon$ & Internal energy & $u_{i}$ & Ideal velocity \\
\hline E & Electric field intensity & $u_{m}$ & Mean velocity $=a_{2} U_{2} / a_{m}$ \\
\hline$=x$ & Electric field on the $x$-direction & $u_{n}$ & Velocity at position $n ; n=1,2, \ldots$ \\
\hline & Aspect ratio $=a_{1} / a_{2}$ & $v$ & Generator terminal voltage \\
\hline to & Skin-friction factor & $v_{0}$ & Induced emf \\
\hline$g_{c}$ & Conversion factor $=32.17(\mathrm{lb} / \mathrm{lb} \mathrm{f})\left(\mathrm{r} / \mathrm{sec} \mathrm{ec}^{2}\right)$ & $v_{o c}$ & Open-circuit voltage \\
\hline H, & Enthalpy per unit mass & v & Specific volume \\
\hline$H_{n}$ & Enthalpy at position $n ; n=1,2, \ldots$ & $v_{n, f}$ & Specific volume of liquid at position $n ; n=1,2, \ldots$ \\
\hline$h_{n, f}$ & Enthalpy of liquid at position $n ; n=1,2, \ldots$ & $v_{n, g}$ & Specific volume of vapor at position $n ; n=1,2, \ldots$ \\
\hline$h_{n, g}$ & Enthalpy of vapor at position $n ; n=1,2, \ldots$ & w & Total mass flowrate \\
\hline & Heat of vaporization at temperature $T_{b}$ & $\mathrm{x}$ & Quality of flowing fluid \\
\hline I & Current through external load resistance, $R_{0}$ & $x_{i}$ & Quality of flowing fluid in isentropic equilibrium flow \\
\hline$I_{e}$ & Current through end loss resistance, $R_{e}$ & $x_{n}$ & Quality of flowing fluid at position $n ; n=1,2, \ldots$ \\
\hline$I_{\mathrm{g}}$ & Total current $=I+I_{c}$ & $x, y, z$ & Coordinates \\
\hline & Current-density vector & Greek' & \\
\hline & Current density. & Symbols & \\
\hline & Slip ratio & $\bar{a}$ & Void fraction \\
\hline & Length of the generator & $\gamma$ & Specific heat ratio $=c_{p} / c_{v}$ \\
\hline m & Molecular weight of vapor & $\varepsilon_{c}$ & MHD cycle efficiency \\
\hline$m_{\mathrm{f}}$ & Liquid mass flowrate in two-component system & $\varepsilon_{d}$ & Diffuser efficiency \\
\hline$m_{g}$ & Vapor mass flowrate in two-component system & $\varepsilon_{g}$ & Generator efficiency \\
\hline$p^{3}$ & Pressure & $\varepsilon_{n}$ & Nozzle efficiency \\
\hline$P_{G}$ & Generator net output per unit mass of fluid & $\varepsilon_{\mathrm{p}}$ & EM pump efficiency ; \\
\hline$P_{G}^{\prime}$ & Generator output with 100\% efficiency. & $\pi$ & Ideal generator loading factor \\
\hline$P_{i}$ & Total mechanical flow energy input to the generator & $\eta^{\prime}$ & Nonideal generator loading factor \\
\hline$P_{n}$ & Pressure at position $n ; n=1,2, \ldots$ & $\theta$ & Half divergent angle of generator \\
\hline$P_{0}$ & Generator total power output & p & Density \\
\hline$P_{p}$ & Power input for EM pump per unit mass of fluid & $\rho_{n, f}$ & Density of liquid at position $n ; n=1,2, \ldots$ \\
\hline & Power supplied by reaclor per unit mass of fluid & $\sigma^{\circ}$. & Electric conductivity of the liquid-phase fluid \\
\hline$\Delta \mathrm{P}$ & Pressure drop across the generator & $.0 \mathrm{TP}$ & Electric conductivity of the two-phase fluid \\
\hline$\Delta P_{c}$ & Pressure drop across the condenser & $\emptyset$ & Electric potential \\
\hline$\Delta P_{R}$ & Pressure drop across the reactor & $\phi_{0}$ & Electric potential on electrode \\
\hline$\Delta P_{H S}$ & Pressure drop across the heat source & 1 & Separator half vertex angle \\
\hline$\Delta \mathrm{P}_{\mathrm{m}, \mathrm{f}}$ & Pressure drop across the mixer for liquid & Subscripts & \\
\hline$\Delta \mathrm{P}_{\mathrm{m}, \mathrm{g}}$ & Pressure drop across the mixer for vapor & $\overline{\ell, L}$ & Liquid \\
\hline & Heat removed in the condenser & $g \mathrm{v}$ & Vapor \\
\hline
\end{tabular}




\title{
LIQUID MHD POWER CYCLE STUDIES
}

\author{
by \\ Michael Petrick and Kung-You Lee
}

\begin{abstract}
The potential of liquid metal MHD power cycles has been investigated by means of extensive cycle studies and has been found to be excellent. Overall efficiency of a binary cycle employing a liquid metal topping cycle and a bottoming steam cycle approaching $60 \%$ may be feasible. Detailed analyses and cycle data are presented. The potential of the binary cycle for commercial application is discussed.
\end{abstract}

\section{INTRODUCTION}

For all practical purposes effective further development of the steam power cycle is rapidly reaching an end. The relatively small gains in efficiency which have been achieved by increasing the pressure and temperatures to very high levels in the steam cycle have been reported to be uneconomical. As a result, new or unconventional power sources are being sought which can meet the ever-increasing demand for additional power more efficiently and economically. A major impetus for this research has been the need for specialized power systems for space and military application. The "fallout" from this extensive effort is almost certain to benefit the commercial power industry.

Based upon recent developments in reactor technology and magnetohydrodynamics (MHD), a power system is evolving which appears to have a very strong potential for both commercial and space application. The concept involves the coupling of a fast reactor to a liquid-metal MHD generator with liquid metal acting both as the cooling medium and the working. fluid.

The development of the fast breeder reactor is the primary objective of the US Nuclear Power Program. A major stimulus for this development is the accumulation of the byproduct plutonium from the present generation. of thermal power reactors. Since the fast reactors are much more effective users of plutonium their development is being spurred.

Recent advances in the field of magnetohydrodynamics and in particular of liquid-metal magnetohydrodynamics indicate that the direct 
conversion of heat into electricity appears quite feasible. The plasma MHD cycle still has formidable obstacles to overcome, namely, the attainment of adequate electrical conductivity within feasible temperature limits. The liquid metals on the other hand have an electrical conductivity which is five orders of magnitude higher than that of plasma. The velocities that can be achieved in a liquid-metal generator, however, are about two orders of magnitude lower than the plasma. Since the power density of an MHD generator is proportional to $\sigma \mathrm{V}^{2} \mathrm{~B}^{2}$, the potential of the liquid-metal MHD generator and cycle appears to be at least equal that of the plasma cycle and, in fact, it probably exceeds it. An additional consideration that favors the liquid-metal MHD cycle is that it possesses essentially no moving or rotating rnmpnnents which are a necessary requirerrent for a system of long lifetime. Also, the liquid-metal cycle does not require any pump or compressors which rob the cycle of very substantial amounts of power for operation.

Three basic cycles that have been proposed for a liquid-metal MHD power system are the two-component, two-phase cycle, (1) the condensing injector cycle, (2) and the one-component, two-phase cycle.(3) The cycles are basically similar in that they are based on the conversion of thermal energy into kinetic energy or stagnation head which is then converted into electrical energy by an MHD device. The cycles differ primarily in the manner in which the conversion of the thermal energy is achieved.

Although much interest has been expressed in the concept and the various cycles as evidenced by the efforts currently underway, very little quantitative data or comparisons of the cycles have been reported.

It is the purpose of this study to investigate the potential of the liquidmetal MHD concept by means of extensive cycle analyses and, in particular, to make a preliminary judgment on the relative merits of the aforementioned cycles as applied to commercial and space power systems.

Various working fluids sụch as mercury, mercury-potassium alloy, potassium, cesium, and sodium were investigated over wide parameter ranges that would be compatible with both commercial and space systems. Preliminary economic evaluations were also made to demonstrate economic incentive for developing the concept. 


\section{THE MHD GENERATOR}

A. General Consideration

The MHD generator is the key component of the MHD cycle. The overall cycle efficiency is essentially directly proportional to the generator efficiency and performance. The electrical energy extracted from the generator is at the expense of the flow work, kinetic energy, and internal energy. An energy balance across the generator with negligible potential energy change is

$$
d(P v)+d E+d\left(U^{2} / 2 g_{C}\right)=d Q^{\prime}-d P G \text {, }
$$

where $Q^{\prime}$ is heat absorbed by the flowing fluid from the surroundings, $P_{G}$ is the work done by the flowing fluid on the surroundings (i.e., generator output). Recalling that

$$
\mathrm{dE}=\mathrm{TdS}-\mathrm{Pdv}
$$

where TdS is the change of internal energy due to heat effects and Pdv is the change of internal energy due to compression effects, Eq. (II-l) becomes

$$
v d P+T d S+\left(U d U / g_{C}\right)=d Q^{\prime}-d P G
$$

In any process the increase in internal energy due to heat effects $T d S$ is equal to the sum of the heat absorbed from the surroundings and all other energy dissipated into heat effects within the system due to irreversibilities, such as overcoming friction, occurring in the process. Therefore

$$
T d S=d Q^{\prime}+d Q_{f}+d Q_{0} \text {, }
$$

where $Q_{f}$ is lost work due to friction and $Q_{0}$ is ohmic heat loss due to generator internal resistance. Substituting (II-4) into (II-3) one obtains

$$
v d P+\left(U d U / g_{c}\right)+d Q_{f}+d Q_{0}=-d P G
$$

or

$$
d P_{G}+d Q_{0}=-v d P-\left(U d U / g_{c}\right)-d Q_{f} .
$$

After integration (referring to Fig. II-1),

$$
P_{G}+Q_{0}=\int_{P_{3}}^{P_{2}} v d P+\left(1 / g_{c}\right) \int_{U_{3}}^{U_{2}} U d U-Q_{f} .
$$


The generator efficiency $\epsilon_{\mathrm{g}}$ is

$$
\epsilon_{\mathrm{g}}=\mathrm{P}_{\mathrm{G}} /\left(\mathrm{P}_{\mathrm{G}}+\mathrm{Q}_{0}\right)=\left[1+\left(\mathrm{R}_{\mathrm{i}} / \mathrm{R}_{0}\right)+\left(\mathrm{R}_{\mathrm{i}} / \mathrm{R}_{\mathrm{e}}\right)\right]^{-1} .
$$

Therefore

$$
P_{G}=\epsilon_{g}\left[\int_{P_{3}}^{P_{2}} v d P+(1 / g c) \cdot \int_{U_{3}}^{U_{i}} U d U-Q_{f}\right]
$$

The amount of energy that can be extracled from the working fluid, and henre. the cycle efficiency, depends upon the fluid itself and on the type of MHD generator used: The working fluid can be compressible or incompressible, and the generator can be of either a constant-area or a variable-area geometry.

If the working fluid is incompressible and it is assumed that frictional loss is negligible, the energy extraction from the generator is manifested'by either a change in the kinetic energy of the fluid or by a pressure drop across the generator, or by both [see Eq. (II-9)]. For a constant-area generator the velocity and density would remain essentially constant and a pressure drop would occur. If the generator is of the variable-area design, the energy removed is proportional to the velocity or kinetic energy change, and the pressure $P$ can remain constant, decrease, or increase, depending upon system conditions and generator geometry.

Equation (II-1) can be expressed in terms of enthalpy:

$$
d H+\left(U d U / g_{C}\right)=d Q^{\prime}-d P_{G} .
$$

If the system is insulated, $d^{\prime} Q^{\prime}=0$, so that

$$
d P_{G}=-d H-\left(U d U / g_{c}\right)
$$

or

$$
P_{G}=\left(H_{2}-H_{3}\right)+\frac{\left(U_{2}^{2}-U_{3}^{2}\right)}{2 g_{c}}
$$

From overall cycle considerations it is immaterial, however, whether the conversion of enthalpy to kinetic energy occurs completely in the nozzle or partially in the nozzle and partially in the generator. The cycle output depends only upon the enthalpy change between the inlet to the nozzle and the exit of the MHD generator, assuming that the efficiency of the conversion process would be the same in both components. This is evident from a simple energy balance across the nozzle and generator. Referring to Fig. II-1, 


$$
\left(\mathrm{U}_{1}^{2} / 2 \mathrm{~g}_{\mathrm{c}}\right)+\mathrm{H}_{1}=\left(\mathrm{U}_{2}^{2} / 2 \mathrm{~g}_{\mathrm{C}}\right)+\dot{\mathrm{H}}_{2}
$$

Substituting Eq. (II-13) into (II-12), we obtain

$$
P_{G}=\left[\left(U_{1}^{2}-U_{3}^{2}\right) / 2 g_{C}\right]+\left(H_{1}-H_{3}\right) \text {. }
$$

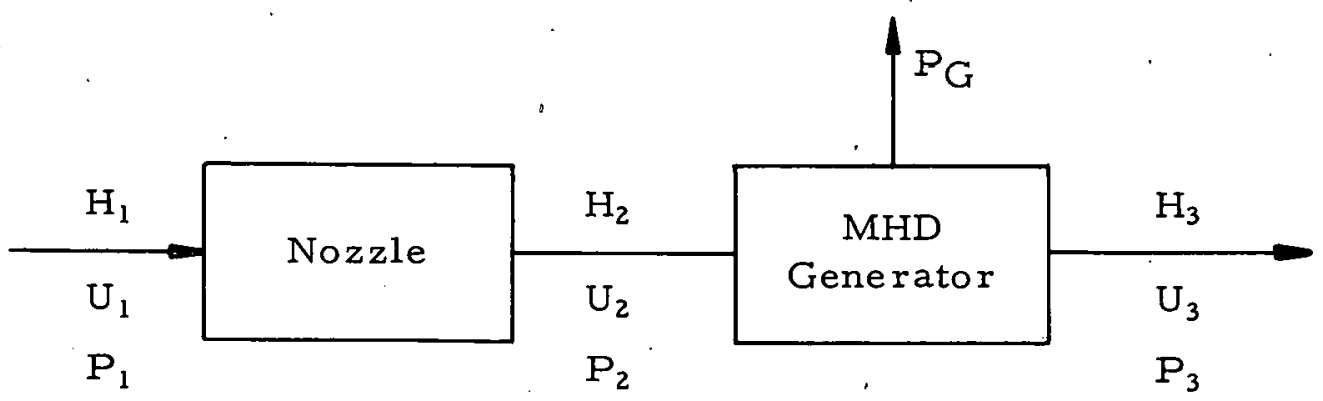

Fig. II-1. Schematic of Nozzle and Generator Component

From an analytical viewpoint the above considerations are quite important. The entire enthalpy and pressure drop can be taken across the nozzle, and the generator can be considered as operating at a constant pressure. The generator analysis then becomes greatly simplified since under these conditions $\Delta \mathrm{P}=0, \Delta \mathrm{T}=0, \dot{\mathrm{H}}=0, \Delta \rho=0, \Delta \mathrm{U} \neq 0$, and $\Delta \mathrm{A} \neq 0$, where $\mathrm{A}$ is the cross-sectional area of the generator channel.

If the working fluid is a two-phase mixture, $\Delta x=0$, and the fluid can be essentially treated as incompressible. A theoretical development for a variable-area generator operating under these conditions is given below. The performance characteristics of the constant-area generator is also summarized.

B. The Constant-area Generator for Incompressible Fluid

The theory of the constant cross-section MHD generator has been developed and presented in several reports. $(4-8)$ The results of the analysis by Petrick and Lee for single-phase or two-component, two-phase working fluids are especially pertinent to this investigation and are, therefore, summarized briefly. For the case in which the magnetic field abruptly terminates at the end of the electrodes, the equations obtained are:

$$
\begin{aligned}
& \mathrm{V}=\eta^{\prime} \mathrm{aUB} \mathrm{B}_{0} ; \\
& \eta^{\prime}=\left[1+\left(\mathrm{R}_{\mathrm{i}} / \mathrm{R}_{0}\right)+2 \ln \{2 /(\mathrm{c} \pi)\}\right]^{-1} ; \\
& \mathrm{R}_{\mathbf{i}}=\mathrm{a} / \mathrm{a}_{1} L \sigma_{i} .
\end{aligned}
$$




$$
\begin{gathered}
\mathrm{c}=\mathrm{L} / \mathrm{a} ; \\
\mathrm{I}=\mathrm{a}_{1} \mathrm{~L} \sigma \mathrm{UB}_{0}\left\{1-\eta^{\prime}[1+2 \ln \{2 /(\mathrm{c} \pi)\}]\right\} \\
-\Delta \mathrm{P}=\left(1-\eta^{\prime}\right) \mathrm{L} \sigma \mathrm{UB}_{0}^{2} \\
\epsilon_{\mathrm{g}}=\eta^{\prime}\left\{1-\eta^{\prime}[1+2 \ln \{2 /(\mathrm{c} \pi)\}]\right\} /\left(1-\eta^{\prime}\right) \\
\mathrm{P}_{\mathrm{G}}=\mathrm{VI} / \mathrm{m}_{\mathrm{f}}=\left(-\Delta \mathrm{P} / \rho_{\mathrm{f}}\right) \epsilon_{\mathrm{g}}=\eta^{\prime}\left\{1-\eta^{\prime}[1+2 \ln \{2 /(\mathrm{c} \pi)\}]\right\} \mathrm{L} \sigma U \mathrm{UB}_{0}^{2} / \rho_{\mathrm{f}} \\
\left(\mathrm{R}_{\mathrm{i}} / \mathrm{R}_{0}\right)_{\mathrm{max}} \epsilon_{\mathrm{g}}=\{[2 \ln \{2 /(\mathrm{c} \pi)\}][1+2 \ln \{2 /(\mathrm{c} \pi)\}]\}^{1 / 2} ; \\
\epsilon_{\mathrm{g}, \max }=\left(1+4 \ln [2 /(\mathrm{c} \pi)]+2\{[2 \ln \{2 /(\mathrm{c} \pi)\}][1+2 \ln \{2 /(\mathrm{c} \pi)\}]\}^{1 / 2}\right)^{-1} \\
\eta_{\max \epsilon_{\mathrm{g}}}^{\prime}=\left(1+2 \ln [2 /(\mathrm{c} \pi)]+\{[2 \ln \{2 /(\mathrm{c} \pi)\}][1+2 \ln \{2 /(\mathrm{c} \pi)\}]\}^{1 / 2}\right)^{-1}
\end{gathered}
$$

If a two-phase working fluid is used, $\sigma$ in the above equations should be replaced by $\sigma_{\mathrm{TP}}$.

C. The Variable-area Generator for Incompressible Fluid

\section{Induced Emf}

The simplest case of a variable-area generator is that of a flow channel with a constant height (in the direction of applied magnetic field) but with varying width in the flow direction. The generator operates

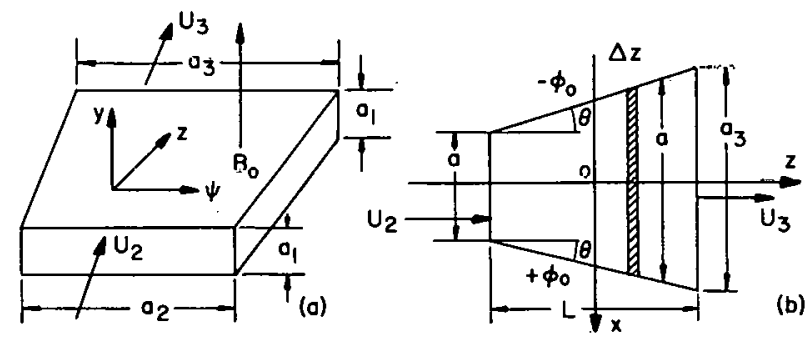

Fig. II-2: Schematic of, MHD Generator such that $\triangle P=0$, and the fluid can be treated as incompressible, as described previously. Consider a MHD generator duct with dimensions $a_{1}, a_{2}$, and $a_{3}$ and a constant applied magnetic field $\mathrm{B}_{0}$, as shown in Fig. II-2. Neglecting the Hall effect, Ohm's law for a moving medium expressed in vector form is

$$
\underset{\sim}{J}=\sigma[\underset{\sim}{\mathrm{E}}+(\underset{\sim}{\mathrm{U}} \times \underset{\sim}{\mathrm{B}})]
$$

where $\underset{\sim}{J}$ is the current density, $\underset{\sim}{\mathrm{E}}$ is the electric field intensity, $\underset{\sim}{\mathrm{U}}$ is velocity, and $\underset{\sim}{\mathrm{B}}$ is magnetic field intensity. Since $\underset{\sim}{\mathrm{B}}$ is steady, $\nabla \times \underset{\sim}{\mathrm{E}}=0$, and $\underset{\sim}{\mathrm{E}}$ may be expressed in terms of an electric potential $\phi:$

$$
\underset{\sim}{E}=-\nabla \phi
$$


The value of $\phi$ on one electrode is $\phi_{0}$; on the other it is $-\phi_{0}$. In a small element, $a_{1} a \Delta z$ (see Fig. II-2) the induced emf, $V_{0}$, is

$$
\mathrm{V}_{0}=\mathrm{aUB} B_{0}
$$

Both $a$ and $U$ are functions of $z$. However, the mass flowrate $W$ is constant and at any cross section in the generator

$$
\begin{aligned}
& \mathrm{W}=a_{1} a_{2} U_{2} \rho=a_{1} a_{3} U_{3} \rho=a_{1} a U \rho ; \\
& a U=a_{2} \dot{U}_{2}=a_{3} U_{3}=W / a_{1} \rho=\text { constant. }
\end{aligned}
$$

Therefore, $V_{0}$ is not a function of $z$. This corresponds to the case of the constant cross-section MHD generator with both a and $U$ constant.

2. Internal Rèsistance

In the element $a_{1} a z$ the internal resistance is

$$
r_{i}=a / \sigma a_{1} \Delta z
$$

since

$$
a=\left[\left(a_{3}-a_{2}\right) z / L\right]+a_{2} \text {. }
$$

The internal resistance $r_{i}$ is a function of $z$. The total internal resistance of the generator, $R_{i}$, is obtained from the integration of $r_{i}$ :

$1 / R_{i}=\int_{-\frac{L}{2}}^{\frac{L}{2}}\left(\sigma a_{1} / a\right) d z=\sigma a_{1} \int_{-\frac{L}{2}}^{\frac{L}{2}} a^{-1} d z=\sigma a_{1} L \ln \left(a_{3} / a_{2}\right) /\left(a_{3}-a_{2}\right)$.

Let

$$
a_{m}=\left(a_{3}-a_{2}\right) / \ln \left(a_{3} / a_{2}\right)
$$

then

$$
\mathrm{R}_{\mathrm{i}}=\mathrm{a}_{\mathrm{m}} / \sigma \mathrm{a}_{\mathrm{l}} \mathrm{L}
$$

Since both $\mathrm{V}_{0}$, the induced emf, and $\mathrm{V} .\left(=\mathrm{IR}_{0}\right)$, the terminal voltage, are constant along the electrode, the current density $j$ is not constant but varies with length. Considering a small area $\Delta y \Delta z$ on the electrode, the current density is 


$$
\begin{aligned}
j & =\left(V_{0}-V\right) /[a / \sigma \Delta y \Delta z] / \Delta y \Delta z \\
& =\left(v_{0}-V\right) \sigma / a \\
& =\left(v_{0}-V\right) \sigma /\left[\left(a_{3}-a_{2}\right) z /\left(L+a_{2}\right)\right]
\end{aligned}
$$

The total current $I_{t}$ passing through internal resistance $R_{i}$ is

$$
\begin{aligned}
I_{t} & =\iint j d y d z \\
& =\int_{0}^{a_{1}} \int_{0}^{L}\left[\left(V_{0}-V\right) \sigma / a\right] d y d z \\
& =\left(V_{0}-V\right) / R_{i} .
\end{aligned}
$$

The above equation is simply a result of Ohm's law. The loading factor of the generator is therefore

$$
\eta=1+\left(\mathrm{R}_{\mathrm{i}} / \mathrm{R}_{0}\right)^{-1}=\mathrm{V} / \mathrm{V}_{0}
$$

The end loss $R_{e}$ is considered as a shunt resistance and is the sum of losses upstream and downstream of the generator. Since it is in parallel with the external load resistance $R_{0}$, the overall load resistance $R_{t}$ for the generator is

$$
R_{t}=\left[\left(1 / R_{0}\right)+\left(1 / R_{e}\right)\right]^{-1}
$$

The loading factor which includes end losses is

$$
\eta^{\prime}=\left[1+\left(\mathrm{R}_{\mathrm{i}} / \mathrm{R}_{\mathrm{t}}\right)\right]^{-1}=\left[1+\left(\mathrm{R}_{\mathrm{i}} / \mathrm{R}_{0}\right)+\left(\mathrm{R}_{\mathrm{i}} / \mathrm{R}_{\mathrm{e}}\right)\right]^{-1}=\mathrm{V} / \mathrm{V}_{0}
$$

For the open-circuit condition, i.e., $\mathrm{R}_{0}=\infty$,

$$
\mathrm{V}_{0 C}=\mathrm{V}_{0} /\left[1+\left(\mathrm{R}_{\mathrm{i}} / \mathrm{R}_{\mathrm{e}}\right)\right]=\mathrm{aUB}_{0} /\left[1+\left(\mathrm{R}_{\mathrm{i}} / \mathrm{R}_{\mathrm{e}}\right)\right]
$$

\section{3.: Current Equation}

The generator and its load can be expressed in a simple circuit diagram as shown in Fig. II-3, where

$$
I_{e}=V / R_{e} ; \quad I=V / R_{0}
$$

From Eq. (II-37),

$$
I_{t}=I+I_{e}=\left(V_{0}-V\right) / R_{i}
$$


Thereforc,

$$
\begin{aligned}
I & =\left[\left(\mathrm{V}_{0}-\mathrm{V}\right) / \mathrm{R}_{\mathrm{i}}\right]-\left(\mathrm{V} / \mathrm{R}_{\mathrm{e}}\right)=\left(\mathrm{V}_{0} / \mathrm{R}_{\mathrm{i}}\right)-\left(\eta^{\prime} \mathrm{V}_{0} / \mathrm{R}_{\mathrm{i}}\right)-\left(\eta^{\prime} \mathrm{V}_{0} / \mathrm{R}_{\mathrm{e}}\right) \\
& =\mathrm{V}_{0}\left[1-\eta^{\prime}\left\{1+\left(\mathrm{R}_{\mathrm{i}} / \mathrm{R}_{\mathrm{e}}\right)\right\}\right] / \mathrm{R}_{\mathrm{i}} \\
& =\mathrm{a}_{2} \mathrm{U}_{2} \mathrm{~B}_{0} L \sigma a_{1}\left[1-\eta^{\prime}\left\{1+\left(\mathrm{R}_{\mathrm{i}} / \mathrm{R}_{\mathrm{e}}\right)\right\}\right] / \mathrm{a}_{\mathrm{m}} .
\end{aligned}
$$

Let

$$
\mathrm{U}_{\mathrm{m}}=\mathrm{a}_{2} \mathrm{U}_{2} / \mathrm{a}_{\mathrm{m}}
$$

Then

$$
I=a_{1} L \sigma U_{m} B_{0}\left[1-\eta^{\prime}\left\{1+\left(R_{i} / R_{e}\right)\right\}\right] .
$$

The current equation is exactly of the same form as Eq. (II-19), but $R_{i} / R_{e}$ or $R_{e}$ is still unknown at this point.

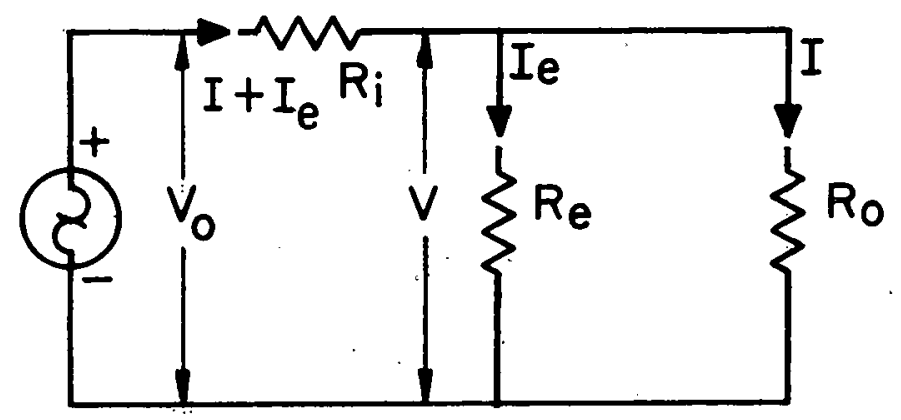

Fig. II-3. Circuit Diagram for a MHD Generator

Sutton et al. (9) solved for $\mathrm{R}_{i} / \mathrm{R}_{\mathrm{e}}$ for a constant-cross-section. generator where a is constant. From their analysis, the term equivalent to $R_{i} / R_{e}$ is a $(2 \ln 2) / L \pi$, which is shown in Eq. (II-19). For the varying area generator, a similar form for $R_{i} / R_{e}$ is expected. The value of a would be expected to be some mean value of $a_{2}$ and $a_{3}$. Designating $a_{a v}$ as the proper value, it should satisfy

$$
I=a_{1} \operatorname{LoU} U_{m} B_{0}\left\{1-\eta^{\prime}\left[1+\left\{\left(2 a_{a v} \ln 2\right) / c v\right\}\right]\right\} \text {. }
$$

The following procedure is used to obtain aav. From Eqs. (II-26) and (II-27), and referring to Fig. II-2(b), 


$$
\begin{aligned}
I= & a_{1} \sigma \int_{0}^{\frac{L}{2}}\left(E_{x}+U B_{0}\right) d z+a_{1} \sigma \int_{-\frac{L}{2}}^{0}\left(E_{x}+U B_{0}\right) d z \\
= & a_{1} \sigma \int_{0}^{\frac{L}{2}}\left[(-\partial \phi / \partial x)+U B_{0}\right] d z+a_{1} \sigma \int_{-\frac{L}{2}}^{0}\left[(-\partial \phi / \partial x)+U B_{0}\right] d z \\
= & a_{1} \sigma B_{0} a_{3} U_{3} L \ln \left[2 a_{3} /\left(a_{2}+a_{3}\right)\right] /\left(a_{3}-a_{2}\right) \\
& +a_{1} \sigma B_{0} a_{2} U_{2} L \ln \left[\left(a_{3}+a_{2}\right) / 2 a_{2}\right] /\left(a_{3}-a_{2}\right) \\
& \cdot \int_{0}^{\frac{L}{2}}(\partial \phi / \partial x) d z-a_{1} \sigma \int_{-\frac{L}{2}}^{0}(\partial \phi / \partial x) \cdot d z \\
& -a_{1} \sigma \int_{0}^{\frac{L}{2}}(\partial \phi / \partial x) d z-a_{1} \sigma \int_{-\frac{L}{2}}^{0}(\partial \phi / \partial x) d z
\end{aligned}
$$

To evaluate $\partial \phi / \partial x$ and the end-loss term for both ends of the generator a procedure similar to that followed by Sutton(9) was used. The variablearea generator was approximated by a constant-area generator with $\mathrm{a}=\mathrm{a}_{\mathrm{av}}$ [see Fig. II-4(a)]. Upon taking the divergence of Eq. II-27, one obtains

$$
\nabla^{2} \phi=0
$$

The value of $\phi$ is specified on the electrode; thus for $|z|<L / 2$,

$$
\phi\left( \pm \mathrm{a}_{\mathrm{av}} / 2, \mathrm{z}\right)= \pm \phi_{0}= \pm \eta^{\prime} \mathrm{U}_{\mathrm{av}} \mathrm{a}_{\mathrm{av}} \mathrm{B}_{0} / 2
$$

Upstream and downstream of the electrodes, the current to the walls at $\mathbf{x}= \pm \mathrm{a}_{\mathrm{av}} / 2$ is zero, from Eq. II- 26 becomes

$$
|z|>L / 2 ; \quad x=a_{a v} / 2
$$

and

$$
\partial \phi / \mathbf{x}=\dot{U} B(z)
$$

where $B(z)$ is the applied magnetic field beyond the electrodes. Thus Eq. (II-47) must be solved subject to the boundary conditions of Eqs. (II-48) and (II-49). 


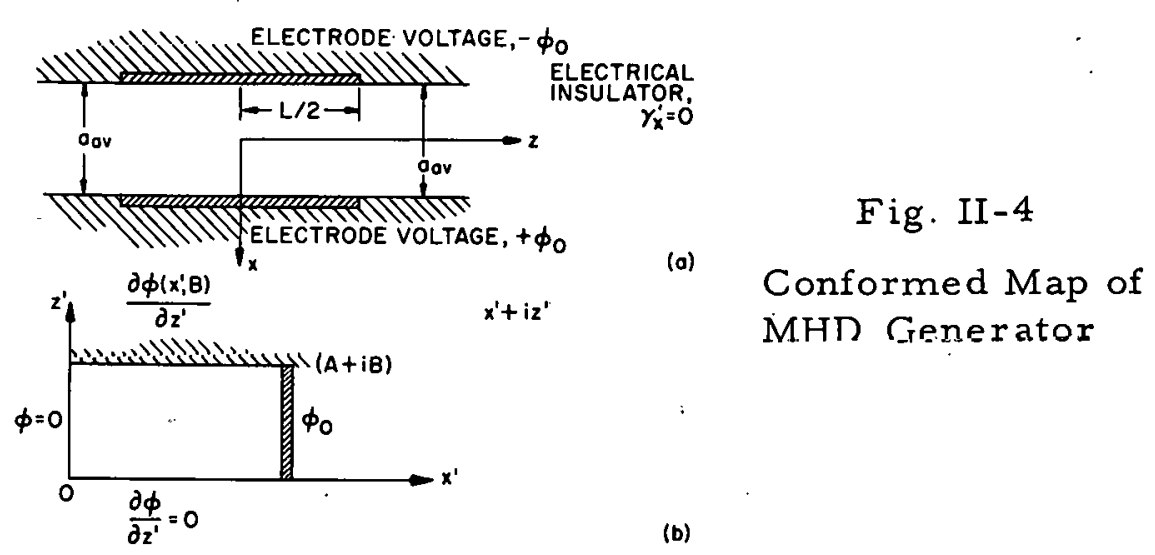

First, transform $x, z$ to $X, Z$ by

$X=2 \pi x / a_{a v} ; \quad z=2 \pi z / a_{a v}$.

The boundary conditions for one quadrant of the channel and magnetic field are

$$
\begin{aligned}
& \mathrm{X}=0 \text { and }-\infty<\mathrm{z}<\infty: \quad \phi=0 ; \\
& \mathrm{z}=0: \quad \partial \phi / \partial \mathrm{z}=0 ; \\
& \mathrm{X}= \pm \pi / 2 \text { and }|\mathrm{z}|<\mathrm{L} \pi / \mathrm{a}_{\mathrm{av}}: \quad \phi=\phi_{0} ; \\
& \mathrm{X}= \pm \pi / 2 \text { and }|\mathrm{z}|>L \pi / \mathrm{a}_{\mathrm{av}}: \quad \partial \phi / \partial \mathrm{X}=0 .
\end{aligned}
$$

To solve'Eq. (II-47) with boundary conditions (II-5l) the region considered is mapped into the upper half of the complex $w$-plane by the transform

$$
\mathrm{w}=\frac{1}{2}(\sin \mathrm{Y}+1) ; \quad \mathrm{Y}=\mathrm{X}+\mathrm{i} Z
$$

The upper half of the $w$-plane is next mapped into a rectangle in the complex $y^{\prime}-$ plane by means of a Schwarz-Christoffel transformation [see Fig: II-4(b)]. The boundary conditions in the $y^{\prime}$-plane become

$$
\begin{array}{ll}
\mathbf{x}^{\prime}=0: & \phi=0 ; \\
\mathbf{x}^{\prime}=\mathrm{A}: & \phi=\phi_{0} ; \\
\mathbf{z}^{\prime}=0: & \partial \phi / \partial \mathbf{z}^{\prime}=0 ; \\
\mathbf{z}^{\prime}=\mathrm{B}: & \partial \phi / \partial \mathbf{z}^{\prime}=0 .
\end{array}
$$

The last boundary condition arises from the requirement that the current to the insulator be zero in the region beyond the electrode. Since no 
magnetic field exists in this region, the normal gradient of the electric potential must be zero. For the boundary conditions given by the Eq. (II-53) the potential is simply

$$
\begin{aligned}
& \phi=\left(\phi_{0} / \mathrm{A}\right) \mathrm{x}^{\prime} \\
& \partial \phi / \partial \mathrm{x}^{\prime}=\phi_{0} / \mathrm{A} .
\end{aligned}
$$

Now Eq. (II-46) becomes

$$
\begin{aligned}
I & =a_{1} \sigma B_{0} U_{m} I-2 a_{1} \sigma \int_{0}^{\frac{L}{2}}(\partial \phi / \partial x) d z \\
& =a_{1} \sigma B_{0} U_{m} L-2 a_{1} \sigma \int_{0}^{B}\left(\partial \phi / \partial x^{\prime}\right) d z^{\prime} \\
& =a_{1} \sigma B_{0} U_{m} L-2 a_{1} \sigma \phi_{0}(B / A) .
\end{aligned}
$$

According to Sutton, (9) for values of $L \pi / a_{a v}>0.7$,

$$
\mathrm{B} / \mathrm{A} \doteq\left[2 \ln 2+\left(\mathrm{L} \pi / \mathrm{a}_{\mathrm{av}}\right)\right] / \pi=[(2 \ln 2) / \pi]+\left(\mathrm{L} / \mathrm{a}_{\mathrm{av}}\right)
$$

Equation (II-56) becomes

$$
\begin{aligned}
I & \left.=a_{1} \sigma B_{0} U_{m} L-a_{1} \sigma a U B_{0} \eta^{\prime} \cdot[(\dot{2} \ln 2) / \pi\}+\left(L / a_{a v}\right)\right] \\
& =a_{1} L \sigma U_{m} B_{0}\left\{1-\eta^{\prime}\left[\left(a_{m} / a_{a v}\right)+\left\{\left(2 a_{m} \ln 2\right) / L \pi\right\}\right]\right\} .
\end{aligned}
$$

Comparing Eq. (II-58) with (II-45), one obtains

$$
1+\left[\left(2 a_{a v} \ln 2\right) / L \pi\right]=\left(a_{m} / a_{a v}\right)+\left[\left(2 a_{m} \ln 2\right) / L \pi\right]
$$

It is obvious that

$$
a_{a v}=a_{m}=\left(a_{3}-a_{2}\right) / \ln \left(a_{3} / a_{2}\right)
$$

Then

$$
R_{i} / R_{e}=\left(2 a_{m} \ln 2\right) / L \pi
$$

and

$$
\begin{aligned}
& I=a_{1} L \sigma \dot{U}_{m} B_{0}\left\{1-\eta^{\prime}\left[1+\left\{\left(2 a_{m} \ln 2\right) / L \pi\right\}\right]\right\} \\
& \eta^{\prime}=\left[1+\left(R_{i} / R_{0}\right)+\left\{\left(2 a_{m} \ln 2\right) / L \pi\right\}\right]^{-1} .
\end{aligned}
$$


4. Generator Power Output

The terminal voltage $V$. can be expressed as

$$
\mathrm{V}=\eta^{\prime} \mathrm{a}_{\mathrm{m}} \mathrm{U}_{\mathrm{m}} \mathrm{B}_{0} .
$$

The power uutput of the generator is

$$
\begin{aligned}
P_{0} & =V I=a_{1} L \sigma a_{m} U_{m}^{2} B_{0}^{2} \eta^{\prime}\left\{1-\eta^{\prime}\left[1+\left\{\left(2 a_{m} \ln 2\right) / L \pi\right\}\right]\right\} \\
& =\left(a_{2} \dot{U}_{2}\right)^{2} B_{0}^{2} \eta^{\prime}\left\{1-\eta^{\prime}\left[1+\left\{\left(2 a_{m} \ln 2\right) / L \pi\right\}\right]\right\} / R_{j} .
\end{aligned}
$$

\section{Pressure Drop}

If the friction loss in the generator is negligible, the energy obtained from the generator in the form of heat is

$$
\begin{aligned}
P_{S} & =\left(I+I_{e}\right)^{2} R_{i}+I_{e}^{2} R_{e}+I^{2} R_{0} \\
& =\left(V_{0}-V\right)\left(I+I_{e}\right)+V I_{e}+V I \\
& =\eta^{\prime}\left(a_{2} U_{2} B_{0}\right)^{2}\left[\left(1 / R_{0}\right)+\left(1 / R_{e}\right)\right] .
\end{aligned}
$$

The total mechanical flow energy is

$$
P_{i}=\left[W\left(U_{2}^{2}-U_{3}^{2}\right) / 2 g_{c}\right]+\left[W\left(P_{2}-P_{3}\right) / \rho\right] \text {. }
$$

From considerations of continuity,

$$
\begin{aligned}
& a_{2} / a_{3}=U_{3} / U_{2} ; \\
& W=a_{1} a_{2} U_{2} \rho ; \\
& P_{i}=\left\{a_{1} a_{2} U_{2}^{3} \rho\left[1-\left(a_{2} / a_{3}\right)^{2}\right] / 2 g_{C}\right\}+a_{1} a_{2} U_{2}\left(P_{2}-P_{3}\right) .
\end{aligned}
$$

Since $P_{i} \equiv P_{s}$,

$$
\left.\left\{a_{1} a_{2} U_{2}^{3} \rho\left[1-\left(a_{2} / a_{3}\right)^{2}\right] / 2 g_{c}\right\}+a_{1} a_{2} \dot{U}_{2}\left(P_{2}-P_{3}\right)=\eta^{\prime}\left(a_{2} U_{2} B_{0}\right)^{2}\left[1 / R_{0}\right)+\left(1 / R_{e}\right)\right] \text {. }
$$

Solving for pressure drop $-\Delta P$,

$$
-\Delta P=P_{2}-P_{3}=\left(1-\eta^{\prime}\right) L \sigma U_{m} B_{0}^{2}-\left\{\left(a_{m} U_{m}\right)^{2} \rho\left[\left(1 / a_{2}^{2}\right)-\left(1 / a_{3}^{2}\right)\right] / 2 g_{c}\right\} . \quad(I I-70)
$$

It can be seen that for the case in which $a_{2}=a_{3}$, i.e., $U_{2}=U_{3}=$ $U_{m}$, the second term of the right-hand side becomes zero and the equation for $-\triangle \mathrm{P}$ becomes identical with Eq. (II-20) of the constant-cross-section MHD generator. 
Generator power output $P_{0}$ can be expressed as

$$
P_{0}=\epsilon_{g} P_{i}
$$

Equation (II-66) can be written in the following form:

$$
\mathrm{P}_{0} / \epsilon_{\mathrm{g}} \mathrm{W}=\left[\left(\mathrm{U}_{2}^{2}-\mathrm{U}_{3}^{2}\right) / 2 \mathrm{gc}\right]+\left[\left(\mathrm{P}_{2}-\mathrm{P}_{3}\right) / \rho\right]
$$

or

$$
\left(P_{2}-P_{3}\right) / \rho=\left(P_{G} / \epsilon_{g}\right)-U_{2}^{2}\left[1-\left(a_{2} / a_{3}\right)^{2}\right] / 2 g_{C}
$$

where

$$
P_{G}=P_{0} / W
$$

For a generator with fixed $a_{2}, a_{3}$, and $U_{2}$,

$$
\mathrm{U}_{2}^{2}\left[1-\left(\mathrm{a}_{2} / \mathrm{a}_{3}\right)^{2}\right] / 2 \mathrm{~g}_{\mathrm{c}}=\text { constant }=\mathrm{C}_{1} .
$$

Equation $(\mathrm{II}-72)$ gives a linear relationship between $\left(\mathrm{P}_{2}-\mathrm{P}_{3}\right) / \rho$ and $P_{G} / \epsilon_{g}$ :

$$
\left(P_{2}-P_{3}\right) / \rho=\left(P_{G} / \epsilon_{g}\right)-C_{1} \text {. }
$$

A. plot of Eq. (II-74) is shown in Fig. II-5.

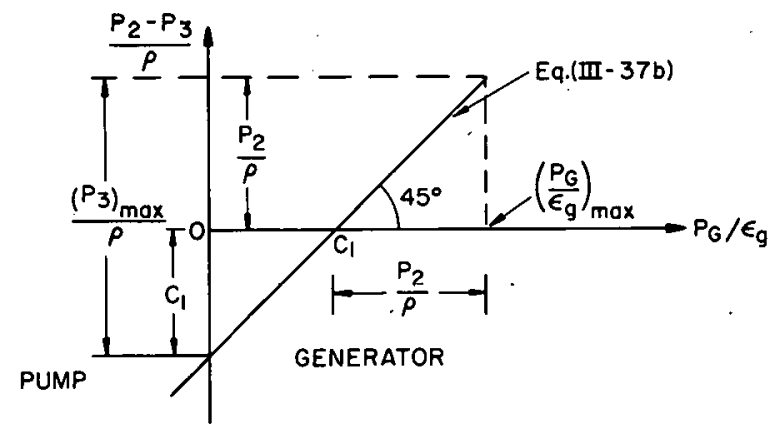

Fig. II- 5

Diagram Depicting Performance of Variable-area Generator

The pressure drop [which is proportional to $\left(\mathrm{P}_{2}-\mathrm{P}_{3}\right) / \rho$ ]

always increases with increasing power output (which is proportional to $\left.P_{G} / \epsilon_{g}\right)$. If $P_{2}$ is fixed, an increase in pressure drop means a decrease in $\mathrm{P}_{3}$. Hence, power output increases with decreasing $P_{3}$, and vice versa. When

$$
\mathrm{P}_{\mathrm{G}} / \epsilon_{\mathrm{g}}=\mathrm{C}_{1} ; \quad\left(\mathrm{P}_{2}-\mathrm{P}_{3}\right) / \rho=0
$$

then

$$
P_{3}=P_{2}
$$


and the power generation is due to the change in kinetic energy. If

$$
\mathrm{P}_{\mathrm{G}} / \epsilon_{\mathrm{g}}>\mathrm{C}_{1}
$$

then

$$
\mathrm{P}_{3}<\mathrm{P}_{2}
$$

and power generation results from both a kinetic energy change and a pressure drop. The maximum value of $\mathrm{P}_{\mathrm{G}} / \epsilon_{\mathrm{g}}$ is

$$
\left(\mathrm{P}_{\mathrm{G}} / \epsilon_{\mathrm{g}}\right)_{\max }=\mathrm{C}_{1}+\left(\mathrm{P}_{2} / \rho\right)
$$

because $\mathrm{P}_{3}$ cannot be less than zero. If

$$
\mathrm{PG}_{\mathrm{G}} / \epsilon_{\mathrm{g}}<\mathrm{C}_{1}
$$

then

$$
\left(P_{2}-P_{3}\right) / \rho=\text { negative; }
$$

it means. $P_{3}>P_{2}$. The fluid is pressurized. The maximum $P_{3}$ occurs when $\cdot P_{G}=0$ :

$$
\left(P_{3}\right)_{\max } / \rho=\left(P_{2} / \rho\right)+C_{1}
$$

The generator becomes a diffuser. The value of $P_{G}$ can be negative; this . means that external work has been done. on the fluid, and

$$
P_{3} / \rho=\left(P_{2} / \rho\right)+C_{1}+\left(P_{p} / \epsilon_{p}\right)
$$

This essentially is the case for an electromagnetic pump, so that $-P_{G}=P_{p}$ and $\epsilon_{\mathrm{g}}$ is replaced by the efficiency of the pump, $\epsilon_{\mathrm{p}}$.

Suppose $a_{2}$ and $a_{3}$ are fixed, $U_{2}$ is variable, and

$$
C_{2}=\left[1-\left(a_{2} / a_{3}\right)^{2}\right] / 2 g_{c}
$$

then

$$
\left(\mathrm{P}_{2}-\mathrm{P}_{3}\right) / \rho=\left(\mathrm{P}_{\mathrm{G}} / \epsilon_{\mathrm{g}}\right)-\mathrm{C}_{2} \mathrm{U}_{2}^{2}
$$

A plot of Eq. (II-80) is shown in Fig. II-6. If $P_{G} / \epsilon_{g}$ is kept constant, pressure drop increases with $\mathrm{U}_{2}^{2}$ or $\mathrm{P}_{3}$, and decreases with decreasing $\mathrm{U}_{2}^{2}$, when

$$
\mathrm{P}_{\mathrm{G}} / \epsilon_{\mathrm{g}}=\mathrm{C}_{2} \mathrm{U}_{2}^{2} ; \quad \mathrm{P}_{3}=\mathrm{P}_{2} \text {. }
$$


Again, when $P_{3}=0$, the minimum value of $\mathrm{C}_{2} \mathrm{U}_{2}^{2}$ is given by

$$
\left(\mathrm{C}_{2} \mathrm{U}_{2}^{2}\right)_{\min }=\left(\mathrm{P}_{\mathrm{G}} / \epsilon_{\mathrm{g}}\right)-\left(\mathrm{P}_{2} / \rho\right)
$$

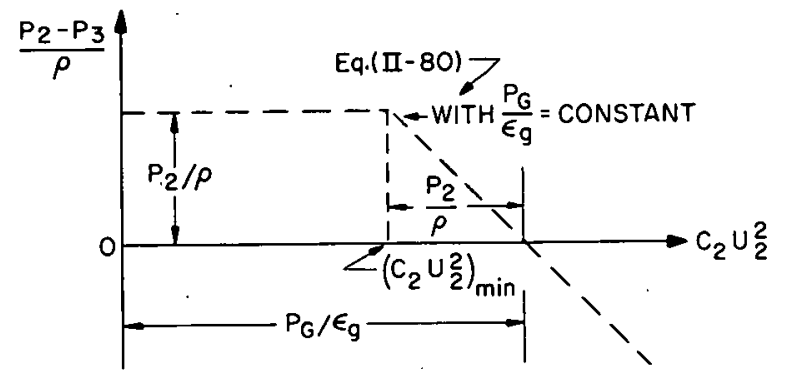

Fig. II-6

Diagram Showing Relationship between Performance Parameters of Variable-area Generator

For the case that both $P_{G} / \epsilon_{g}$ and $U_{2}$ change simultaneously, the relation between $\left(\mathrm{P}_{2}-\mathrm{P}_{3}\right) / \rho$ and $\mathrm{U}_{2}$ depends upon how $\mathrm{P}_{\mathrm{G}} / \epsilon_{\mathrm{g}}$ changes. For simplicity and illustration purposes the following relationship is as sumed:

$$
\mathrm{P}_{\mathrm{G}} / \epsilon_{\mathrm{g}}=\mathrm{C}_{3} \mathrm{U}_{2}^{2} \text {. }
$$

Then Eq. (II-80) becomes

$$
\left(P_{2}-P_{3}\right) / \rho=\left(C_{3}-C_{2}\right) U_{2}^{2} \text {. }
$$

If $C_{3}=C_{2}$, then $P_{3}=P_{2}$. For this condition, no matter how $U_{2}$ changes, the pressure drop would remain zero. An overall view of the variations which can occur are shown in Fig. II-7. If $\mathrm{C}_{3}-\mathrm{C}_{2}>0$, i.e., $\mathrm{P}_{\mathrm{G}} / \epsilon_{\mathrm{g}}>\mathrm{C}_{2} \mathrm{U}_{2}^{2}$, the pressure drop will increase. If $\mathrm{C}_{3}-\mathrm{C}_{2}<0$, i.e., $\mathrm{P}_{\mathrm{G}} / \epsilon_{\mathrm{g}}<\mathrm{C}_{2} \mathrm{U}_{2}^{2}$, the pressure drop will decrease. There are four lines shown in the figure with $\mathrm{C}_{3}-\mathrm{C}_{2}= \pm 1$ and $\mathrm{C}_{3}-\mathrm{C}_{2}= \pm 0.4$.

Fig. II -7

Schematic Showing Relationships among Pressure Drop, Power, and Velocities in Variable-area Generator

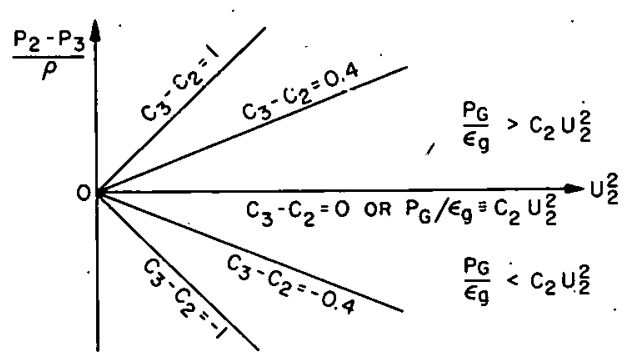

\section{Generator Efficiency}

The efficiency of the generator is defined as

$$
\begin{aligned}
\epsilon_{\mathrm{g}}= & \mathrm{P}_{0} / \mathrm{P}_{\mathrm{i}}=\left(\mathrm{a}_{1} L \sigma / \mathrm{a}_{\mathrm{m}}\right)\left(\mathrm{a}_{2} \mathrm{U}_{2} \mathrm{~B}_{0}\right)^{2} \eta^{\prime}\left\{1-\eta^{\prime}\left[1+\left\{\left(2 \mathrm{a}_{\mathrm{m}} \ln 2\right) / L \pi\right\}\right]\right\} /\left\{\left(\mathrm{a}_{1} \mathrm{a}_{2} \mathrm{U}_{2}^{3} \rho\right)^{\prime} / 2 \mathrm{~g}_{\mathrm{c}}\right]\left[1-\left(\mathrm{a}_{2} / \mathrm{a}_{3}\right)^{2}\right] \\
& \left.+\mathrm{a}_{1} \mathrm{a}_{2} \mathrm{U}_{2}\left[\left(1-\eta^{\prime}\right) L \sigma \mathrm{U}_{\mathrm{m}} \mathrm{B}_{0}^{2}-\left(\mathrm{a}_{2} \mathrm{U}_{2}\right)^{2} \rho\left\{\left(1 / \mathrm{a}_{2}^{2}\right)-\left(1 / \mathrm{a}_{3}^{2}\right)\right\} / 2 \mathrm{~g}_{\mathrm{c}}\right]\right\} .
\end{aligned}
$$


After simplification

$$
\epsilon_{\mathrm{g}}=\eta^{\prime}\left\{1-\eta^{\prime}\left[1+\left\{\left(2 \mathrm{a}_{\mathrm{m}} \ln 2\right) / \mathrm{L} \pi\right\}\right]\right\} /\left(1-\eta^{\prime}\right),
$$

exactly the same as obtained for a constant-area generator.

The efficiency $\epsilon_{g}$ can also be derived in another manner:

$$
\begin{aligned}
\epsilon_{\mathrm{g}}=\mathrm{P}_{0} / \mathrm{P}_{\mathrm{S}} & =\mathrm{VI} /\left[\mathrm{V}_{0}\left(\mathrm{I}+\mathrm{I}_{\mathrm{e}}\right)\right]=\eta^{\prime} \mathrm{V}_{0} / \mathrm{V}_{0}\left[1+\left(\mathrm{R}_{0} / \mathrm{R}_{\mathrm{e}}\right)\right] \\
& =\eta^{\prime}\left[1+\left(\mathrm{R}_{0} / \mathrm{R}_{\mathrm{e}}\right)\right]^{-1}=\eta^{\prime}\left[\mathrm{R}_{0}\left\{\left(1 / \mathrm{R}_{0}\right)+\left(1 / \mathrm{R}_{\mathrm{e}}\right)\right\}\right]^{-1} \\
& =\mathrm{R}_{\mathrm{i}} \eta^{\prime}\left[\mathrm{R}_{0}\left\{\left(\mathrm{R}_{\mathrm{i}} / \mathrm{R}_{0}\right)+\left(\mathrm{R}_{\mathrm{i}} / \mathrm{R}_{\mathrm{e}}\right)\right\}\right]^{-1}=\left(\mathrm{R}_{\mathrm{i}} / \mathrm{R}_{0}\right) \eta^{\prime}\left[\eta^{\prime} /\left(1-\eta^{\prime}\right)\right] .
\end{aligned}
$$

Since

$$
1-\eta^{\prime}\left[1+\mathrm{a}_{\mathrm{m}}{ }^{2} \ln (2 / \mathrm{L} \pi)\right] \equiv\left(\mathrm{R}_{\mathrm{i}} / \mathrm{R}_{0}\right) \eta^{\prime}
$$

it follows that

$$
\epsilon_{\mathrm{g}}=\eta^{\prime}\left\{1-\eta^{\prime}\left[1+\left\{\left(2 \mathrm{a}_{\mathrm{m}} \ln 2\right) / \mathrm{L} \pi\right\}\right]\right\} /\left(1-\eta^{\prime}\right) .
$$

The maximum value of the efficiency and its dependence upon the generator loading $R_{i} / R_{0}$ is obtained by differentiating the efficiency F.r. (II-84) with respect ti $\cdot R_{i} / R_{0}$; the result is

$$
\left(\mathrm{R}_{\mathrm{i}} / \mathrm{R}_{0}\right)_{\max } \epsilon_{\mathrm{g}}=\left\{\left[\mathrm{a}_{\mathrm{m}} 2 \ln (2 / \mathrm{L} \pi)\right]\left[1+\left\{\left(2 \mathrm{a}_{\mathrm{m}}{ }^{2} \ln 2\right) / \mathrm{L} \pi\right\}\right]\right\}^{1 / 2} .
$$

The absolute maximum efficiency which can be attained in an MHD generator is determined by the magnitude of the end losses occurring in the generator and is independent of the generator loading. This can be seen by substituting Eq. (II-85) into Eq. (II-84). The efficiency becomes $\epsilon_{\mathrm{g}, \max }=\left(i+a_{m} 4 \ln (2 / L \pi)+2\left\{\left[a_{m} 2 \ln (2 / L \pi)\right]\left[1+\left\{\left(2 a_{m} \ln 2\right) / L \pi\right\}\right]\right\}^{1 / 2}\right)^{-1}$.

\section{Divergent Angle}

The half divergent angle is denoted by $\theta$ [see Fig. 2(b)]. The value of $\theta$ is bounded since flow separation may occur if the angle becomes too large. The aspect ratio; $\mathrm{L} / \mathrm{a}_{\mathrm{m}}$, is closely related to $\theta$. The smaller the value of $\theta$, the larger the aspect ratio. The relationships are given by 


$$
\begin{aligned}
& \mathrm{a}_{3}=\mathrm{a}_{2}+2 \mathrm{~L} \tan \theta ; \quad \mathrm{a}_{3} / \mathrm{a}_{2}=\left(\mathrm{a}_{2}+2 \mathrm{~L} \tan \theta\right) / \mathrm{a}_{2}=\mathrm{U}_{2} / \mathrm{U}_{3} ; \\
& \mathrm{L}=\left[\left(\mathrm{U}_{2} / \mathrm{U}_{3}\right)-1\right] \mathrm{a}_{2} / 2 \tan \theta . \\
& \mathrm{L} / \mathrm{a}_{\mathrm{m}}=\ln \left(\mathrm{U}_{2} / \mathrm{U}_{3}\right) / 2 \tan \theta .
\end{aligned}
$$

\section{Geometry Performance Characteristics}

The cycle analysis specifies the operating conditions for a given power system. Detailed examination of the various components are then necessary to determine the feasibility of the derived operating conditions. As mentioned previously, the crucial component of the system is the MHD generator. The performance characteristics and generator geometry which complies with varying operational parameters can be rapidly evaluated by means of generalized charts. The bases for such charts are derived and discussed in the following sections. In addition, several charts prepared for illustrative purposes are presented.

\section{The Constant-area Generator}

From the equations given in the previous section it is evident that there are six independent variables which describe the MHD generator. The other pertinent variables can be expres'sed in terms of these six.

If it is specified that the generator operates at maximum efficiency, there remain five independent variables to be specified.

In considering the constant-area generator, $-\triangle \mathrm{P}$ is fixed by operating conditions for the cycle; therefore the pressure drop across the generator, $-\triangle P$, should be specified as an independent variable. From a design viewpoint, it is generally desirable to specify the generator output $P_{0}$. Since the magnetic field, $B_{0}$, is limited by present technology, it also qualifies as an independent variable. Two additional parameters which are highly pertinent and descriptive of the generator performance are designated as the remaining independent variables. The aspect ratios of the generator, namely, $c$, and $f$, where

$$
c=L / a \text { and } f=a_{1} / a \text {. }
$$

When $c$ is specified and the generator operates at maximum efficiency, then $\epsilon_{g}$ and $\eta^{\prime}$ can be determined immediately. It should be noted that there are practical limits on the value of $c$; although larger values of $c$ reflect higher generator efficiency, the generator dimensions become unrealistic. This is a major reason for specifying $c$ as an independent variable. 
In summary, the performance characteristics of the constantarea generator is calculated from the following specified parameters:

$$
\cdot P_{0},-\Delta P, B_{0}, c, f, \text { and } \epsilon_{g \text { max }}
$$

From the se parameters, $V, a_{1}, L, a$, and $U_{7}$ are calculated, and generalized charts can be prepared. The values of $P_{0}, B_{0}, c$, and $f$ can be adjusted to. give suitable sizes and terminal voltage of the generator.

Referring to Eqs. (II-15) and (II-19) describing the constantarea MHD generator section, the power output is

$$
P_{0}=V I=\left(\eta^{\prime} a U_{7} B_{0}\right) a_{1} L \sigma U_{7} B_{0}\left\{1-\eta^{t}[1+\{(2 \ln 2) / c \pi\}]\right\} \text {. }
$$

Since

$$
a_{1}=f a \text {, and } L=c a \text {, }
$$

then

$$
P_{0}=f^{3} \sigma U_{7}^{2} B_{0}^{2} c \eta^{\prime}\left\{1 \ldots \eta^{\prime}[1+\{(2 \ln 2) / c \pi\}]\right\}
$$

The pressure drop is related to $B_{0}$ and $\sigma$ by the following equation:

$$
-\Delta P=\left(1-\eta^{\prime}\right) \operatorname{L} \sigma U_{7} B_{0}^{2}-\left(1-\eta^{\prime}\right) c \sigma U_{7} B_{0}^{2} a .
$$

Solving for the velocity in the generator, $U_{7}$, we obtain

$$
\mathrm{U}_{7}=-\Delta \mathrm{P} /\left(1-\eta^{\prime}\right) \mathrm{c} \sigma \mathrm{B}_{0}^{2} \mathrm{a} \text {. }
$$

Substituting $U_{7}$ in Eq. (II-90), we find

$$
P_{0}=\left[f a(-\Delta P)^{2} / \sigma B_{0}^{2}\right] \eta^{\prime}\left\{1-\eta^{\prime}[1+\{(2 \ln 2) / c \pi\}]\right\} / c\left(1-\eta^{\prime}\right)^{2}
$$

and

$$
\mathrm{P}_{0} \mathrm{~B}_{0}^{2} / \mathrm{fa}=\left[(-\Delta \mathrm{P})^{2} / \mathrm{u}^{0}\right] \mathrm{F}_{1}(\mathrm{c})
$$

where

$$
F_{1}(c)=\eta^{\prime}\left\{1-\eta^{\prime}[1+\{(2 \ln 2) \cdot c \pi\}]\right\} / c\left(1-\eta^{\prime}\right)^{2} .
$$

Referring to Eq. (II-93) it is apparent that a plot of $P_{0} B_{0}^{2} / f a$ vs $F_{1}(c)$ would yield a family of straight lines which pass through the origin and whose slopes are $-\Delta P^{2} / \sigma$. The pressure drop across the generator, $\triangle \mathrm{P}$, is determined by cycle condition. It can be shown that the pressure drop is essentially a function of $\mathrm{m}_{\mathrm{f}} / \mathrm{m}_{\mathrm{g}}$; therefore the slopes can be calculated directly. The slopes will differ for the various liquid 
metals because of the variation of the electrical conductivity. A plot of this type" was constructed for a constant-area generator operating in the two-phase, two-component cycle (described in Section III) and is shown in Fig. II-8. As an example of the utility of this graph consider the following numerical example.

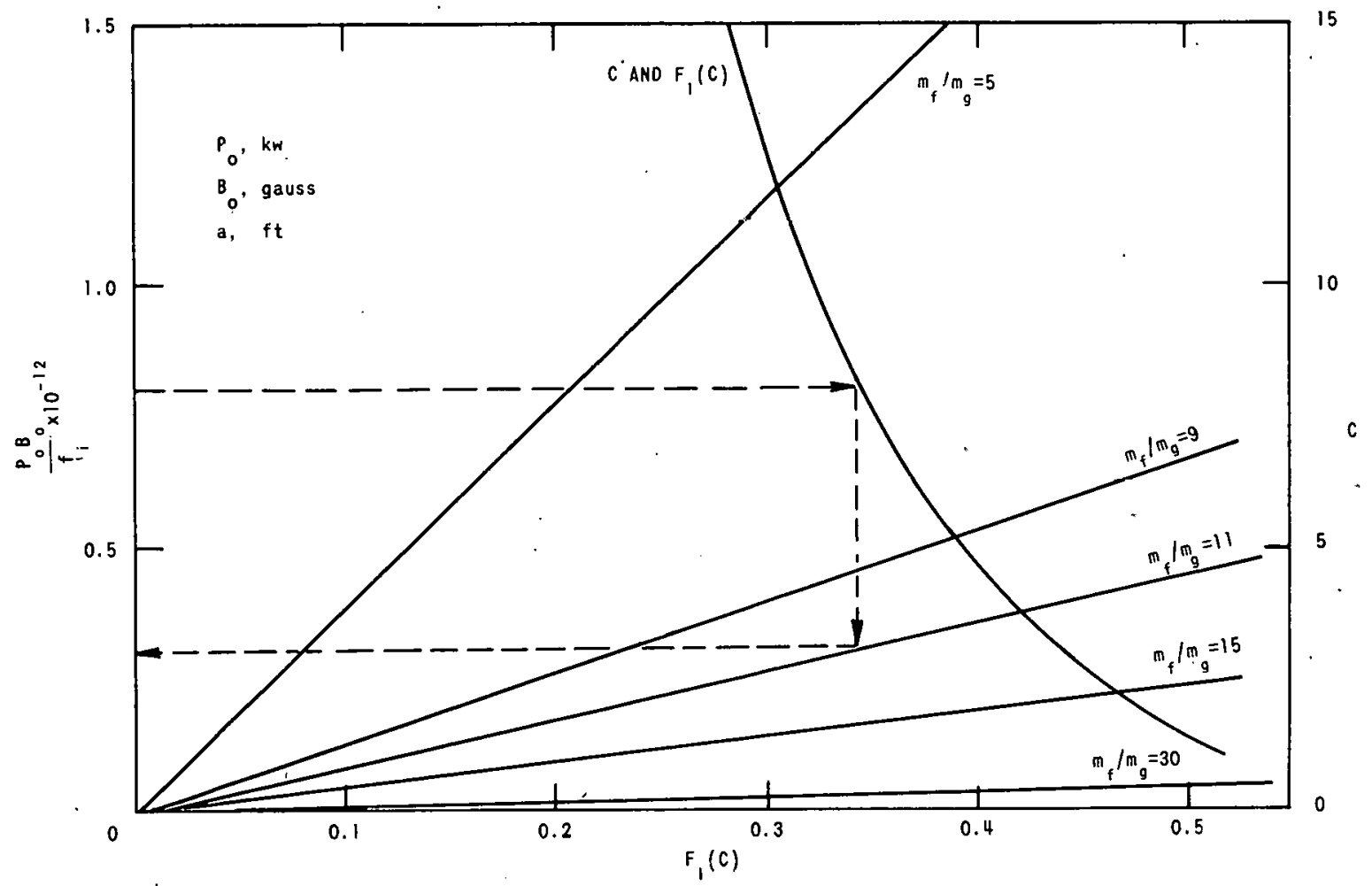

Fig. II-8. Generalized Performance Parameter $\mathrm{P}_{0} \mathrm{~B}_{0}^{2} / \mathrm{fa}$ for the Constant-area Generator

For $\mathrm{m}_{\mathrm{f}} / \mathrm{m}_{\mathrm{g}}=11$ and $\mathrm{c}=8$, one obtains (see dotted line in

Fig. II-8)

$$
\left(P_{0} B_{0}^{2} / f a\right) \times 10^{-12}=0.305
$$

If

$$
\begin{aligned}
& \mathrm{B}_{0}=10,000 \text { gauss; } P_{0}=500 \mathrm{~kW} ; \quad m_{f}=95.2 \mathrm{lb} / \mathrm{sec} ; \\
& \rho_{\mathrm{f}}=27.3 \mathrm{lb} / \mathrm{ft}^{3},
\end{aligned}
$$

then

$$
f a=500 \times(10,000)^{2} \times 10^{-12} / 0.305=0.164
$$


If $f$ is specified to be 0.1 ,

$$
\begin{aligned}
a & =1.64 \mathrm{ft}=19.68 \mathrm{in} . ; \\
L & =8 \times 1.64=13.12 \mathrm{ft} ; \\
d_{1} & =0.164 \mathrm{ft}=1.97 \mathrm{in} ; \\
U_{7} & =m_{f} / \rho_{f} a_{1}=95.2(27.3 \times 1.64 \times 0.164)^{-1}=12.97 \mathrm{ft} / \mathrm{sec} .
\end{aligned}
$$

The terminal voltage $V$ is given by

$$
\mathrm{V}=\eta^{\prime} \mathrm{a} \mathrm{U}_{7} \mathrm{~B}_{0}
$$

Rearrangement gives

$$
\mathrm{v} / \mathrm{aU}_{7} \mathrm{~B}_{0}=\eta^{\prime} \text {. }
$$

A plot of $\mathrm{V} / \mathrm{aU}_{7} \mathrm{~B}_{0}$ against $\eta^{\prime}$ is shown in Fig. II-9. The slope of the straight line is the unit-conversion constant $9.29 \times 10^{-6}$.

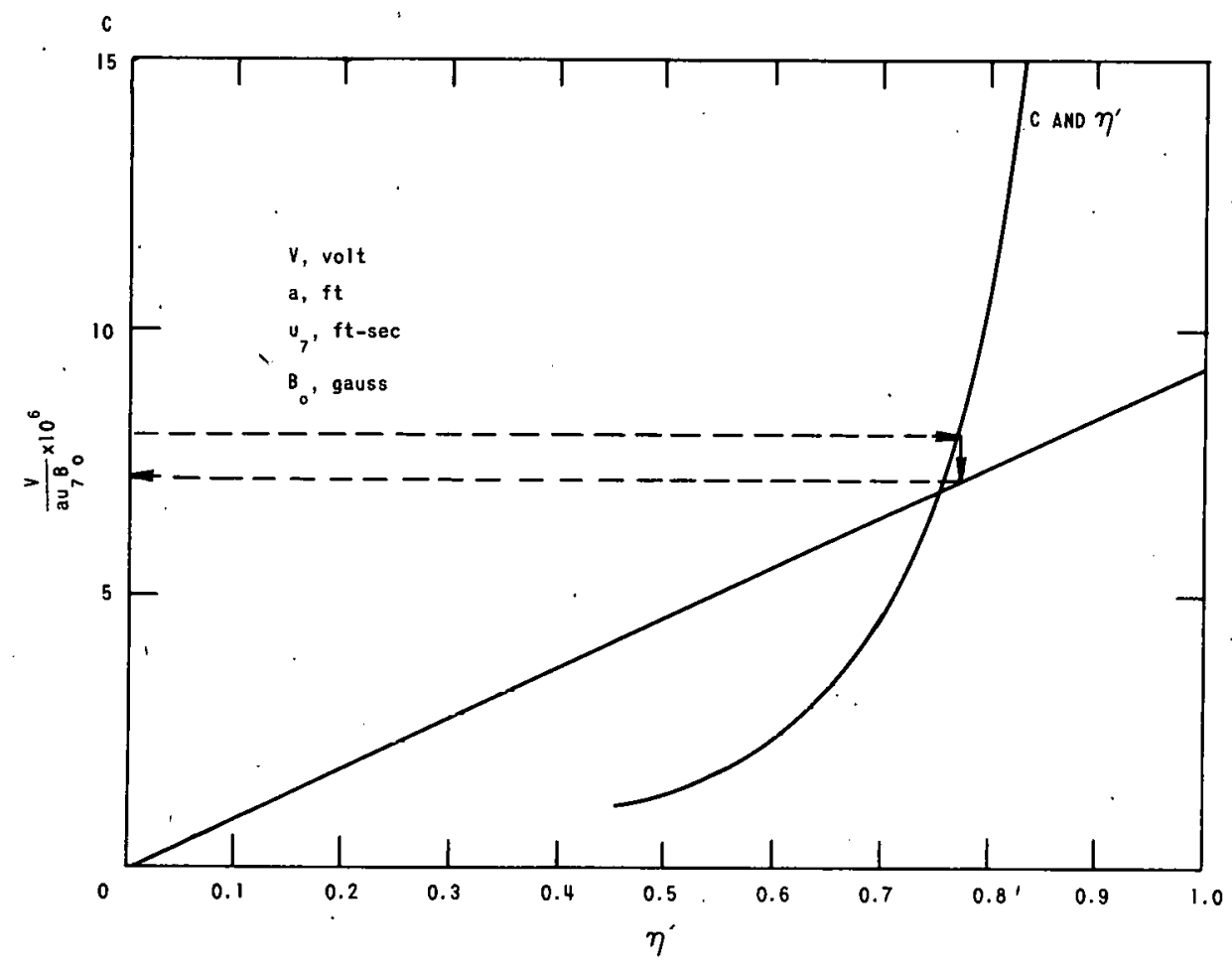

Fig. II-9. Generalized Performance Parameter V/aU $\mathrm{U}_{7}$ for the Constant-area Generator

When $c=8$ (see dotted line in Fig. II-9),

$\left[\mathrm{V} / \mathrm{aU}_{7} \mathrm{~B}_{0}\right] 10^{6}=7.12$ 
The refore,

$$
\mathrm{V}=7.12 \times 10^{-6} \times 1.64 \times 12.97 \times 10,000=1.51 \mathrm{~V}
$$

It should be noted that $V$ is fixed when $P_{0}, B_{0}, c$, and $m_{f} / m_{g}$ are fixed, because

$$
\begin{aligned}
\mathrm{V} & =\eta^{\prime} \mathrm{aU}_{7} \mathrm{~B}_{0}=\eta^{\prime} \mathrm{aB} \mathrm{B}_{0} \mathrm{~m}_{\mathrm{f}} / \rho_{\mathrm{faa}}=\eta^{\prime} \mathrm{B}_{0} \mathrm{~m}_{\mathrm{f}} / \rho_{\mathrm{f}} \mathrm{a}_{1} \\
& =\eta^{\prime} \mathrm{B}_{0} \mathrm{~m}_{\mathrm{f}} / \rho_{\mathrm{f}} \mathrm{fa} .
\end{aligned}
$$

The product $f a$ is fixed by fixing $P_{0}, B_{0}, c$, and $m_{f} / m_{g}$; hence, $V$ cannot be changed. Different values of $f$ only affect the value of $U_{7}$.

The generalized plot completely describes the performance of the constant-area MHD generator.

\section{The Variable-area Generator}

The basis for the development of generalized charts for the variable-area generator was obtained in the following manner. Referring to Eq. (II-63),

$$
\mathrm{V}=\eta^{\prime} \mathrm{a}_{\mathrm{m}} \mathrm{U}_{\mathrm{m}} \mathrm{B}_{0}=\eta^{\prime} \mathrm{a}_{2} \mathrm{U}_{2} \mathrm{~B}_{0}
$$

Since $B_{0}$ is specified, and $\eta^{\prime}$ and $U_{2}$ are set from the operating conditions, the inlet width of the generator $c$ an be determined if the terminal voltage is set:

$$
a_{2}=V / \eta^{\prime} U_{2} B_{0}
$$

Since $a_{2}$ and $a_{3}$ are related by the continuity relationship, $a_{3}$ can be computed directly from $a_{2} U_{2}=a_{3} U_{3}$; also $a_{m}$ and $L$ can be calculated from Eqs. (II-34) and (II-88). If the generator power output $P_{0}$ is assumed to be an independent parameter,

$$
\begin{aligned}
P_{0} & =V I=V a_{1} L \sigma U_{m} B_{0}\left\{1-\eta^{\prime}\left[1+\left\{\left(2 a_{m} \cdot \ln 2\right) / L \pi\right\}\right]\right\} \\
& =V f a_{2} B_{0} \sigma\left(a_{2} U_{2} L / a_{m}\right)\left\{1-\eta^{\prime}\left[1+\left\{\left(2 a_{m} \ln 2\right) / L \pi\right\}\right]\right\} \\
& =V f a_{2}^{2} B_{0} \sigma U_{2}\left(L / a_{m}\right)\left\{1-\eta^{\prime}\left[1+\left\{\left(2 a_{m} \ln 2\right) / L \pi\right\}\right]\right\} .
\end{aligned}
$$

From Eq. (II-98)

$$
\mathrm{a}_{2}^{2}=\mathrm{V}^{2} /\left(\eta^{\prime} \mathrm{U}_{2} \mathrm{~B}_{0}\right)^{2}
$$


and

$$
\begin{aligned}
P_{0} & =f V^{3} B_{0} U_{2}\left(\eta^{\prime} U_{2} B_{0}\right)^{-2} \sigma\left(L / a_{m}\right)\left\{1-\eta^{\prime}\left[1+\left\{\left(2 a_{m} \ln 2\right) / L \pi\right\}\right]\right\} \\
& =\left(f V^{3} / B_{0}\right)\left(\sigma / U_{2}\right)\left(L / a_{m}\right)\left\{1-\eta^{\prime}\left[1+\left\{\left(L / a_{m}\right)^{-1}(2 \ln 2) / \pi\right\}\right]\right\} \eta^{\prime},
\end{aligned}
$$

where $U_{2}$ is a function of $x_{1}\left(\dot{x}_{1}\right.$ is inlet quality to the nozzle; refer to Section IV, ) and $\mathrm{L} / \mathrm{a}_{\mathrm{m}}=\ln \left(\mathrm{U}_{2} / \mathrm{U}_{3}\right) /(2 \tan \theta)$ is a function of $\mathrm{x}_{1}$ and $\theta$. If a two-phase mixture is stipulated as the working fluid, then $\sigma$ is a function of $x_{1}$. For maximum generator efficiency,

$\eta^{\prime}=\left(1+\left[\left(\mathrm{L} / \mathrm{a}_{\mathrm{m}}\right)^{-1}(2 \ln 2) / \pi\right]+\left\{\left[\left(\mathrm{L} / \mathrm{a}_{\mathrm{m}}\right)^{-1}(2 \ln 2) / \pi\right]\left[1+\left\{\left(\mathrm{L} / \mathrm{a}_{\mathrm{m}}\right)^{-1}(2 \ln 2) / \pi\right\}\right]\right\}^{1 / 2}\right)^{-1}$

is a function of $x_{1}$ and $\theta$. Therefore

$$
\mathrm{P}_{0}=\left(f \mathrm{fV}^{3} / \mathrm{B}_{0}\right) \mathrm{F}_{\mathrm{i}}\left(\mathrm{x}_{1}, \theta\right)
$$

and

$$
\begin{aligned}
F_{1}\left(x_{1}, \theta\right) & =P_{0}\left(\mathrm{fV}^{3} / \mathrm{B}_{0}^{\prime}\right)^{-1} \\
& =\left(\sigma / \mathrm{U}_{2}\right)\left[\left\{\left(\mathrm{L} / \mathrm{a}_{\mathrm{m}}\right)\left(1-\eta^{\prime}\right) / \eta^{\prime 2}\right\}-\left\{(2 \ln 2) / \eta^{\prime} \pi\right\}\right]
\end{aligned}
$$

A plot of $F_{1}\left(x_{1}, \theta\right)$ vs $x_{1}$ with $\theta$ as a parameter is shown in F-ig. II- 10 for cesium and potassium. A two-phase working fluid in the generator was

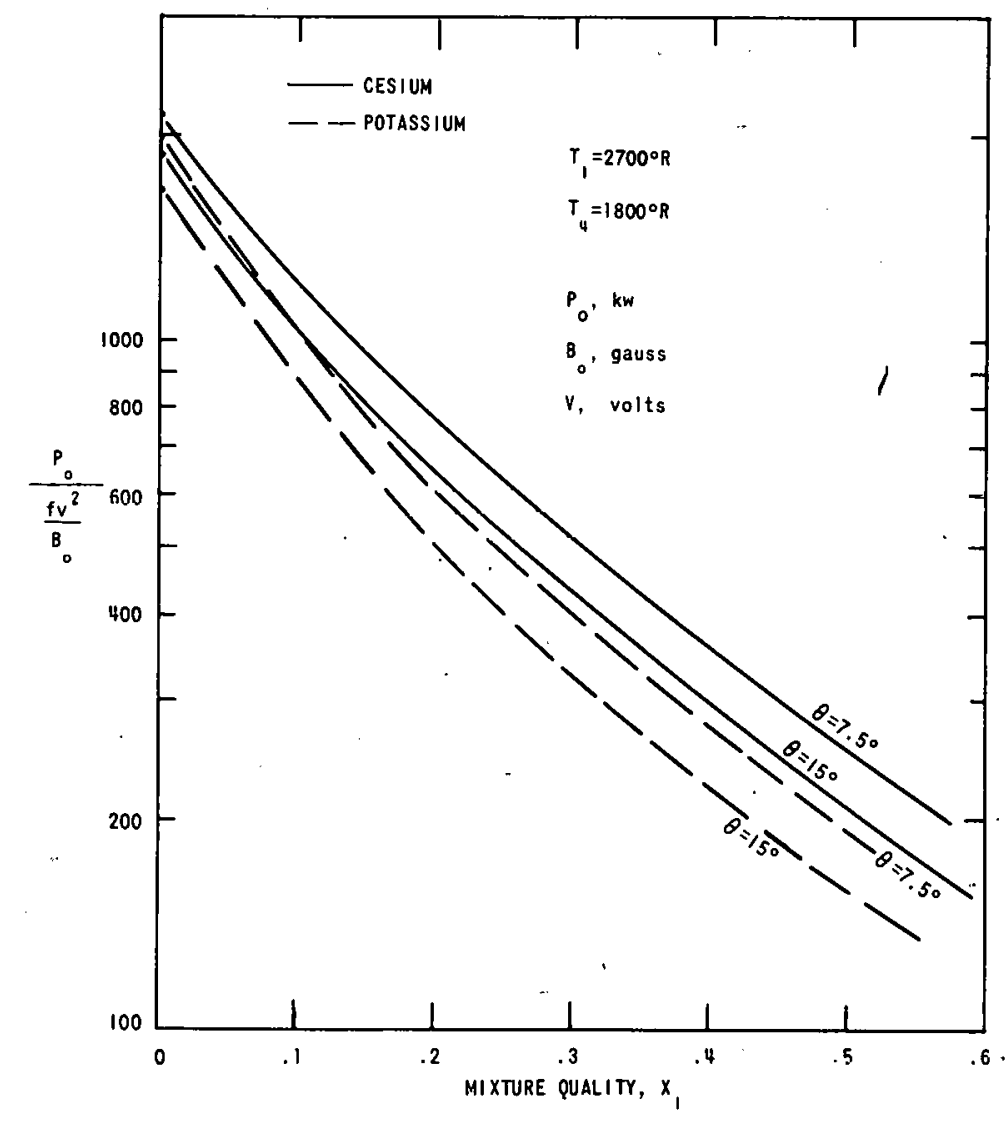

Fig. II-10

$F_{1}\left(x_{1}, \theta\right)$ vs $x_{1}$ for

Cesium and Potassium 
specified. It was arbitrarily assumed that the conductivity $\sigma$ follows Maxwell's relationship and that the relative velocity between phases was zero.

A second function of $x_{1}$ and $\theta$ is obtained by rewriting Eq. (II-63):

$$
a_{2} B_{0} / V=\left(\eta^{\prime} U_{2}\right)^{-1}=F_{2}\left(x_{1}, \theta\right) \text {. }
$$

Figure II- 11 is a plot of $F_{2}\left(x_{1}, \theta\right)$ vs $x_{1}$ for cesium; Fig. II-12 is for potassium. The ratio of $a_{3}$ to $a_{2}$ (which is not a function of $\theta$ ) and $L / a_{2}$ are also shown in the graph. Once $x_{1}$ and 0 are specified, $a_{3} / a_{2}$ and $L / a_{2}$ can be immediately read from the plot.

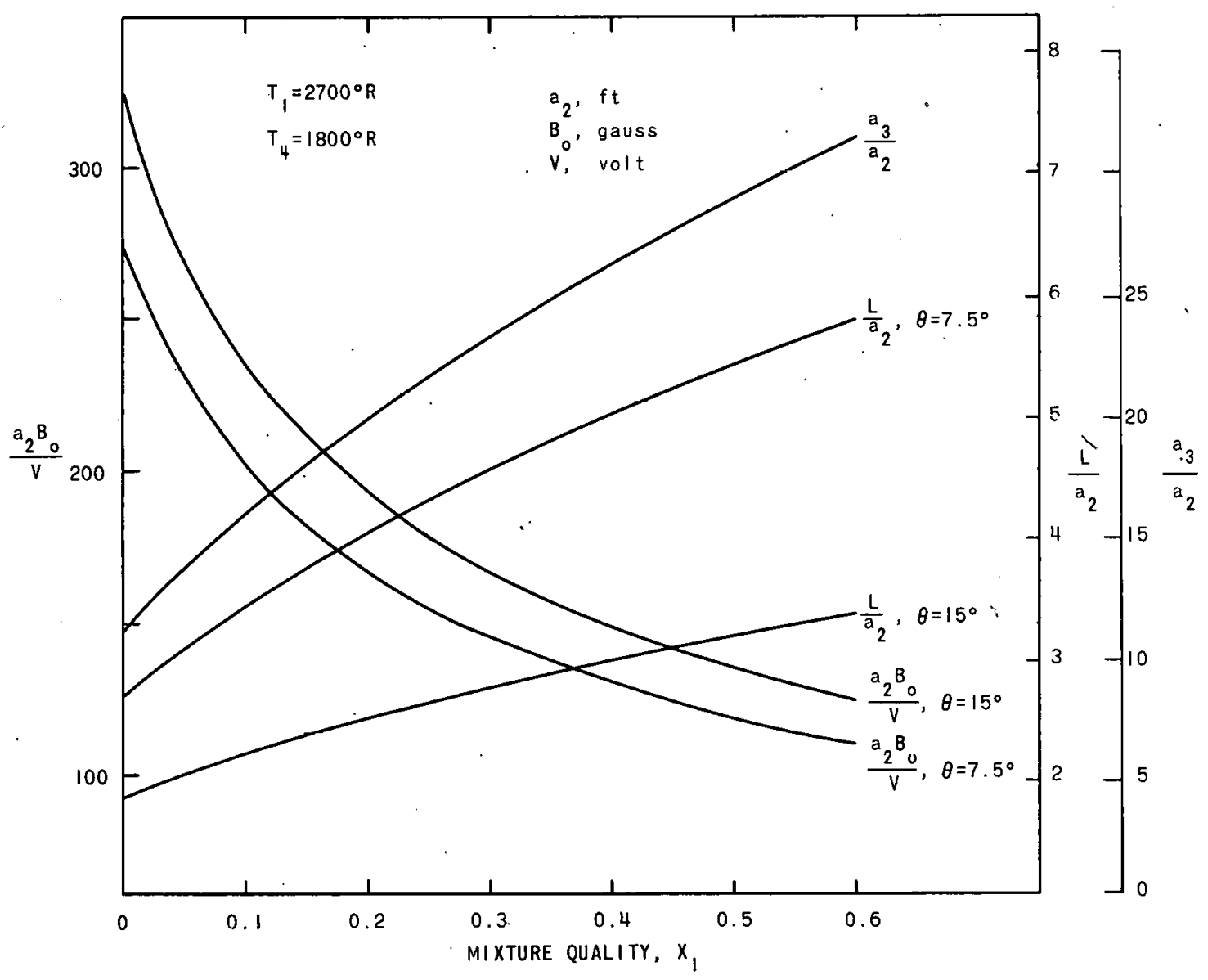

Fig. II-11. $F_{2}\left(x_{1}, \theta\right)$ vs $\mathbf{x}_{1}$ for Cesium 

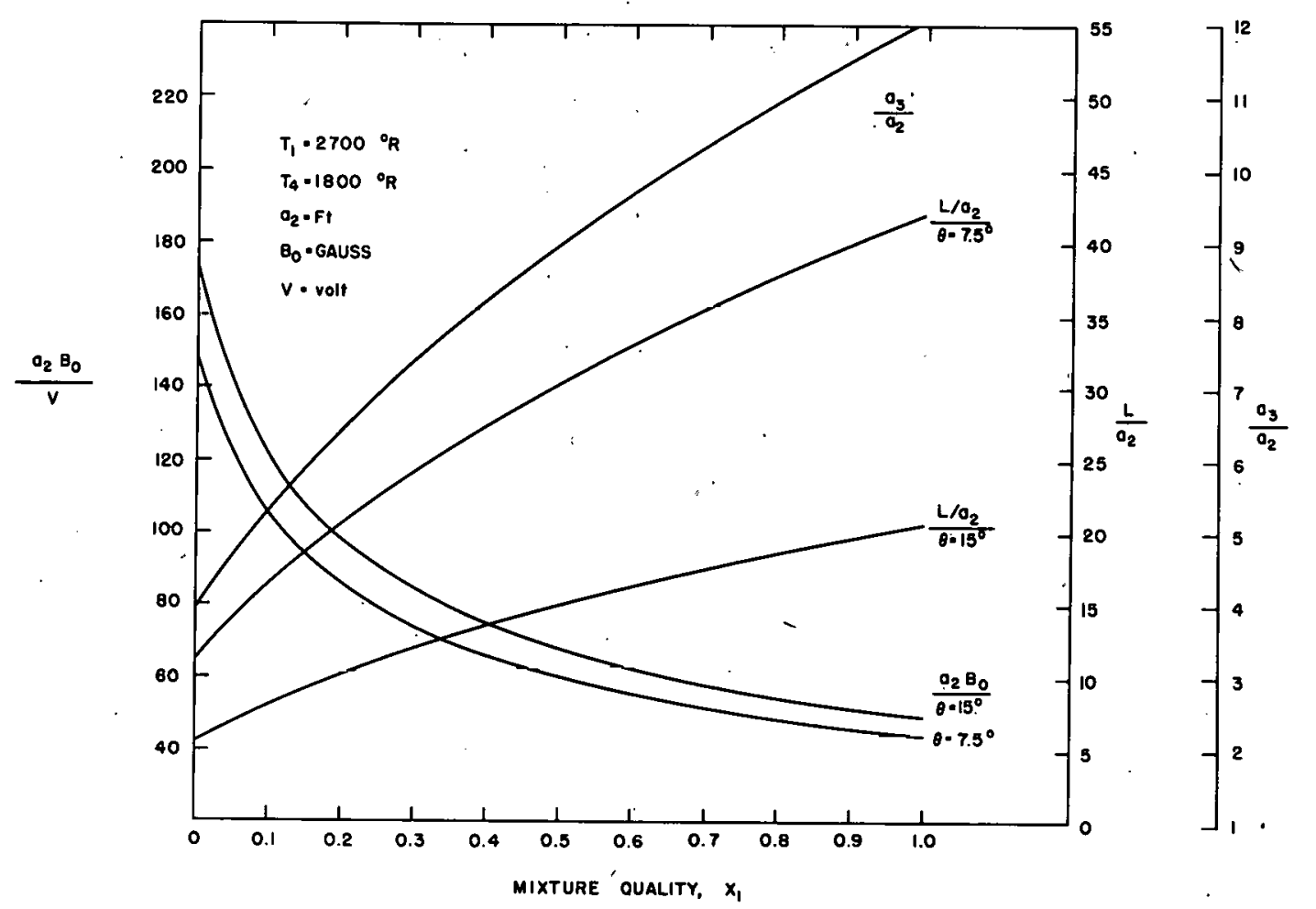

Fig. II-12. $F_{2}\left(x_{1}, \theta\right)$ vs $x_{1}$ for Potassium

As an example, consider a cesium cycle with $x_{1}=0.3$ and $\theta=15^{\circ}$. From Iig. II-10,

$$
F_{1}\left(0.3,15^{\circ}\right)=P_{0}\left(f V^{3} / B_{0}\right)^{-1}=431
$$

For $P_{0}=400 \mathrm{~kW}$

$$
\mathrm{fV}^{3} / \mathrm{B}_{0}=400 / 431
$$

If $B_{0}$ is specified to be 10,000 gauss,

$$
f V^{3}=4,000,000 / 431
$$

$\mathrm{V}$ can be calculated for a specified f. From Fig. II-1l,

$$
a_{3} / a_{2}=5.60 ; \quad L / a_{2}=8.59 ; \quad a_{2} B_{0} / V=166.5
$$

Since $B_{0 .}=10,000$ gauss was specified previously,

$$
a_{2} / v=166.5 / 10,000
$$

After $V$ is determined, $a_{2}$ can be calculated, as well as $a_{3}$ and $L$.

Similar types of generalized charts can be developed to give the total flow rate, cycle efficiency, etc. 


\section{THE TWO-COMPONENT, TWO-PHASE MHD CYCLE}

The two-component, two-phase MHD cycle was initially proposed and analyzed by Elliott, $(1)$ and is schematically illustrated in Fig. III- 1.

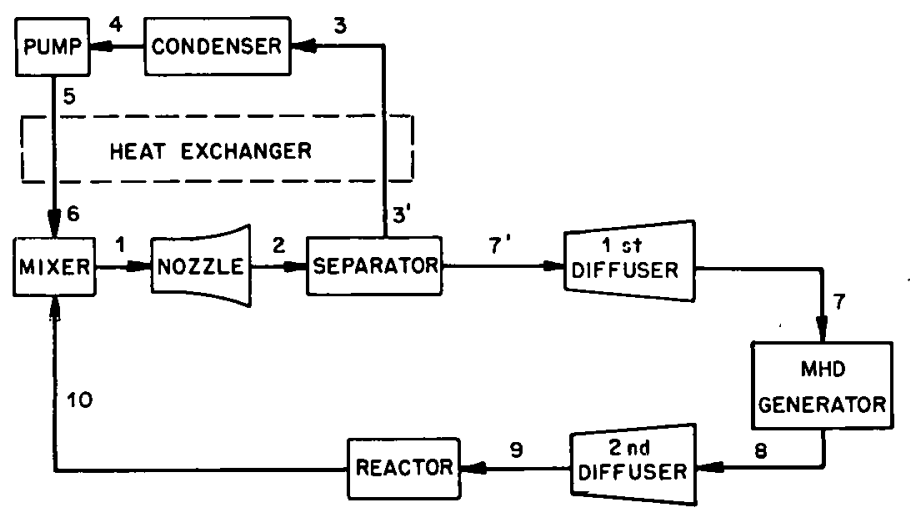

Fig. III-1. Schematic of Elliott Cycle

One fluid circulates in the vapor loop and the other in the liquid loop. The fluid circulating in the vapor loop leaves the condenser as condensate and is pumped (by a nonrotating electromagentic pump) to the mixer, where it vaporizes on contact with the liquid. The vapor expands with the liquid through a two-phase nozzle, separates from the liquid in the separator, and recondenses in the condenser. To raise the cycle efficiency, a heat exchanger cools the vapor while preheating the condensate.

In the liquid loop, the liquid is heated in the reactor and cooled as it vaporizes the condensate in the mixer. The liquid is then accelerated by the vapor in the nozzle, separated from the vapor in the separator, decelerated by the production of electric power in the MHD generator, and returned through the diffuser to the reactor. The energy-conversion steps in the process are: (1) the transfer of heat from the reactor to the liquid; (2) conversion of part of this heat to vapor enthalpy (subsequently rejected by the condenser); (3) the conversion of the remaining heat to kinetic energy of the liquid in the nozzle; and (4) conversion of most of this kinetic energy to electric power in the generator, the remainder going to losses and to pressure recovery in the diffuser.

The overall cycle efficiency is determined by the efficiency of the conversion steps. In particular, the kinetic energy losses in the separator is a crucial factor which strongly affects the overall cycle efficiency.

\section{A. Cycle Analyses}

The analysis of the cycle is broken down into the various components, each of which is discussed individually. Referring to Fig. III- 1 , the numbers given are used to denote the cycle position and also are used as 
subscripts in the analysis. For ease in computation, a constant-area generator. was used in the study. If a variable-area generator had been used, the results would have been essentially the same, since pressure and velocity heads are interconvertible. With the constant-area.generator there is an additional loss due to the use of the diffuser before the generator; hence, the cycle efficiency of a variable-area generator would be slightly higher.

The following simplifying assumptions were made:

1. The liquid and condensate (the liquid phase in the vapor loop) are incompressible and have constant specific heats.

2. There are no heat losses from the cycle except through the condenser.

3. All condensate is vaporized in the mixer and remains vaporized until it reaches the condenser.

4. All vapor is condensed in the condenser and remains condensed until it reaches the mixer.

5. The vapor is an ideal gas with constant specific heat.

6. The condensate does not chemically react with liquid.

7. The vapor is insoluble in the liquid.

8. The liquid has zero vapor pressure.

9. Complete separation of the liquid and vapor occurs in the separator.

1. Two-phase Nozzle

A substantial amount of information has been accumulated on the efficiency of the expansion of two-phase mixtures through nozzles. The data indicate the nozzles may be designed to yield efficiencies in the range of 80-90\%, based on an isentropic homogeneous expansion. The following assumptions are made for the derivation of the isentropic velocity:

a. steady flow, frictionless, one-dimensional;

b. gas and liquid are uniformly mixed; same temperature, same velocity;

c. no heat loss through nozzle wall;

d. no external work;

e. only forces acting on mixture are due to pressure;

f. no potential energy chánges. 
Since $S_{1}=S_{2}$, we have

$$
\Delta S=0=\left(1-x_{1}\right)\left[C_{f} \ln \left(T_{2} / T_{1}\right)\right]+x_{1}\left[C_{g} \ln \left(T_{2} / T_{1}\right)-(R / M) \ln \left(P_{2} / P_{1}\right)\right] .
$$

Solving for $T_{2} / T_{1}$, one obtains

$$
\ln \left(T_{2} / T_{1}\right)=\left(x_{1} R\right) M^{-1}\left[x_{1} C_{g}+\left(1-x_{1}\right) C_{f}\right]^{-1} \ln \left(P_{2} / P_{1}\right)
$$

$n r$

$$
\mathrm{T}_{2} / \mathrm{T}_{1}=\left(\mathrm{P}_{2} / \mathrm{P}_{1}\right) \exp \left\{\mathrm{x}_{1} \mathrm{RM}^{-1}\left[\mathrm{x}_{1} \mathrm{C}_{\mathrm{g}}+\left(1-\mathrm{x}_{1}\right) \mathrm{C}_{\mathrm{f}}\right\rfloor^{-1}\right\}
$$

For values of $x_{1}$ of practical interest, the exponent is very small and $T_{2} / T_{1}$ can be expressed, within a few percent, by the first two terms of the series expansion:

$$
\mathrm{T}_{2} / \mathrm{T}_{1} \doteq 1+\mathrm{x}_{1} \mathrm{RM}^{-1}\left[\mathrm{x}_{1} \mathrm{C}_{\mathrm{g}}+\left(1-\dot{x}_{1}\right) \mathrm{C}_{\mathrm{f}}\right]^{-1} \ln \left(\mathrm{P}_{2} / \mathrm{P}_{1}\right)
$$

The enthalpy change in the nozzle is

$$
-\Delta \mathrm{H}=\mathrm{U}_{\mathrm{i}}^{2} / 2 \mathrm{gc}=\left(1-\mathrm{x}_{1}\right)\left[\mathrm{C}_{\mathrm{f}}\left(\mathrm{T}_{1}-\mathrm{T}_{2}\right)+\left\{\left(\mathrm{P}_{1}-\mathrm{P}_{2}\right) / \rho_{\mathrm{f}}\right\}\right]+\mathrm{x}_{1} \mathrm{C}_{\mathrm{g}}\left(\mathrm{T}_{1}-\mathrm{T}_{2}\right),
$$

with $\mathrm{U}_{1} \doteq 0$. Substituting Eq. (III-3) into (III-4), we find

$$
\mathrm{U}_{\mathrm{i}}^{2}=2 \mathrm{~g}_{\mathrm{c}}\left[\mathrm{x}_{1}\left(\mathrm{RT}_{1} / \mathrm{M}\right) \ln \left(\mathrm{P}_{1} / \mathrm{P}_{2}\right)+\left\{\left(1-\mathrm{x}_{1}\right)\left(\mathrm{P}_{1}-\mathrm{P}_{2}\right) / \rho_{\mathrm{f}}\right\}\right]
$$

Replacement of $x_{1}$ by $m_{g} /\left(m_{f}+m_{g}\right)$ and of $\left(1-x_{1}\right)$ by $m_{f} /\left(m_{f}+m_{g}\right)$ changes Eq. (III-5) to

$\mathrm{U}_{i}^{2}=2 \mathrm{~g}_{\mathrm{c}} \mathrm{P}_{1} \rho_{\mathrm{f}}^{-1}\left[1+\left(\mathrm{m}_{\mathrm{g}} / \mathrm{m}_{\mathrm{f}}\right)\right]^{-1}\left[\left(\mathrm{~m}_{\mathrm{g}} / \mathrm{m}_{\mathrm{f}}\right)\left(\rho_{\mathrm{f}} / \mathrm{M}\right)\left(\mathrm{RT} \mathrm{T}_{1} / \mathrm{P}_{1}\right) \ln \left(\mathrm{P}_{1} / \mathrm{P}_{2}\right)+\left\{\left(\mathrm{P}_{1}-\mathrm{P}_{2}\right) / \mathrm{P}_{1}\right\}\right]$

The actual liquid velocity leaving the nozzle is

$$
\mathrm{U}_{2}^{2}=\epsilon_{\mathrm{n}} \mathrm{U}_{\mathrm{i}}^{2}
$$

Equation (III-3) can be written as

$$
\begin{aligned}
T_{2} & =T_{1}-\left(m_{g} / m_{f}\right)\left(R T_{1} / M\right) \ln \left(P_{1} / P_{2}\right)\left[C_{f}+\left(m_{g} / m_{f}\right) C_{g}\right]^{-1} \\
& =T_{1}-\left[\left\{1+\left(m_{g} / m_{f}\right)\right\}\left(U_{i}^{2} / 2 g_{c}\right)-\left(P_{1}-P_{2}\right) \rho_{f}^{-1}\right]\left[C_{f}+\left(m_{g} / m_{f}\right) C_{g}\right]^{-1} .
\end{aligned}
$$


The above equations for the nozzle were derived by Elliott.

\section{Separator and Diffuser}

The separator is assumed to be of conical shape with a half vertex angle of $\omega$ :

\section{$\mathrm{U}_{2}$}
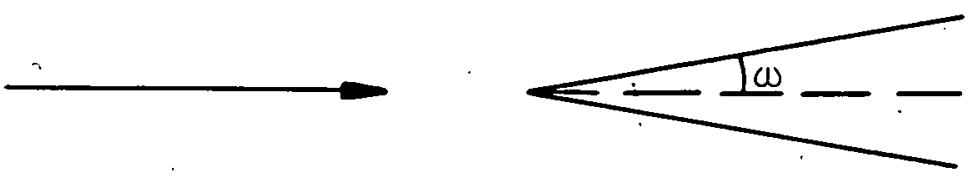

In the vapor phase, it is assumed that

$$
\mathrm{P}_{31}^{\prime}=\mathrm{P}_{2} ; \quad \mathrm{T}_{31}=\mathrm{T}_{2} ; \quad \mathrm{U}_{31} \doteq 0 \text {. }
$$

The kinetic energy of vapor is completely lost. For the liquid phase, it is assumed that:

a. $\mathrm{P}_{7^{\prime}}=\mathrm{P}_{2} ; \quad \mathrm{T}_{7^{\prime}}=\mathrm{T}_{2}$;

b. The component of $U_{2}$ that is perpendicular to the cone surface, $\mathrm{U}_{2} \sin \omega$, is completely lost.

c. There is'a skin-friction loss on the surface of the cone. . The friction factor is denoted by $f_{0}$.

An energy balance across the separator yields

$$
\left(U_{2} \cos \omega\right)^{2} / 2 g_{c}=\left(U_{71}^{2} / 2 \dot{g}_{c}\right)+\left[f_{0}\left(U_{2} \cos \omega\right)^{2} / 2 g_{c}\right]
$$

or

$$
U_{71}^{2}=\left(1-f_{0}\right)\left(U_{2} \cos \omega\right)^{2}
$$

The total vertex angle of the conical separator was assumed to be 60\%; therefore $\omega=30^{\circ}, \cos \omega=0.866$, and $(\cos \omega)^{2}=0.75$. No attempt was made to optimize this angle. Referring to Eq. (III-9), the velocity loss is approximately $13 \%$, and the kinetic energy loss $\sim 25 \%$ in the separator, due only to changing flow direction.

The friction, factor $f_{0}$ was estimated from studies reported by Ibragimov et al. (10) of the flow over curved surfaces and was set at $f_{0}=0.275$. These data tended to agree with analysis based on skinfriction losses. From Eq. (III-9),

$$
\mathrm{U}_{71}^{2} / \mathrm{U}_{2}^{2}=\left(1-\mathrm{f}_{0}\right)(\cos \omega)^{2}=0.54375
$$


and

$$
\mathrm{U}_{7} 1 / \mathrm{U}_{2}=0.74
$$

Hence, the total kinetic energy loss in the separator will be $\sim 46 \%$, and the velocity loss will be $\sim 26 \%$. According to Elliott!'s separator studies, (11) the velocity losses in a conical separator were between $17 \%$ and $30 \%$; thus the above assumptions of $\omega$ and $f_{0}$ seem quite reasonable and accurate.

$$
\begin{gathered}
\text { If diffuser efficiency is } \epsilon_{\mathrm{d}} \text {, then } \\
\left(\mathrm{P}_{2} / \rho_{\mathrm{f}}\right)+\left(\epsilon_{\mathrm{d}} \mathrm{U}_{71}^{2} / 2 \mathrm{~g}_{\mathrm{c}}\right)=\left(\mathrm{P}_{7} / \rho_{\mathrm{f}}\right)+\left(\mathrm{U}_{7}^{2} / 2 \mathrm{gc}_{\mathrm{c}}\right)
\end{gathered}
$$

Substituting in Eq. (III-9), one obtains

$$
\left(P_{2} / \rho_{f}\right)+\left[\left(\epsilon_{d}-\epsilon_{d_{0}}\right)\left(U_{2} \cos \omega\right)^{2} / 2 g_{c}\right]=\left(P_{7} / \rho_{f}\right)+\left(U_{7}^{2} / 2 g_{\dot{c}}\right)
$$

\section{Constant-area Nonideal Generator}

The performance characteristics of the constant-area generator are summarized in the previous section.

4. Diffuser after Generator

$\mathrm{P}_{9}-\mathrm{P}_{8}=\epsilon_{\mathrm{d}} \rho_{\mathrm{f}} \mathrm{U}_{8}^{2} / 2 \mathrm{~g}_{\mathrm{C}}$.

5. Reactor

$P_{10}=P_{9}+\Delta P_{R}$

where $\Delta \mathrm{P}_{\mathrm{R}}$ is the pressure drop across the reactor. Further,

$$
P_{R}=C_{f}\left(T_{10}-T_{9}\right)
$$

It is assumed that

$$
\mathrm{T}_{9}=\mathrm{T}_{8}=\mathrm{T}_{7}=\mathrm{T}_{2}
$$

\section{Mixer}

A heat balance across the mixer yields

$$
\mathrm{T}_{10}=\mathrm{T}_{1}+\left[\mathrm{mg}_{\mathrm{g}} / \mathrm{m}_{\mathrm{f}} \mathrm{C}_{\mathrm{f}}\right]\left[\mathrm{C}_{\ell}\left(\mathrm{T}_{\mathrm{b}}-\mathrm{T}_{6}\right)+\Delta \mathrm{H}_{\mathrm{b}}+\mathrm{C}_{\mathrm{g}}\left(\mathrm{T}_{1}-\mathrm{T}_{\mathrm{b}}\right)\right]
$$

where $T_{b}$ is the reference temperature and subscript $l$ refers to the condensate. 


$$
P_{1}=P_{6}+\Delta P_{m, g}
$$

or

$$
P_{1}=P_{10}+\Delta P_{m, f}
$$

Here $\Delta \mathrm{P}_{\mathrm{m}, \mathrm{g}}$ and $\Delta \mathrm{P}_{\mathrm{m}, \mathrm{f}}$ are the pressure drops occurring in the mixer for the vapor and liquid, respectively.

7. Heat Exchanger

From a heat balance across the heat exchanger,

$$
\mathrm{T}_{6}=\mathrm{T}_{5}+\left(\mathrm{C}_{\mathrm{g}} / \mathrm{C}_{\ell}\right)\left(\mathrm{T}_{3 !}-\mathrm{T}_{3}\right)
$$

We assume

$$
\begin{aligned}
& T_{3^{\prime}}=T_{2^{\prime}} \\
& P_{3}=P_{3^{\prime}}+\Delta P_{g}=P_{2}+\Delta P_{g},
\end{aligned}
$$

where $\Delta \mathrm{P}_{\mathrm{g}}$ is the pressure drop on the vapor side of the heat exchanger;

$$
\begin{aligned}
& \mathrm{T}_{3}=\text { saturation temperature of } \mathrm{P}_{3} ; \\
& \mathrm{T}_{5}=\mathrm{T}_{4} ; \\
& \mathrm{P}_{6}=\mathrm{P}_{5}+\Delta \mathrm{P}_{\ell},
\end{aligned}
$$

where $\Delta \mathrm{P}_{\ell}$ is pressure drop on the condensate side of the heat exchanger.

$$
\begin{aligned}
& \text { 8. Condénser } \\
& P_{4}=P_{3}+\Delta P_{C},
\end{aligned}
$$

where $\Delta P_{C}$ is the pressure drop across the condenser.

$\mathrm{T}_{4}=$ saturation temperature of $\mathrm{P}_{4}$.

9. EM Pump

If the pump efficiency is $\epsilon_{\mathrm{p}}$,

$P_{p}=m_{g}\left(P_{5}-P_{4}\right) / \epsilon_{p} \rho \ell$

10. Cycle Efficiency

$\epsilon_{c}=\left(m_{f} P_{G}-m_{g} P_{p}\right) / m_{f} P_{R}=\left[P_{G}-P_{p}\left(m_{g} / m_{f}\right)\right] / P_{R}$. 


\section{Specified Component and Cycle Parameters}

Lithium was specified as the working fluid in the liquid loop, and potassium in the vapor loop.

The temperature $T_{1}$ before the nozzle at point $l$ was set at $2470^{\circ} \mathrm{R}\left(2010^{\circ} \mathrm{F}\right.$; at this temperature, the maximum value of $P_{1}$ is 150 psia, the saturation pressure of potassium vapor at $T_{1}$ ). The lithium vapor pressure at this condition, $2 \mathrm{psia}$, is negligible. If $\mathrm{P}_{1}>150$ psia, the potassium would not vaporize and the two-phase mixture before the nozzle could not exist.

assumed to be

The efficiency of the nozzle, diffuser, and EM pump were

$$
\epsilon_{\mathrm{n}}=0.85 ; \quad \epsilon_{\mathrm{d}}=0.90 ; \quad \epsilon_{\mathrm{p}}=0.45 .
$$

The pressure drops across reactor, condenser, heat exchanger, and mixer were set at

$$
\begin{aligned}
-\Delta P_{R}=10 \text { psia } & \text { (i.e.., } \left.P_{9}-P_{10}\right) ; \\
-\Delta P_{C}=5 \text { psia } & \text { (i.e., } \left.P_{3}-P_{4}\right) ; \\
-\Delta P_{g}=5 \text { psia } & \text { (i.e., } \left.P_{31}-P_{3}\right) ; \\
-\Delta P_{\ell}=10 \text { psia } & \text { (i.e., } \left.P_{5}-P_{6}\right) ; \\
-\Delta P_{\mathrm{m}, g}=100 \text { psia } & \text { (i.e., } \left.P_{6}-P_{1}\right) ; \\
-\Delta P_{m, f}=25 \text { psia } & \text { (i.e., } \left.P_{10}-P_{1}\right)
\end{aligned}
$$

It follows that

$$
\begin{aligned}
& P_{6}=P_{1}+\Delta P_{m, g}=150+100=250 \text { psia; } \\
& P_{5}=P_{6}+\Delta P_{\ell}=250+10=260 \text { psia; } \\
& P_{10}=P_{1}+\Delta P_{m, f}=150+25=175 \text { psia; } \\
& P_{9}=P_{10}+\Delta P_{R}=175+10=185 \text { psia. }
\end{aligned}
$$

The temperature in the condenser is fixed by the pressure at the exit of the nozzle, $P_{2}$, through Eqs. (III-18) and (III-20). An arbitrary choice of the condenser temperature is not possible. The pressure drop across and the velocity through the generator are determined by the reactor pressure, position 9 in Fig. III-1, that is, sufficient velocity head must be available at the generator exit to reach reactor pressure by means of a diffuser. If $\mathrm{P}_{8}=178$ psia, then 


$$
\begin{aligned}
U_{7}^{2} & =U_{8}^{2}=\left(P_{9}-P_{8}\right) 2 g_{c} / \epsilon_{d} \rho_{f} \\
& =(185-178) 2 \times 32.17 \times 144(0.9 \times 27.3)^{-1}=51.38 \mathrm{ft} / \mathrm{sec} .
\end{aligned}
$$

The three parameters which remain unspecified, namely,

$$
P_{2}, \mathrm{mg}_{\mathrm{g}} / \mathrm{m}_{\mathrm{f}}\left(\text { or } \mathrm{mf}_{\mathrm{f}} / \mathrm{mg}_{\mathrm{g}}\right) \text {, and } \epsilon_{\mathrm{g}} \text {, }
$$

were assigned the following quantitative values for the parameter study:

$$
\begin{aligned}
\epsilon_{\mathrm{g}} & =50 \%, 60 \%, 70 \% \\
\mathrm{P}_{2} & =0.25,10,16,25,35 \mathrm{psia} \\
\mathrm{m}_{\mathrm{f}} / \mathrm{m}_{\mathrm{g}} & =1,3,5,7,9,11,15,20,30,50 .
\end{aligned}
$$

B. Discussion of Results

The variation of the cycle efficiency as a function of the liquid and gas flow rates, exit nozzle pre'ssure, and generator efficiency is shown in Fig. III-2. It is apparent that the overall cycle efficiencies are on the low side. The theoretical maximum efficiency for the cycle is $\sim 16 \%$ and is based on the assumptions that $\mathrm{P}_{2}=0.25 \mathrm{psi}, \epsilon_{\mathrm{g}}=100 \%, \Delta \mathrm{P}_{\mathrm{c}}=0$, and $\Delta \mathrm{P}_{\mathrm{g}}=0$. The conditions stipulated for the theoretical maximum efficiency are not realistic and therefore $\epsilon_{\mathrm{c} \text { max }}=16 \%$ should be looked on as an absolute upper limit. To obtain the highest cycle performance, $P_{2}$ should be kept as low as possible and $\epsilon_{\mathrm{g}}$ as high as possible. The lower the value of the nozzle exit pressure, the greater will be the conversion of thermal to kinetic energy. The higher the generator efficiency, the higher will be the cycle efficiency. If the pressure drops through the condenser

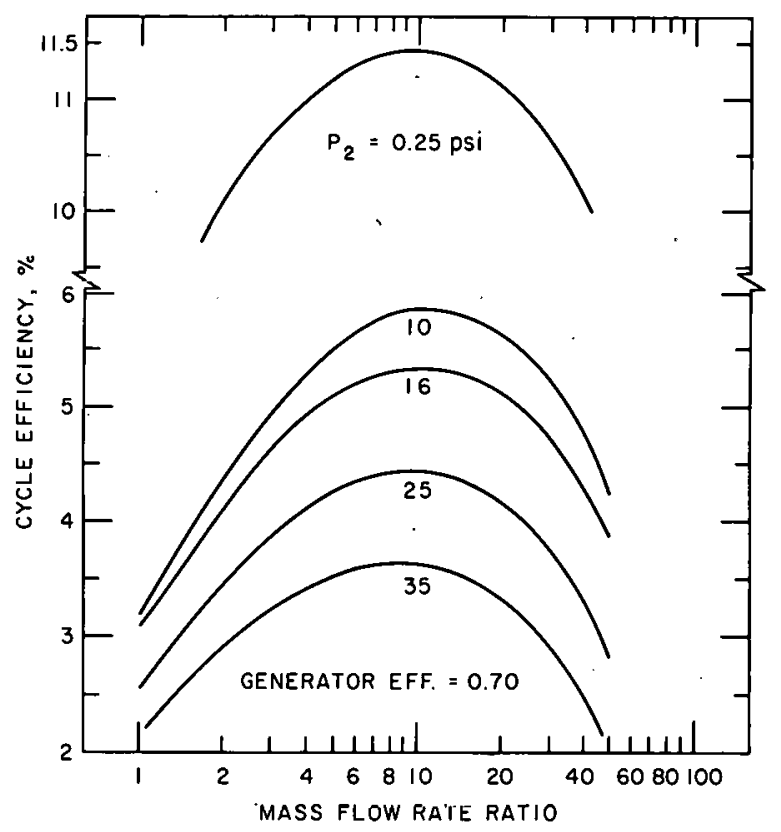

Fig. III-2

Calculated Cycle Efficiency as a Function of System Parameters for the Elliott Cycle 
and heat exchanger are 5 psi, as cited prevously, the lowest pressure that can be maintained at the nozzle exit is $10 \mathrm{psi}$. The sink temperature under these conditions would be $840^{\circ} \mathrm{F}$. Assuming that the generator efficiency is 0.80 , the maximum cycle efficiency which appears feasible is $7.5 \%$.

If the condenser temperature is set at $1850^{\circ} \mathrm{R}$, which corresponds to a near optimum for a space system, then $P_{2}$ is fixed at 25 psia. The maximum cycle efficiency under these conditions, and for $\mathrm{m}_{\mathrm{f}} / \mathrm{m}_{\mathrm{g}}=9$ and $\epsilon_{\mathrm{g}}=70 \%$, is $\sim 4.4 \%$.

Typical cycles with the operating conditions are shown in Figs. III-3, III-4 and III-5. Each cycle illustrated represents a unique point on Fig. III-2. It $c$ an be seen that when $P_{1}, T_{1}, m_{f} / m_{g}$, and $P_{2}$ are fixed, variation of the generator efficiency, and hence power, does not alter the performance or conditions of the other system components in the cycle but does affect the cycle efficiency. (The generator efficiencies which are feasible are discussed in a later section.)

For all the calculations cited, the generator channel velocity was fixed at $51.4 \mathrm{ft} / \mathrm{sec}$. The effect of varying the velocity through the generator on overall. cycle performance is shown in Fig. III-6. For this comparison, the pressure $\mathrm{P}_{2}$ was set at 16 psia and a realistic generator efficiency of $60 \%$ was chosen. Although these stipulations do affect the overall cycle efficiency, they do not affect the purpose of the analysis: to demonstrate the effect of generator velocity on cycle performance.

As is evident in Fig. III-6, the lower the velocity, the higher is the cycle efficiency, but the effect is practically negligible. The major incentive to maintain a high velocity in the generator is that for a fixed voltage the generator geometry (width) can be decreased as the velocity is increased.

The actual relationship between $U_{7}$ and $P_{G}$ in the cycle considered here can be derived as follows:

$$
\begin{aligned}
P_{G} & =\epsilon_{g}(-\Delta P) / \rho_{f} ; \\
P_{7} / \rho_{f} & =\left(P_{2} / \rho_{f}\right)+\left[\epsilon_{d}\left(1-f_{0}\right)(\cos \omega)^{2} U_{2}^{2}-U_{7}^{2}\right] / 2 g_{c} ; \\
P_{8} / \rho_{f} & =\left(P_{9} / \rho_{f}\right)-\left(\epsilon_{d} U_{7}^{2} / 2 g_{c}\right) .
\end{aligned}
$$

Therefore

$$
\begin{aligned}
P_{G} & =\epsilon_{g}\left(P_{7}-P_{8}\right) / \rho_{f} \\
& =\epsilon_{g}\left\{\left(\left[\epsilon_{d}\left(1-f_{0}\right)(\cos \omega)^{2} U_{2}^{2}-\left(1-\epsilon_{d}\right) U_{7}^{2}\right] / 2 g_{c}\right)-\left[\left(P_{9}-P_{2}\right) / \rho_{f}\right]\right\} .
\end{aligned}
$$




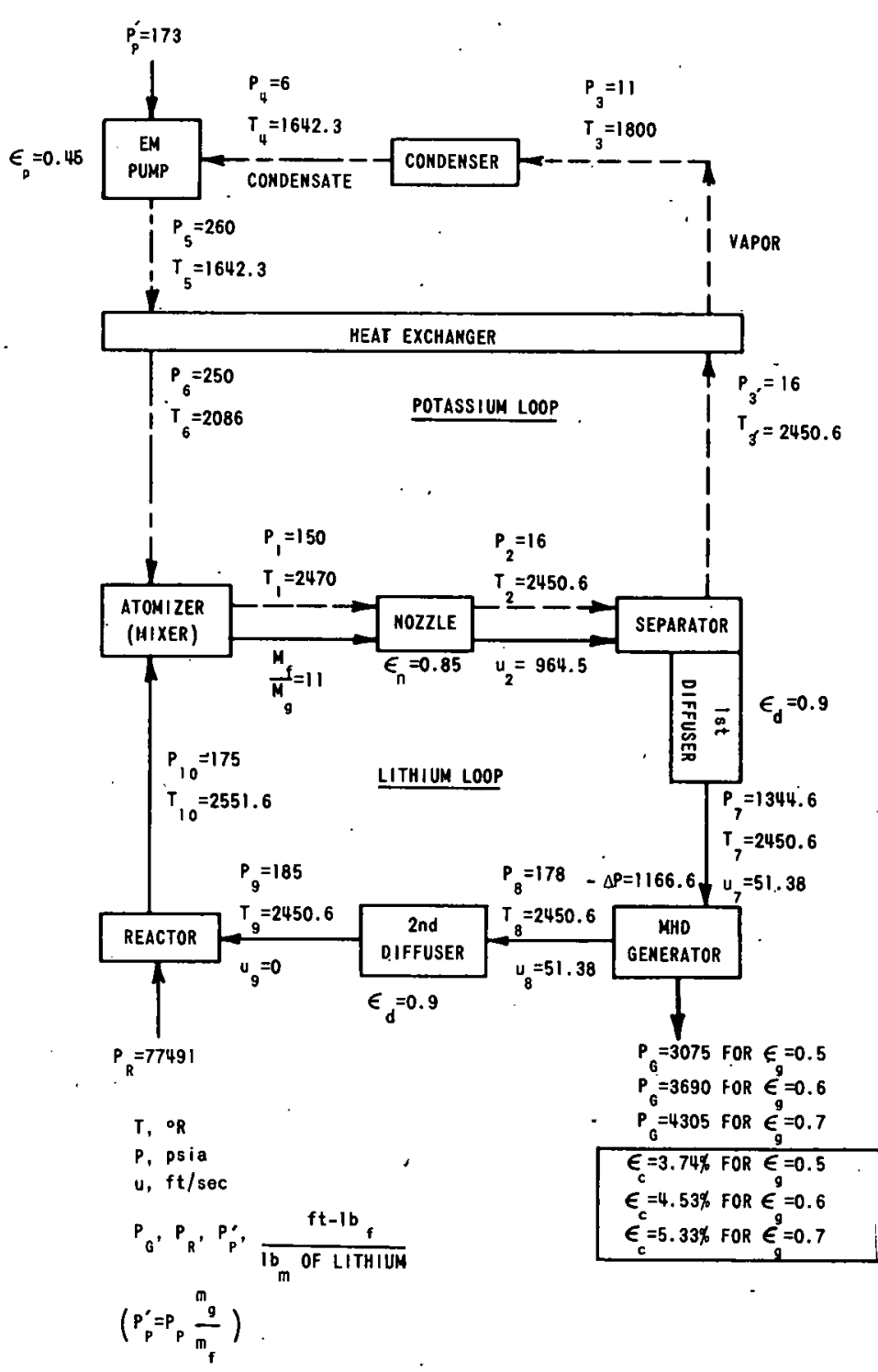

Fig. III-3. Detailed Cycle Parameter for $P_{2}=16$ psia

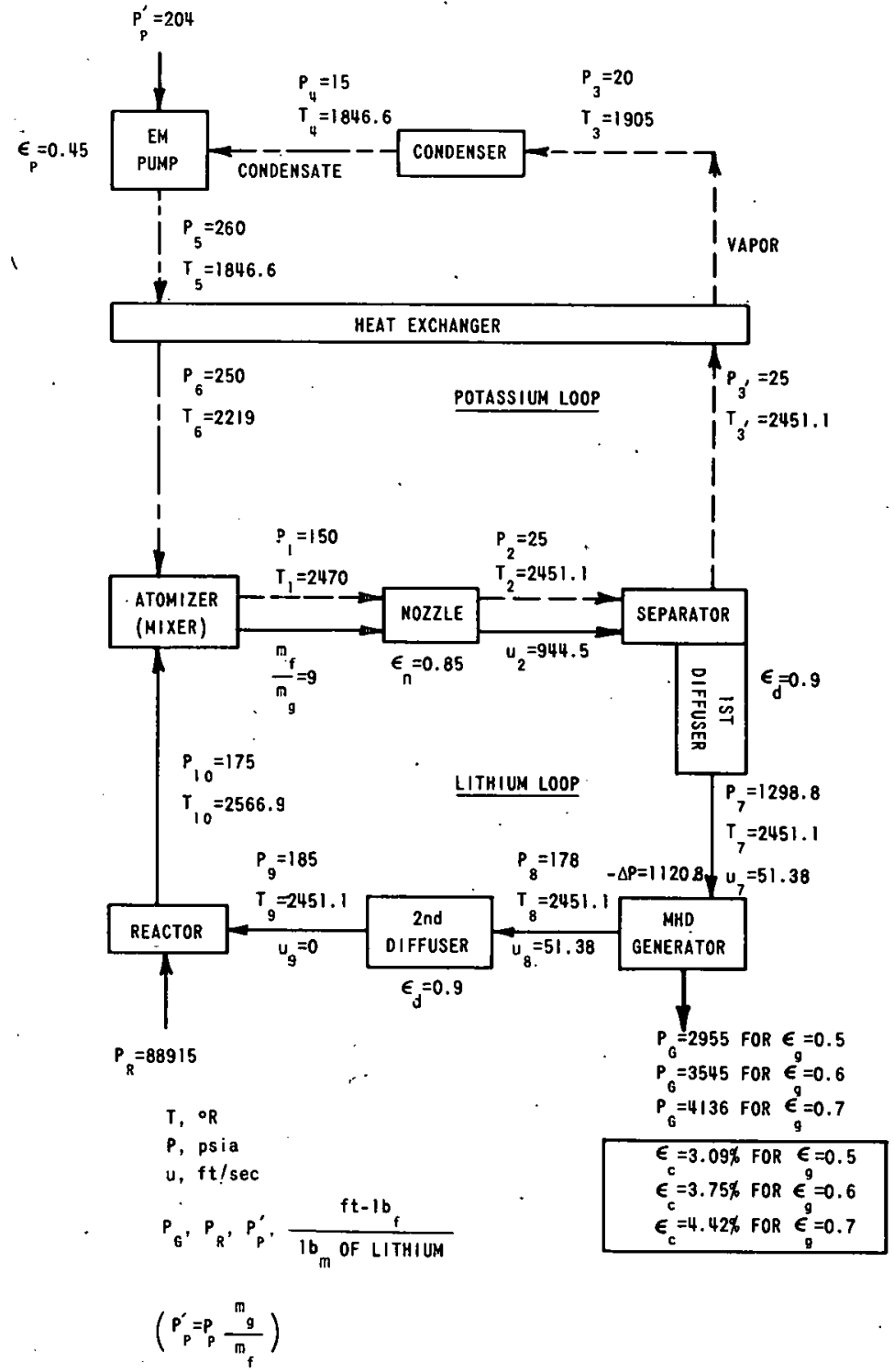

Fig. III-4. Detailed Cycle Parameter for $P_{2}=25$ psia 


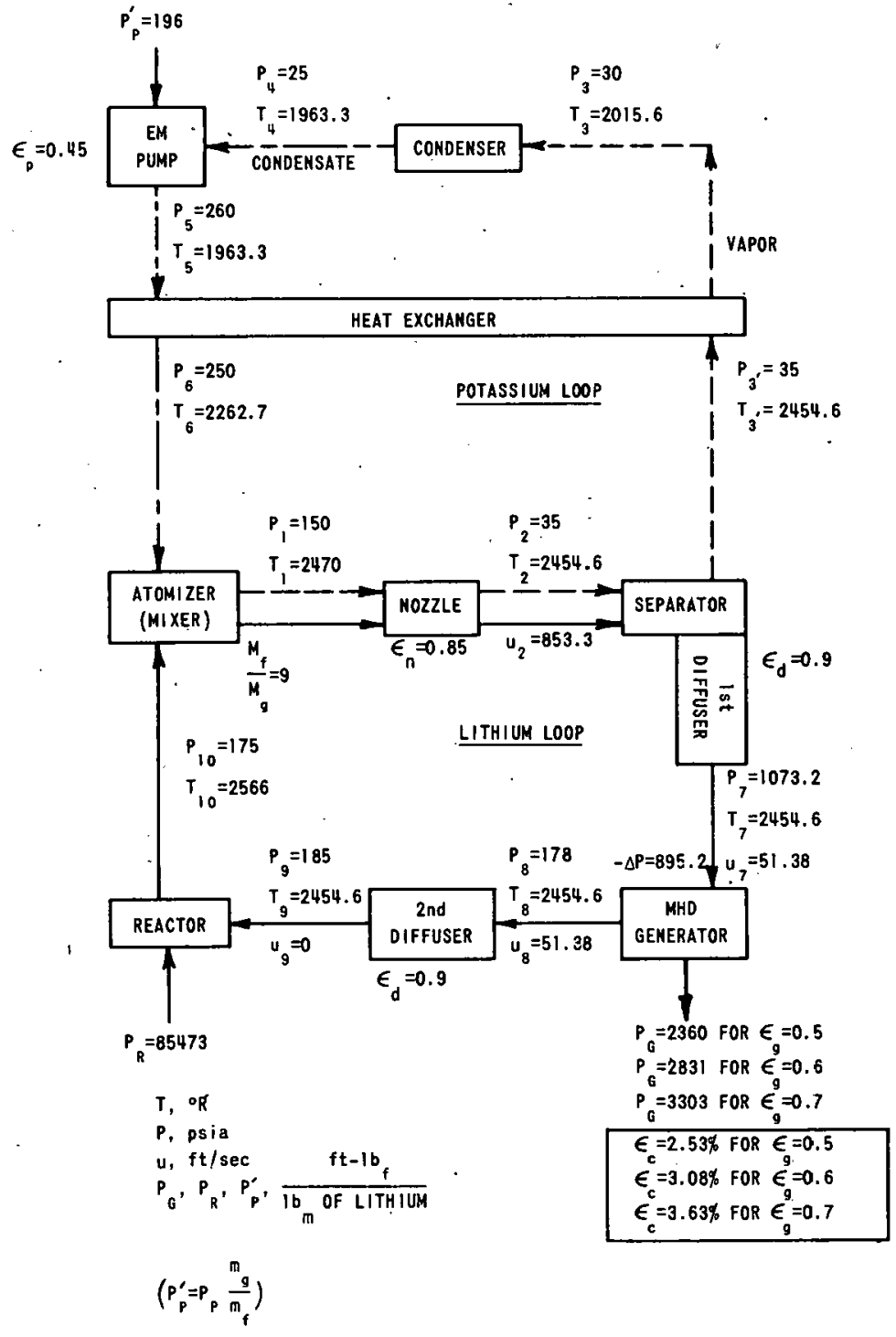

Fig. III-5. Detailed Cycle Parameter for $P_{2}=35$ psia

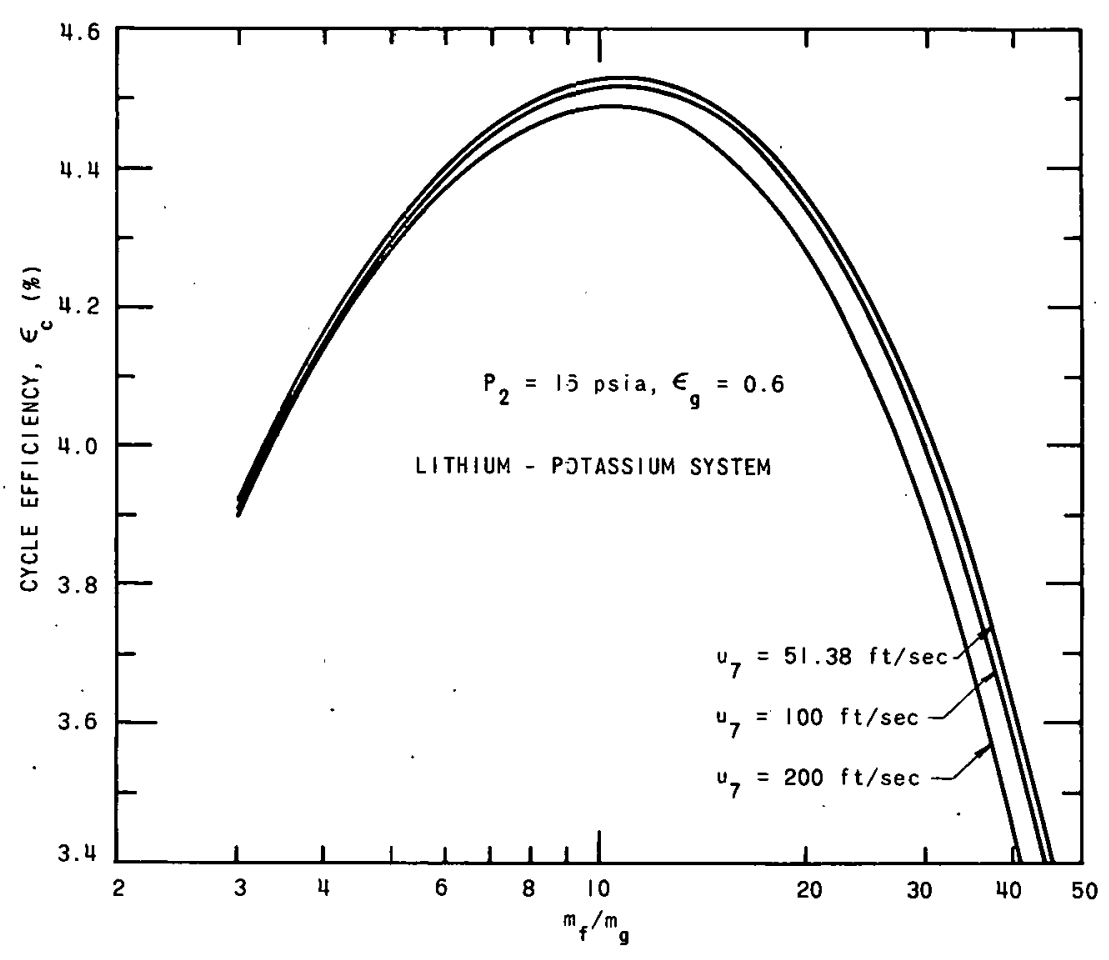

Fig. III-6. Effect of Varying Generator Velocity on Cycle Performance 
From the above equation it $c$ an be seen that $P_{G}$ decreases, as does $\epsilon_{c}$ with increasing $U_{7}$. However, since $U_{2}^{2} \gg U_{7}^{2}$, and $l-\epsilon_{d}=0.1$ is a small value, the variation of $U_{7}$ does not affect $P_{G}$ very strongly.

Figure III- 7 shows a plot of $P_{R}, P_{G}$, and $P_{p}^{\prime}$ vs $m_{f} / m_{g}$. The cycle efficiency for any spècified $\epsilon_{\mathrm{g}}$ and $\mathrm{m}_{\mathrm{f}} / \mathrm{m}_{\mathrm{g}}$ can be calculated by the following equations:

$$
\begin{aligned}
& \epsilon_{c}=\left(\epsilon_{g} P_{G}^{\prime}-P_{p}^{\prime}\right) / P_{R} ; \\
& P_{G}=P_{G}^{\prime} \text { when } \epsilon_{g}=100 \% ; \\
& P_{p}^{\prime}=P_{p}\left(m_{g} / m_{f}\right) .
\end{aligned}
$$

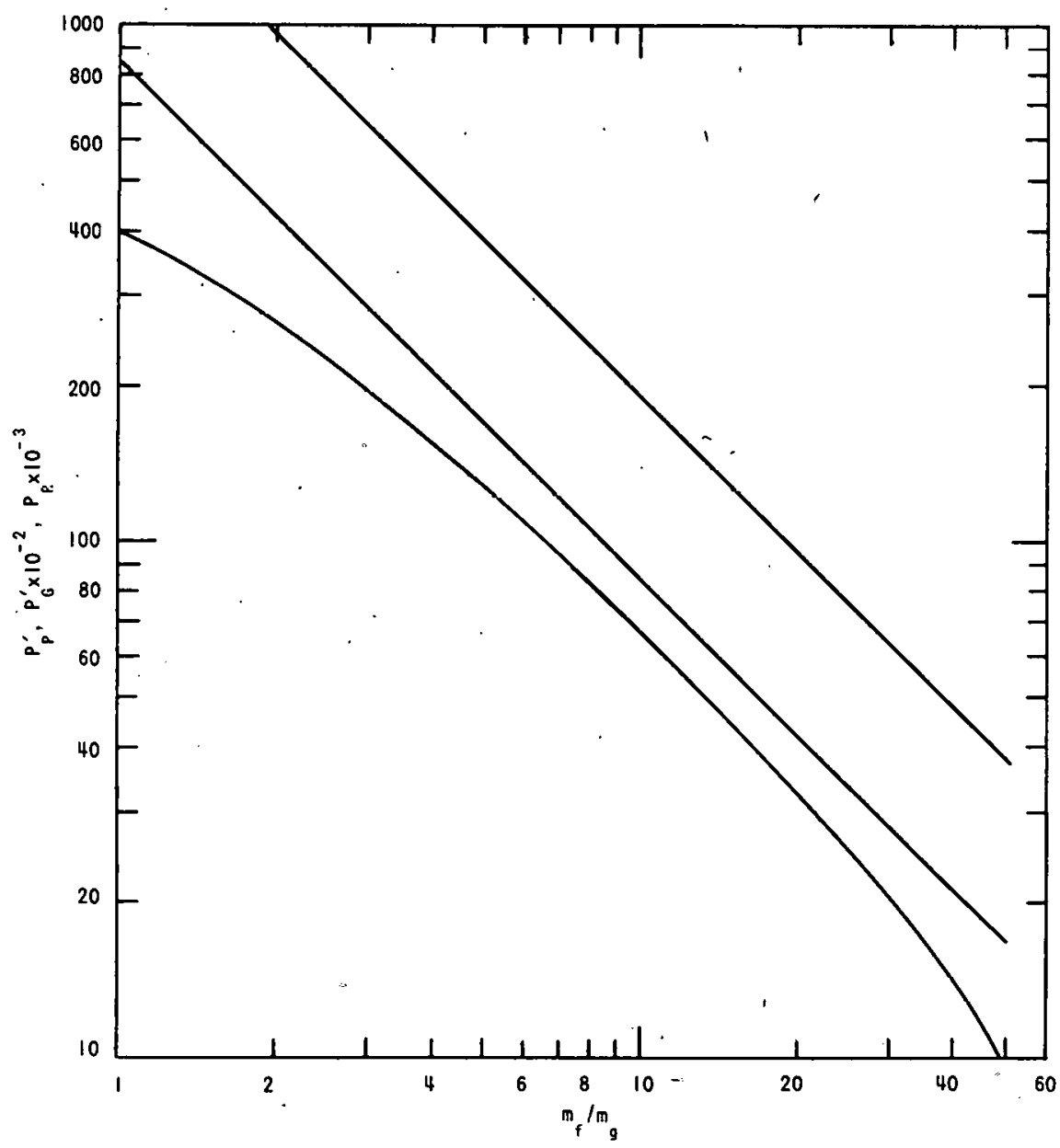

Fig. III-7. Performance Parameter for a Potassium-Lithium System

From the data and analysis presented it is apparent that there are several serious restrictions which limit the cycle performance and efficiency. They are (1) the upstream and downstream pressures on the 
nozzle which establishes a maximum pressure differential. This, in turn, limits the energy input to the cycle and specifies a maximum conversion of thermal to kinetic energy; (2) the velocity head losses in the separator, which is reflected directly as a power loss in the MHD generator. If the losses in the separator could be reduced substantially the cycle efficiency would be improved markedly. 


\section{THE ONE-COMPONENT, TWO-PHASE MHD CYCLE}

The proposed one-component, two-phase cycle schematically illustrated in Fig. IV -1 consists of five basic components, namely, the two-phase nozzle, MHD generator, condenser, diffuser and reactor. A two-phase mixture in a saturated vapor is removed from the reactor and is passed through the nozzle, where its kinetic energy is increased. From the nozzle, the two-phase fluid passes directly through the MHD generator, where the electrical energy is extracted into the condenser. The fluid is returned from the condenser via a diffuser to the reactor.

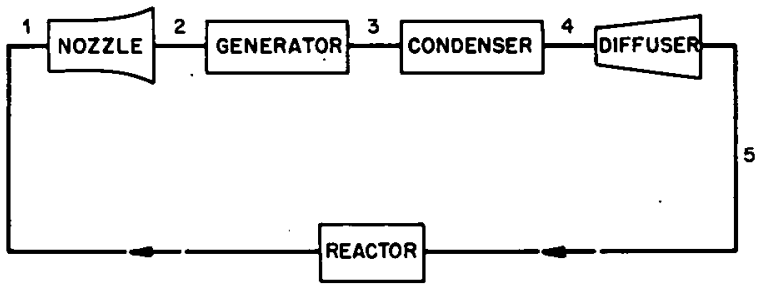

Fig. IV - 1

Schematic of the One-component, Two-phase MHD Cycle

The proposed cycle evolved from preliminary experimental studies of a MHD generator operating with a two-phase mixture. (8) The results from this investigation indicated that it may be feasible to pass the two-phase mixture directly into the MHD generator. The efficiency of the generator, and hence of the cycle, will depend upon the nature of the flow and the conductivity mechanism occurring within and the degree to which the total entering liquid flow interacts with the magnetic field. Because the flow pattern of a two-phase mixture changes from a dispersion of gas in liquid to a dispersion of liquid in gas as the mixture quality is increased, the conductivity of the fluid would also be expected to change sharply. As a result, depending upon the nature of the flow, two different types of generators are proposed and are being studied for this cycle. The first, schematically illustrated in Fig. IV-2(a), is a variable-area

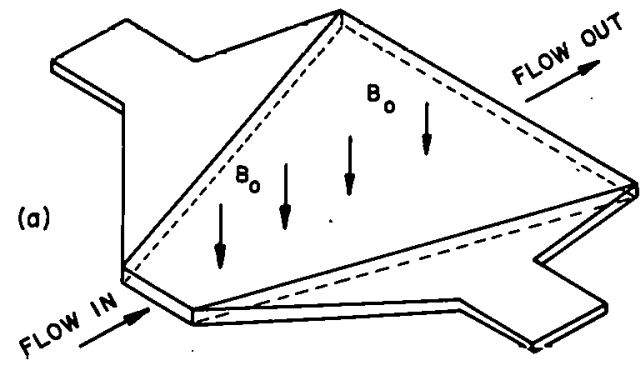

(b)
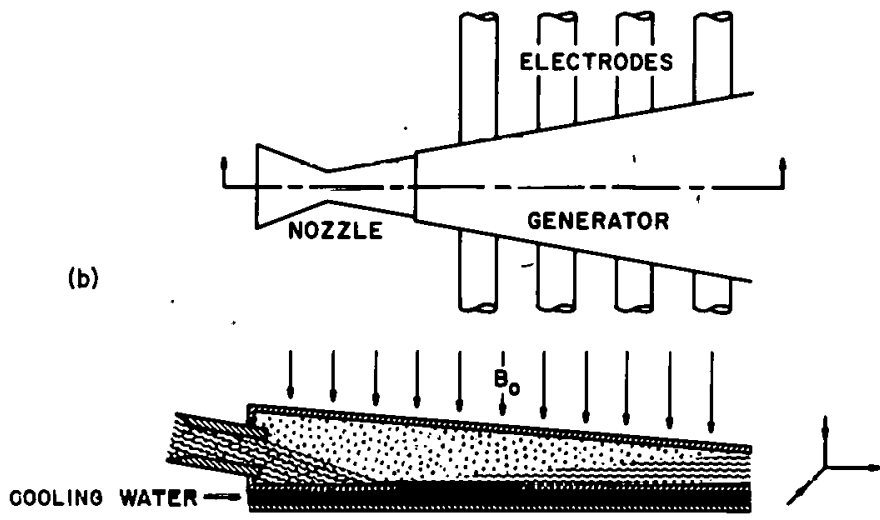

Fig. IV-2a\&b. Schematic of the Two Types of Generators Being Studied for the One-component, Two-phase MHD Cycle,

(a) When $\mathrm{x}_{1}<10 \%$ and (b) When $\mathrm{x}_{1}>10 \%$ 
generatior which operates with a low-quality, two-phase mixture in which the gas phase is dispersed in the liquid.* For this type of flow the mixture quality is generally quite low, $<5 \%$, and the corresponding void fractions are less than $90 \%$.

A study has been made of the conductivity of two-phase mixtures at void fractions up to 0.96 . The data were taken with an air-water loop and encompassed the dispersed annular-flow regimes. An unexpected result of this study was that the measured conductivity ratio can be predicted quite accurately by Maxwell's equation(13) derived for a dispersion of one phase within another (see Fig. IV-3). Maxwell's equation

$$
\sigma / \sigma_{\mathrm{TP}}=(2+\alpha) / 2(1-\alpha)
$$

is based on the assumption that the vapor conductivity is equal to zero. The agreement in the dispersed annular-flow regime (liquid dispersed in gas with a liquid film on the wall) was completely unexpected in view of the physical basis and assumptions inherent in Maxwell's development. It is doubtful whether this agreement would continue beyond the range of void fractions studied.

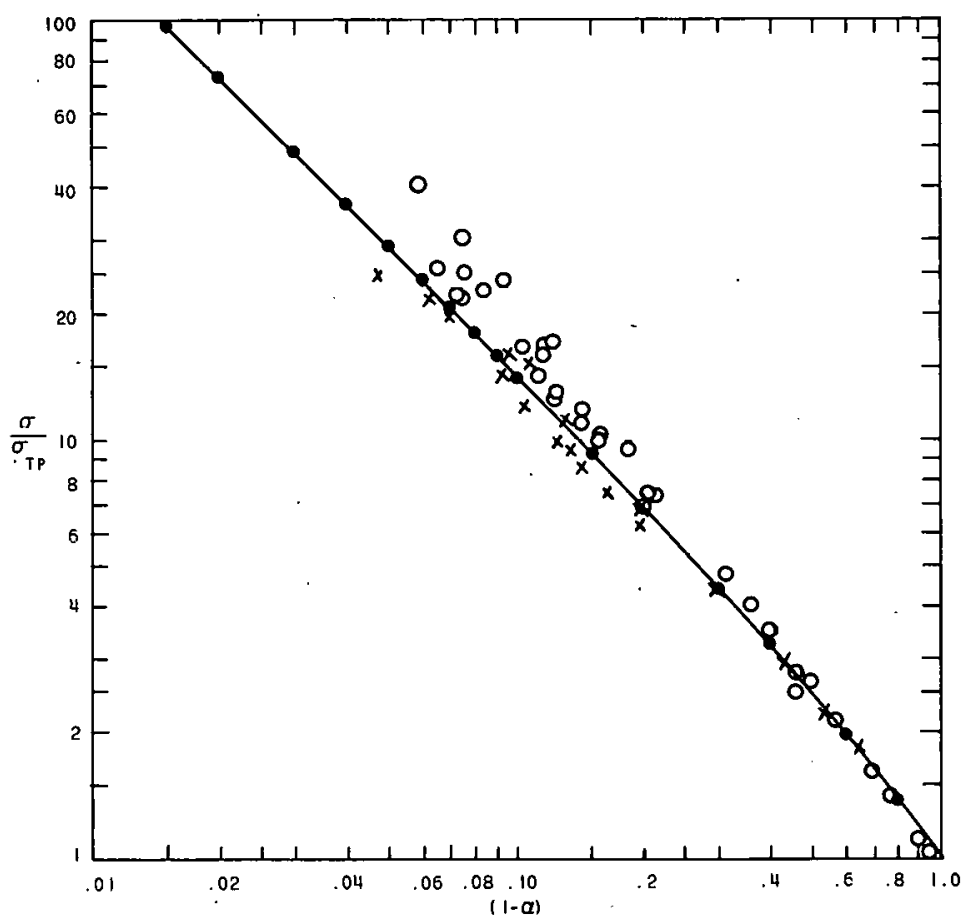

Fig. IV-3. Electrical Conductivity Data for Air-Water Mixture

*It has recently come to the authors' attention that a similar type of. generator has been proposed to operate in a two-component two-phase cycle. (12) 
As the mixture quality is increased beyond. $10 \%$, the degree of dis persion increases, and the flow interaction with the magnetic field would be expected to drop sharply, so that the generator efficiency would decrease rapidly. For the very high-void, highly dispersed liquid-flow regime a generator of the type shown in Fig. IV -2(b) is being studied. The exit flow from a rectangular, high-aspect-ratio nozzle impinges upon the lower surface of the generator at a small angle, $\sim 5^{\circ}$; the liquid is separated from the vapor by impingement in the lower channel where the high-velocity film interacts with the magnetic field. As electrical energy is extracted, the fluid builds up in thickness. The possibility of also condensing the vapor phase on the rapidly moving film by cooling the bottom side of the generator is also being investigated. Thus, separation, power generation, and condensation would occur simultaneously. The efficiency of this type of generator will be a function of the degree of separation which occurs and the skin friction and momentum losses. It should be noted that the electrical-shunt losses at the entrance are eliminated, which tends to enhance the generator efficiency considerably.

The highest cycle efficiency could be obtained with the latter type of generator since a higher-quality, higher-energy fluid can be utilized. As pointed out previously, this means that more energy is put into the cycle at the highest cycle temperature.

\section{A. Cycle Analysis}

Each of the components in Fig: IV-l are analyzed separately by means of energy and momentum balance and then summations are made to yield the overall cycle efficiency. The numbers shown in Fig. IV-1 are used to denote the cycle position.

\section{Two-phase Nozzle}

The assumptions given for the nozzle analysis in the two-component two-phase cycle are adhered to again.

$$
\begin{aligned}
& \quad \text { Since } \\
& s_{1}=s_{2} \\
& s_{1}=x_{1} s_{1, g}+\left(1-x_{1}\right) s_{1, f}=x_{i} s_{2, g}+\left(1-x_{i}\right) s_{2, f}=s_{2} \\
& x_{i}=\left(s_{1, f}-s_{2, f}\right) /\left(s_{2, g}-s_{2, f}\right)+x_{1}\left(s_{1, g}-s_{1, f}\right) /\left(s_{2, g}-s_{2, f}\right)
\end{aligned}
$$

$\mathrm{x}_{\mathrm{i}}$ is the exit quality based on isentropic flow. The energy equation for isentropic homogeneous flow is

$$
\mathrm{U}_{\mathrm{l}}^{2} /\left(2 \mathrm{~g}_{\mathrm{C}}\right)+\mathrm{x}_{1} \mathrm{~h}_{1, \mathrm{~g}}+\left(1-\mathrm{x}_{1}\right) \mathrm{h}_{1, \mathrm{f}}=\mathrm{U}_{\mathrm{i}}^{2} /\left(2 \mathrm{~g}_{\mathrm{c}}\right)+\mathrm{x}_{\mathrm{i}} \mathrm{h}_{2}, \mathrm{~g}+\left(1-\mathrm{x}_{\mathrm{i}}\right) \mathrm{h}_{2, f}
$$


$\mathrm{U}_{\mathbf{i}}$ can be solved in terms of the enthalpies and entropies in the inlet and outlet $\operatorname{stream}\left(U_{1} \stackrel{=}{0}\right)$

$$
\begin{aligned}
U_{i}^{2}= & 2 g_{c}\left(h_{2, g}-h_{2, f}\right)\left\{\left(h_{1, f}-h_{2, f}\right) /\left(h_{2, g}-h_{2, f}\right)-\left(s_{1, f}-s_{2, f}\right) /\left(s_{2, g}-s_{2, f}\right)\right. \\
& \left.+x_{1}\left[\left(h_{1, g}-h_{1, f}\right) /\left(h_{2, g}-h_{2, f}\right)-\left(s_{1, g}-s_{1, f}\right) /\left(s_{2, g}-s_{2, f}\right)\right]\right\} . \quad(I V-3)
\end{aligned}
$$

The actual liquid velocity, according to the definition of nozzle efficiency, $\epsilon_{\mathrm{n}}$, is

$$
U_{2}^{3}=t_{n} U_{i}^{2}
$$

The actual exit quality will be

$$
x_{2}=\left[h_{1, f}-h_{2, f}-U_{2}^{2} /(2 g c)\right] /\left(h_{2, g}-h_{2, f}\right)+x_{1}\left(h_{1, g}-h_{1, f}\right) /\left(h_{2, g}-h_{2, f}\right)
$$

If the velocity of vapor is assumed equal to $U_{i}$, then the slip ratio, $k$, is simply

$$
\mathrm{k}=\mathrm{U}_{\mathrm{i}} / \mathrm{U}_{2}=\left(\epsilon_{\mathrm{n}}\right)^{-1 / 2}
$$

The void fraction is

$$
\begin{aligned}
& \alpha=\left\{k\left[\left(1-x_{2}\right) / x_{2}\right]\left(v_{2, f} / v_{2, g}\right)+1\right\}^{-1} . \\
& \text { 2. Variable-area Generator }
\end{aligned}
$$

a. No friction loss.

b. No pressure drop across the generator, i.e., $P_{3}=P_{2}$.

Hence the generator power is proportional to the kinetic energy change only and Eq. (II-9) becomes

$$
P_{G}=\epsilon_{g}\left(U_{2}^{2}-U_{3}^{2}\right) / 2 g c
$$

For simplicity it is also assumed that

$$
\begin{aligned}
& \mathrm{T}_{3:}=\mathrm{T}_{2} \\
& \mathrm{x}_{3}=\mathrm{x}_{2} .
\end{aligned}
$$

Because $P_{G}$ is a function of $\left(U_{2}^{2}-U_{3}^{2}\right)$ and is not a function of $T_{3}$ and $x_{3}$, the above assumptions do not affect the calculation of cycle efficiency but will affect the analyses of the condenser. The effect is very small, however, 
when comparisons are made with the large amount of heat rejected in the condenser. The detailed analysis of the generator has been given in Section II. The evaluation of $\epsilon \mathrm{g}$ in terms of load resistance, internal resistance andend loss resistance of the generator is given by Eq. (II-84).

\section{Condenser}

The condenser is assumed to operate at the minimum temperature $\mathrm{T}_{4}$ and to be designed to keep the inlet and outlet velocity the same (a tapered. channel is specified whose area is proportional to the void fraction). Therefore

$$
\begin{aligned}
& \mathrm{U}_{4}=\mathrm{U}_{3} \\
& \mathrm{P}_{4}=\text { sat. pressure at } \mathrm{T}_{4} .
\end{aligned}
$$

The pressure drop across the condenser is

$$
\mathrm{P}_{3}-\mathrm{P}_{4}=-\Delta \mathrm{P}_{\mathrm{C}}
$$

The heat ramoved in the condenser is

$$
Q=h_{2, f}+x_{3}\left(h_{2, g}-h_{2, f}\right)-h_{4, f} .
$$

.4. Diffuser

The assumptions àre:
a. An adiabatic system, $T_{5}=T_{4}$, or $h_{5, f}=h_{4, f}$
b. $U_{5} \stackrel{\circ}{=}$
c. Diffuser efficiency is $\epsilon_{\mathrm{d}}$.

Thus

$$
P_{5}=P_{4}+\epsilon_{d} U_{4}^{2} /\left(2 g_{c} v_{4, f}\right) \text {. }
$$

5. Reactor

The pressure drop across the reactor is

$$
-\Delta P_{R}=P_{5}-P_{1} \text {. }
$$

The heat transferred from the reactor to the working fluid is

$$
P_{R}=\left(h_{1, f}-h_{5, f}\right)+x_{1}\left(h_{1, g}-h_{1, f}\right) \text {. }
$$


6. Cycle Efficiency

The cycle efficiency, $\epsilon_{c}$, is

$\epsilon_{\mathrm{c}}=\mathrm{P}_{\mathrm{G}} / \mathrm{P}_{\mathrm{R}}$

B. Specified Components and Cycle Parameters

The temperature range for the heat source was set at $1100-2240^{\circ} \mathrm{F}$. The sink temperature was varied from 500-1340 $\mathrm{F}$. The temperature ranges were selected on the basis of applicability to both space and commercial power systems. The efficiency of the nozzle was assumed to be $\epsilon_{\mathrm{n}}=0.8$. The value is considered to be realistic and based on data available in the literature. It appears, in fact, that a properly designed nozzle can yield efficiencies of $90 \%$ and greater. The diffuser efficiency was taken as $\epsilon_{\mathrm{d}}=0.90$ and is also based on data available in the literature. The pressure drops across the condenser and reactor were arbitrarily assumed to be

$$
\begin{aligned}
-\Delta P_{c} & =10 \mathrm{psi} \\
-\Delta P_{R} & =10 \mathrm{psi}
\end{aligned}
$$

The inlet quality to the nozzle, $x$, was varied from $0-100 \%$.

From Eqs. (IV-14) and (IV-8) it can be seen that cycle efficiency, $\epsilon_{\mathrm{c}}$, is proportional to $\epsilon_{\mathrm{g}}$. Since the maximum efficiency, $\epsilon \mathrm{g}$, depends only upon the aspect ratio, L/am, see Eq. (II-86), and the latter in turn depends on divergent angle, $\theta$, see Eq. (II-88). Various values of $\theta$ were used in the calculations ranging from $\theta=2.5^{\circ}$ to $\theta=15.0^{\circ}$.

Mercury, mercury-potassium alloy, and three alkali metals, cesium, potassium, and sodium, were studied as working fluids in the cycle. The thermodynamic data for each, namely, temperature, vapor pressure, specific volume of liquid and vapor phase, enthalpy of liquid and vapor phase and entropy of liquid and vapor phase were taken from Ref. 14.

C. Discussion of Results

The cycle efficiency for the alkali liquid metals studied is shown in in Figs. IV -4 to IV-9. The overall cycle efficiency is plotted vs the mixture quality at the inlet to the nozzle. The parameters on the curves are the heat source temperatures, generator efficiency, and the half-angle of the MHD generator. As can be seen, cesium and potassium yield the highest cycle efficiencies. For specified system parameters the two metals have virtually identical efficiencies, see Fig. IV-4. Although the cycle efficiency with cesium is essentially the same as for a potassium system the poorer conductivity of cesium reduces its. effectiveness, as discussed in a later section. 


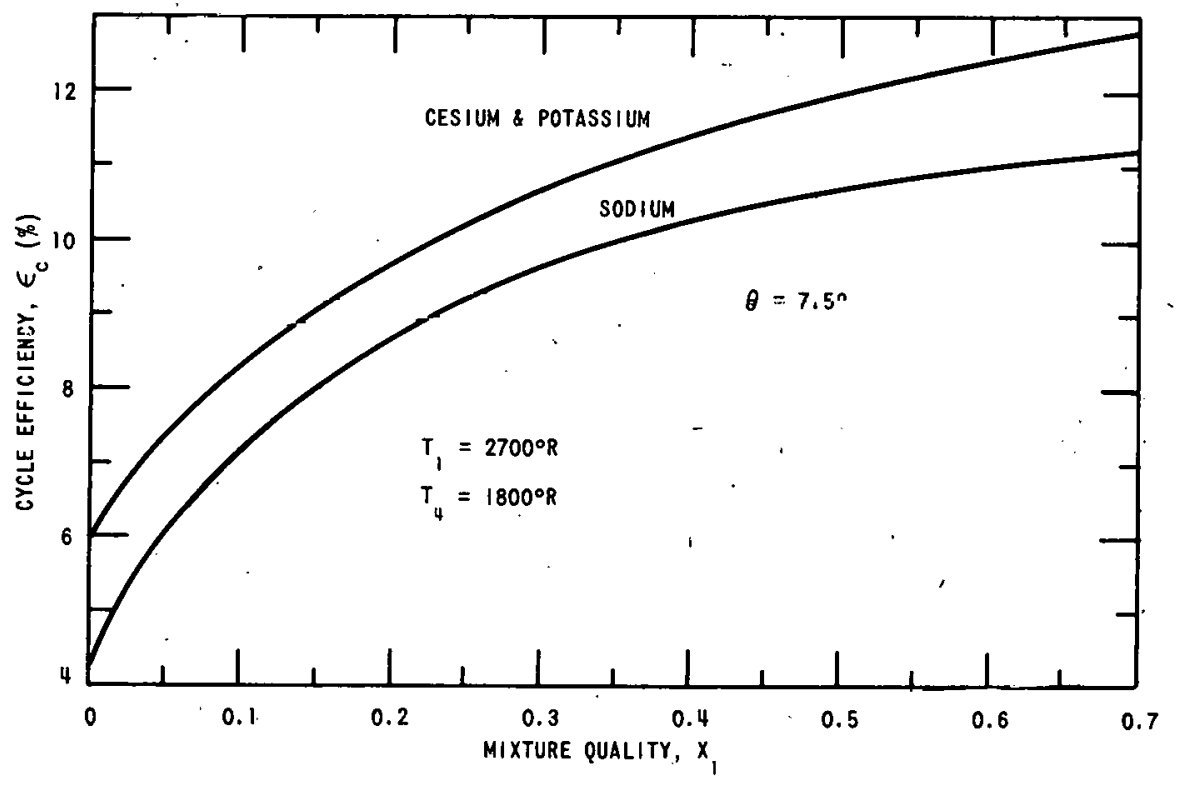

Fig. IV -4 . Cycle Efficiency vs Mixture Qualities for Potassium, Cesium, and Sodium $\left(\mathrm{T}_{2}=2700^{\circ} \mathrm{R}, \mathrm{T}_{4}=1800^{\circ} \mathrm{R}, \theta=7.5^{\circ}\right)$

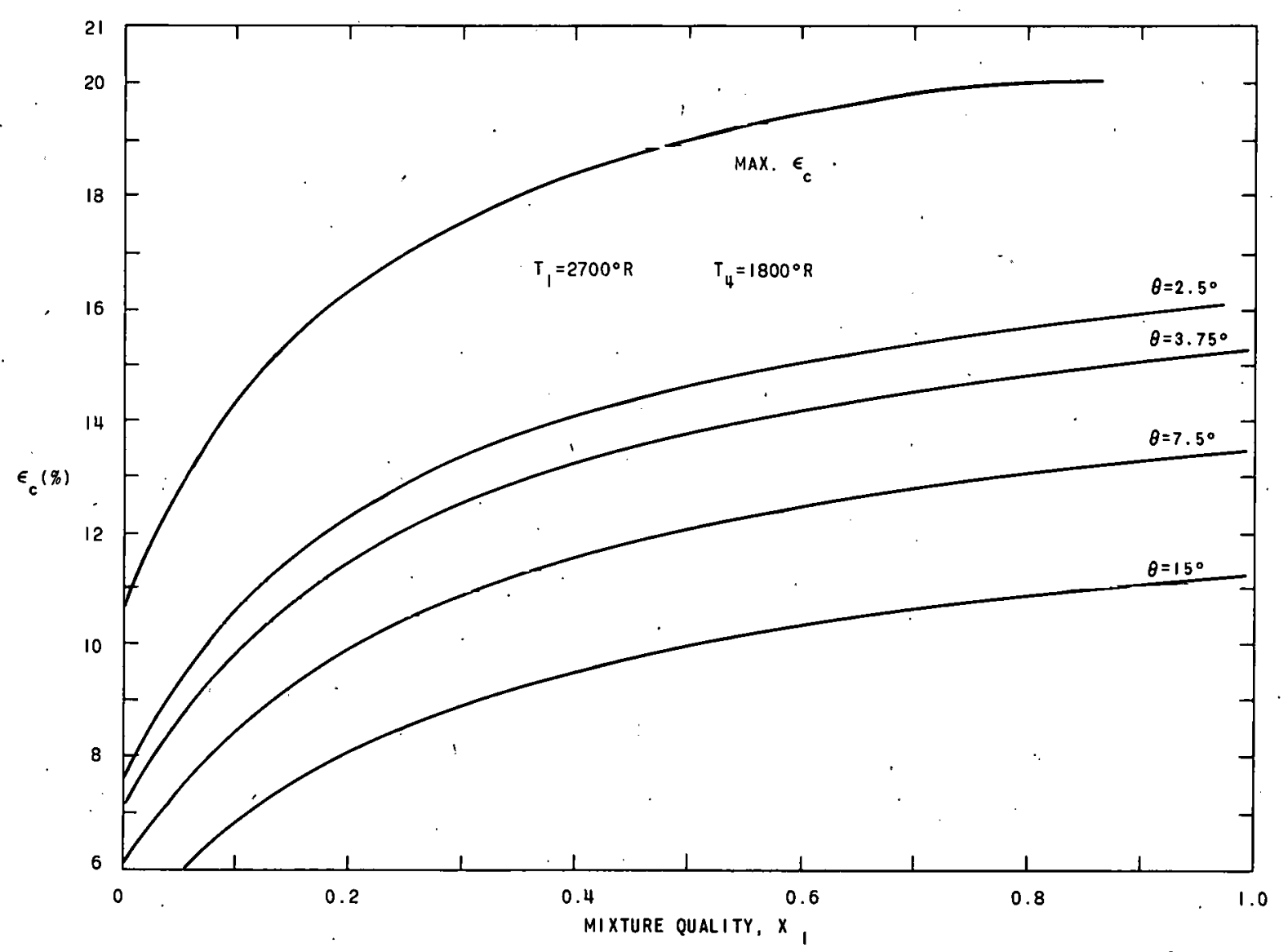

Fig. IV-5. Effect of Generator Efficiency and Half-angle $\theta$ on Cycle Efficiency for Potassium 


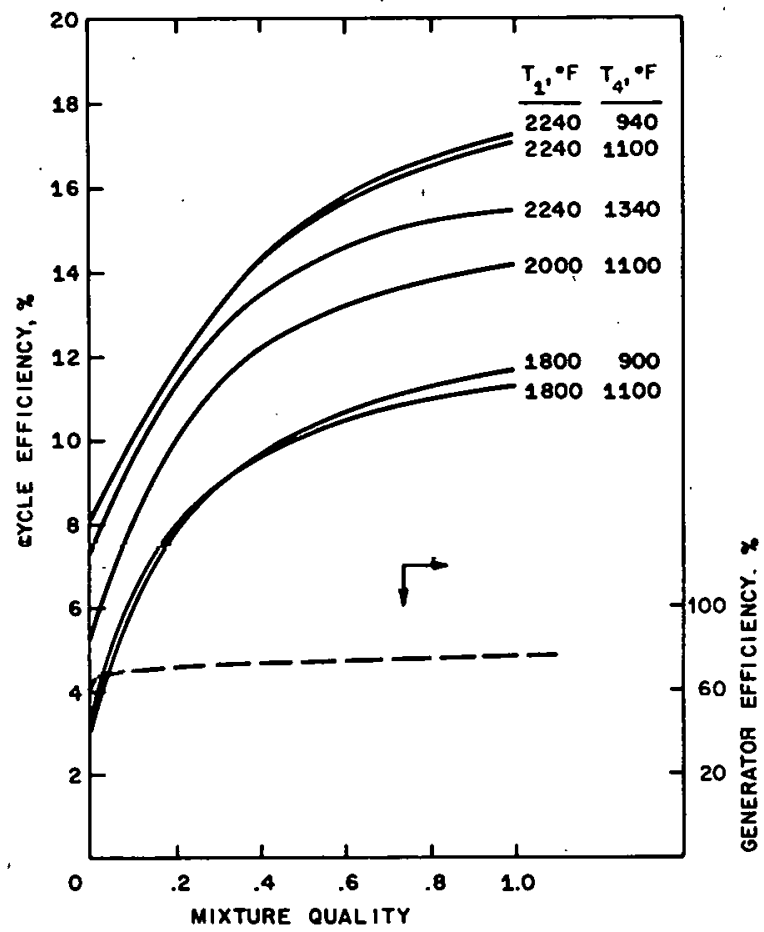

Fig. IV -6

Effect of Heat-source and Sink Temperature on Cycle Efficiency for Potassium

Fig. IV -7

Effect of Condenser Temperature on Cycle Efficiency for Potassium

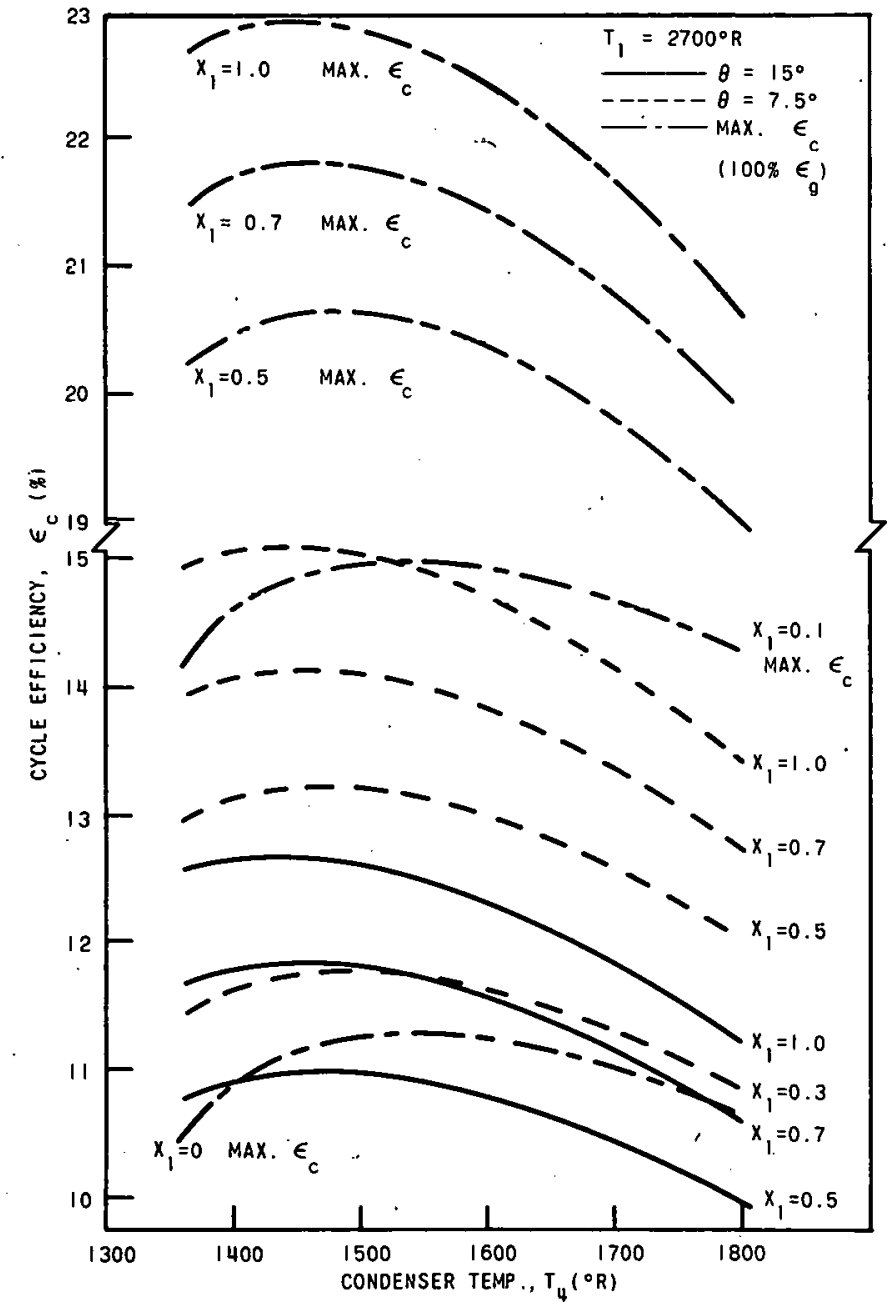




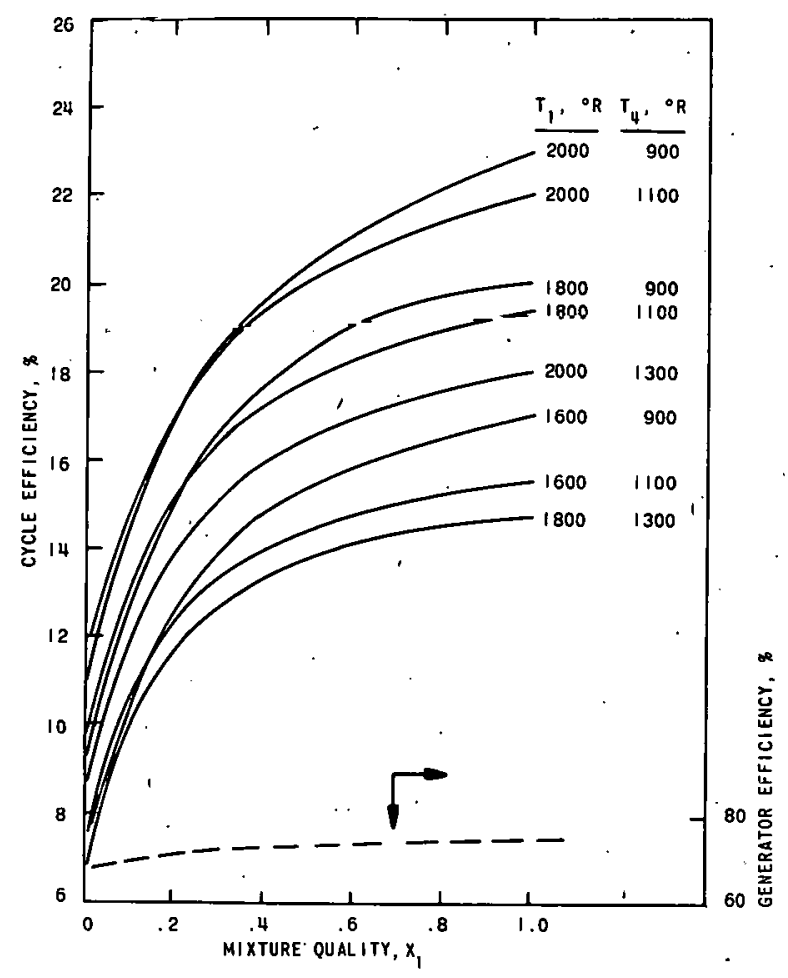

Fig. IV - 8

Cycle Efficiency as a Function of Mixture Quality and Source and Sink Temperature for Mercury

Fig. IV -9

Cycle Efficiency as a Function of Mixture Quality and Source and Sink Temperature for $40 \mathrm{~m} / \mathrm{o}$ Mercury-Potassium Eutectic

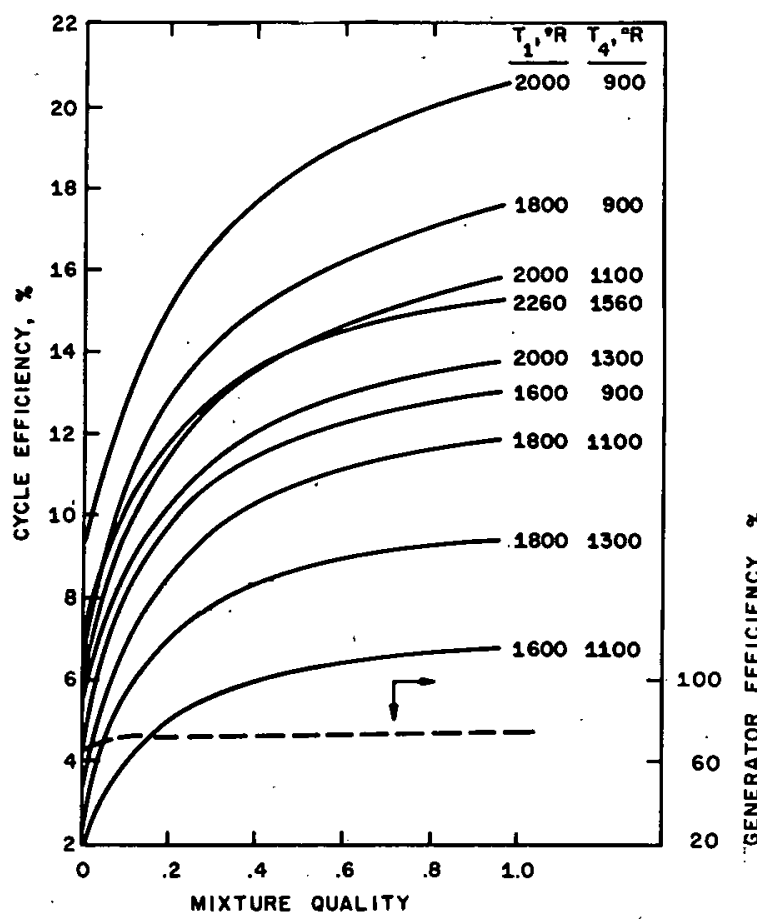


Cesium has the lowest conductivity, whereas sodium has the highest. Sodium as. the working fluid, however, yields the lowest cycle efficiencies.

The maximum cycle efficiency is achieved by using the pure vapor: $x=1.0$. The maximization at $x=1.0$ is due to the fact that the outlet velocity of the two-phase mixture emerging from the nozzle and entering the generator increases with increasing quality. The effect of the half-angle $\theta$ on generator efficiency and the overall cycle efficiency is illustrated in Fig. IV-5 for a potassium system. By decreasing the angle $\theta$, and hence increasing the generator length and reducing the shunt end loss, both the generator and cycle efficiency increase proportionally. As can be seen, for an angle of $\theta=2.50^{\circ}$ the cycle efficiency has reached $16 \%$ for $x_{1}=1.0$. The limiting cycle efficiency would be reached with the ideal generator operating at $100 \%$ efficiency. This is a psuedo condition and is presented for illustrative purposes only.

The effect of varying the heat source temperature is shown in Fig. IV -6 for a potassium cycle. As the source temperature is raised, the cycle efficiency increases. The reason for the increase is due simply to an increase in energy input to the fluid. The behavior is the same for all fluids.

The effect of lowering the sink temperatures on the cycle efficiency is shown in Fig. IV-7. As can be seen, a maximum is observed at a sink temperature between 1400 and $1600^{\circ} \mathrm{R}$ when $\mathrm{T}_{1}=2700^{\circ} \mathrm{R}$. This behavior is due to the thermodynamic properties of the fluid. Since the cycle is based on the conversion of the mixture enthalpy to kinetic energy, the maximum which occurs in the enthalpy-temperature relationship is carried through the cycle. Figure IV -7 also vividly shows the effects of the mixture quality and the heat-source temperature on the overall cycle efficiency.

The efficiency of a cycle based on mercury and mercury-potassium eutectic is shown in Figs. IV -8 and IV-9, respectively. These fluids have the distinct advantage of having lower boiling points and, hence, operating temperature ranges that are close to present technological limits. This advantage rapidly diminishes for the pure mercury system since its vapor pressure increases rapidly with temperature; at $\mathrm{T}=2000^{\circ} \mathrm{R}$ its pressure is 1762 psi. Thus one is then faced with a high-temperature, high-pressure, system. The mercury-potassium alloy has a much lower vapor pressure at a specified temperature than pure mercury. At $T=2000^{\circ} \mathrm{R}$ its vapor pressure is $198 \mathrm{psi}$. It is primarily for this reason that it was studied. Its thermodynamic properties are also quite different from pure mercury. The property data for the eutectic were obtained from Ref. 15.

The highest efficiencies that can be realized for the one-component cycle within the boundary conditions specified is obtained with mercury as the working fluid. An overall cycle efficiency of $22.5 \%$ is obtained for a 
source temperature of $\mathrm{T}=2000^{\circ} \mathrm{R}$ and a sink temperature of $\mathrm{T}=1000^{\circ} \mathrm{R}$. The efficiency of the MHD generator under these conditions is $\epsilon_{\mathrm{g}}=0.75$ : The reason why mercury gives the maximum cycle efficiencies is that the conversion of enthalpy to kinetic energy in the nozzle per pound of fluid flowing is the highest for mercury. The results for the potassium-mercury. mixture are similar to those for pure fluid mercury. The main differences which are apparent are that the cycle is much more sensitive to the source and sink temperatures and the efficiencies are $10-25 \%$ lower.

Of the alkali metals, potassium appears to be the fluid which can most advantageously be used in the cycle: For a source temperature of - $2740^{\circ} \mathrm{F}$ and a sink temperature of $1040^{\circ} \mathrm{F}$, the maximum cycle efficiency which appears feasible is $20 \%$. This is based upon the assumption that the nozzle efficiency can be increased from 0.80 to 0.90 . With this assumption the mercury cycle efficiency reaches a value of $\sim 26 \%$. The Carnot efficiency for the conditions cited lie in the range from 0.35 to 0.50 .

For a space power source an overall cycle efficiency of $\sim 12 \%$ appears to be quite feasible for a heat-source temperature of $2700^{\circ} \mathrm{R}$ and a sink temperature of $1800^{\circ} \mathrm{R}$. This value is comparable to the turbo-electric system. 


\section{THE CONDENSING-INJECTOR CYCLE}

The condensing-injector, liquid-metal MHD power cycle proposed originally by Jacks on and Brown(2) is shown schematically in Fig. V- 1 . The cycle consists of a vapor loop (reactor loop) and a liquid loop (heat rejection loop). The vapor is generated in the reactor heat source and passes into the condensing injector where mixing takes place with the liquid stream which has emerged from the heat exchanger where the waste heat was rejected. In the condensing injector the vapor is condensed and a highstagnation-head liquid is generated. The fluid then passes through the MHD generator, where electrical energy is extracted at the expense of the stagnation-pressure head. The liquid is then coparated into two streams, one of which passes into the vapor loop (and hence to the reactor where it is vaporized), and the other stream to the liquid loop (where heat is rejected in a heat exchanger).

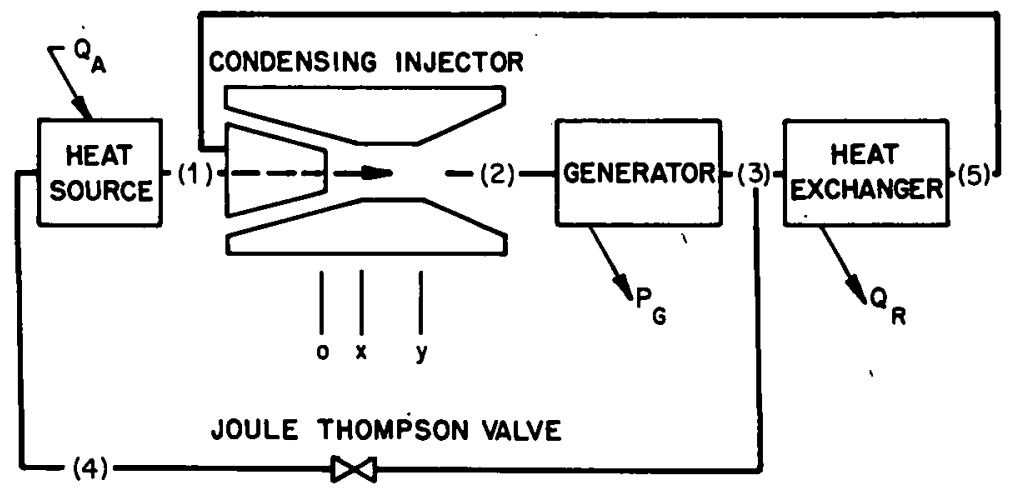

Fig. V-1

Schematic of Condensing Injector Power Cycle

A major advantage of this cycle is the fact that a single-phase liquid metal passes through the MHD generator as in the Elliott cycle. Hence the power density of the generator, as mentioned previously, can approach $10^{10} \mathrm{~W} / \mathrm{cm}^{3}$, which is several orders of magnitude greater than provided by present rotating electrical generators.

The feasibility and potential of the liquid-metal MHD cycle is determined to a very large extent by the performance of the condensing injector.

The condensing injector is not a new device, having been developed extensively as a boiler feedwater pump. It has had a stigma attached to it as being a device of very low efficiency. The apparent low efficiencies may be attributed to the manner in which the efficiency is defined.

Recent. studies, both experimental and analytical, have indicated that the performance of the injector can be very high and, more importantly, analyses predict that the injector can generate very large stagnation pressures--a mandatory requirement for the liquid-metal MHD cycle. The recent condensing-injector studies referred to are those of Brown,(16) 
Brown and Miguel, (17) Hays, (18) and Rose.(19) The performance characteristics of the condensing injector were evaluated from the data presented in the above-mentioned studies. The data presented in the works of Brown, Rose, and Brown and Miguel appear to be consistent in that the ratio of actual performance to predicted performance is comparable. However, the data of Hays show a very large scatter. The performance for the condensing injector is arbitrarily defined as

$$
\eta_{c}=\frac{\Delta P_{\text {act }}}{\Delta P_{\text {calc }}}=\frac{\left(P_{\text {out }}-P_{L_{\text {in }}}\right)_{\text {act }}}{\left(P_{\text {out }}-P_{L_{\text {in }}}\right)_{\text {calc }}} .
$$

This performance factor is not an efficiency, but a measure of accuracy with which the actual injector pressure performance can be predicted from calculations based on continuity, momentum, and energy equations. The procedure used in this study for calculating the pressure generated by the condensing injector is presented later in this chapter.

The performance factors based on Eq. (V-1) calculated from the data of Rose are shown in Fig. V-2. As can be seen, the values range from 70 to $85 \%$ for the range of parameters investigated. Brown and Miguel based these figures on a direct ratio of actual exit pressure to calculated exit pressure from the injector. Their data, when transformed to the basis of Eq. (V-1), yields values comparable with that of Rose.

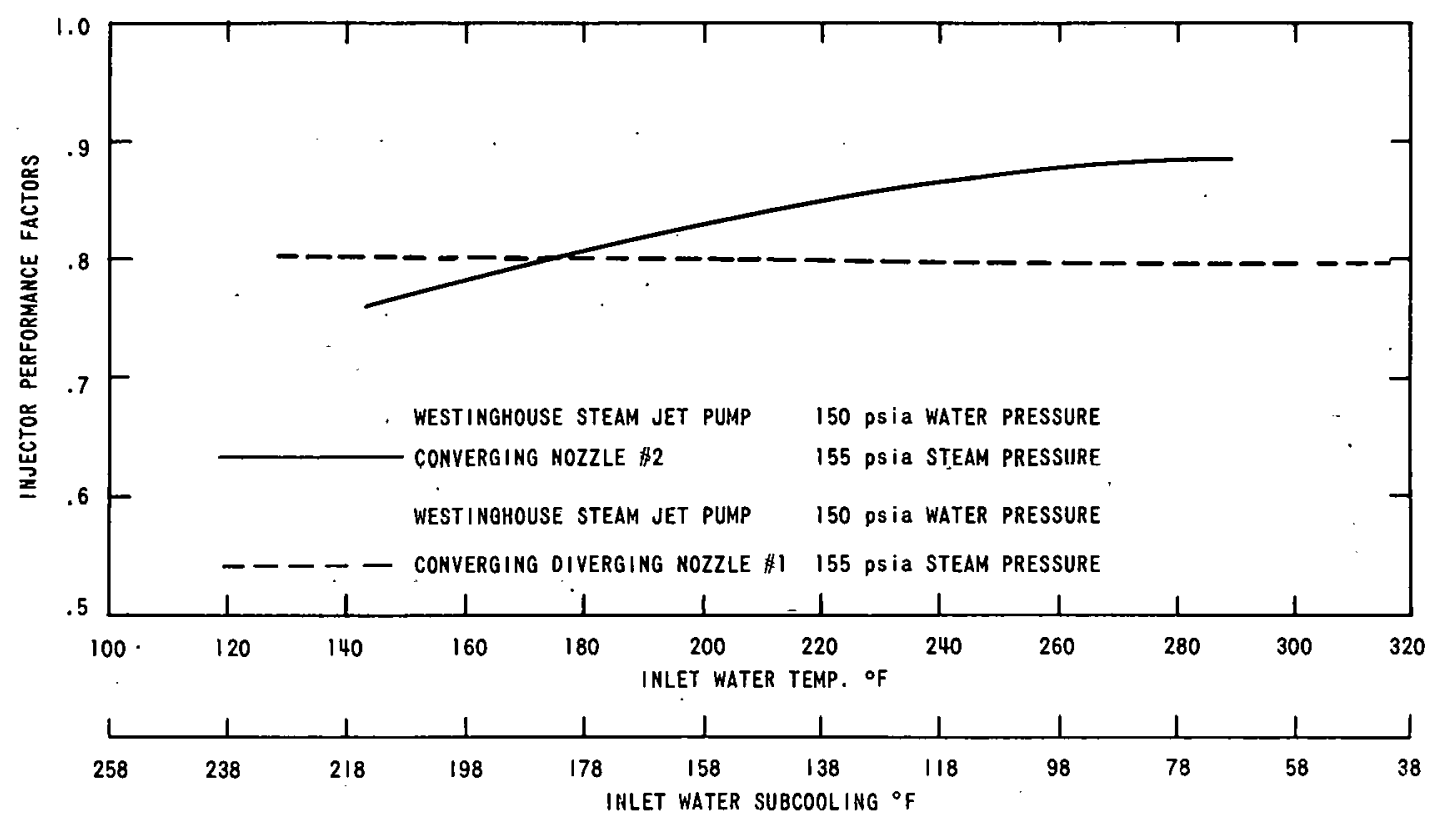

Fig. V-2. Performance Parameters of Condensing Injector Determined by Rose 
The data of Hays exhibits much more scatter. The $\eta_{a}$ defined by Hays as the ratio of measured to calculated pressure rise across the injector, although not directly equivalent to $\mathrm{Eq}$. (V-1), is also a performance parameter indicative of the agreement between actual and calculated performance. Hays' performance parameters ranged from $\sim 2$ to $>100 \%$. The latter values were attributed to the inability to define precisely the injector performance in the test-section geometries used in the investigation.. The methods of analysis are similar in all cases cited. Further, Brown has shown that a convergent-area mixing section will give better pressure performance than a constant-area mixing seclion and that a large pressure rise across the condensing injector is possible.

The geometries, fluids, and parameter ranges of interest to the liquid-metal MHD cycle have, however, not been covered in these investigations, and there are large virgin areas where extrapolations must be made. Several considerations that may seriously limit the performance of the condensing injector have been pointed out, (17) of which the area contraction (ratio of the combined area of liquid and vapor at injection point to the area at the minimum diameter of mixing region) and the vapor Mach number at the injection plane are important. If the minimum area in the mixing section is reduced to a value where it approaches or becomes less than the area of the inlet liquid stream, a shocking phenomenon may occur, since not only the initial liquid stream, but the condensed and noncondensed vapor, must also enter this section. At high contraction ratios the pressure in this minimum-area section may be so low as to cause serious cavitation. problems. The effect of supersonic velocities at the vapor inlct is not clear. It is expected that the injector performance is improved with increasing inlet vapor velocity, but adverse effects such as chocking may be produced by shock formation upstream of the constant-area section of the injector.

It is evident that additional studies arè necessary to explore the many uncertain areas so as to establish the limitations of injector performance. In particular, more effort is required in the range of parameters of specific application to the liquid-metal condensing-injector cycle. The analys is of the injector cycle which follows is, therefore, based on the available data for the condensing injector and extrapolation of the data to the parametric ranges of interest.

A. Cycle Analysis

The performance for the individual components in the cycle follows. The subscripts refer to liquid or vapor properties at given stations denoted in Fig. V-1.

1. Condensing Injector

The analysis of the condensing injector follows that of Hays (18) and Brown.(16). The performance of the condensing injector is calculated 
from an energy and momentum balance with an imposed restraint of the second law of thermodynamics. Referring to Fig. V-1, liquid enters the injector at temperature $T_{5}$ and pressure $P_{5}$. It is assumed that it is feasible to design liquid and vapor nozzles such that the liquid and vapor may be expanded to some low pressure at station $O$ in the injector. The liquid and vapor velocities at station $O$ are calculated as follows:

$$
\begin{aligned}
& \text { For an isentropic expansion of the vapor to station } O \text {, } \\
& S_{i v}^{\prime}=S_{o v}=X_{o v}^{\prime} S_{g o}+\left(1-X_{o v}^{\prime}\right) S_{f o}
\end{aligned}
$$

where $\mathrm{X}_{\mathrm{OV}}^{\prime}$ is the vapor quality at 0 for an isentropic process:

$$
x_{\text {ov }}^{\prime}=\left(s_{i v}-s_{f o}\right) /\left(s_{\text {go }}-s_{f o}\right) \text {. }
$$

Let $\epsilon_{n y}$ denote the vapor nozzle efficiency. Then

$$
\begin{aligned}
& h_{o v}^{\prime}=h_{f o}+X_{o v}^{\prime}\left(h_{i v}-h_{o v}^{\prime}\right) ; \\
& \epsilon_{n v}=\left(h_{i v}-h_{o v}\right) /\left(h_{i v}-h_{o v}^{\prime}\right) ; \\
& h_{o v}=h_{i v}^{\prime}-\epsilon_{n v}\left(h_{i v}-h_{o v}^{\prime}\right) ; \\
& x_{o v}=\left(h_{o v}-h_{f o}\right) /\left(h_{g o}-h_{f o}\right) ; \\
& v_{o v}=v_{f o}+x_{o v}\left(v_{g o}-v_{f o}\right) ;
\end{aligned}
$$

where $h_{f o}, h_{g o}, S_{f o}$, and $S_{g o}$ are evaluated at $T_{o}$ corresponding to $P_{o}$.

From an energy balance,

$$
h_{i v}=h_{o v}+\left(U_{o v}^{2}\right) / 2 g J
$$

Thus

$$
\mathrm{U}_{\mathrm{ov}}=\left[\left(\mathrm{h}_{\mathrm{iv}}-\mathrm{h}_{\mathrm{ov}}\right) 2 \mathrm{gJ}\right]^{1 / 2}
$$

Assuming that the liquid density $\rho_{L}$ is constant and applying Bernoulli!s equation for the noncompressible fluid, we find

$$
\mathrm{U}_{\mathrm{OL}}=\left[2 \mathrm{~g} \epsilon_{\mathrm{n} \ell}\left(\frac{\mathrm{P}_{5}-\mathrm{P}_{\mathrm{o}}}{\rho_{\mathrm{L}}}\right) 0.144\right]^{1 / 2},
$$

where $\epsilon_{\mathrm{n} l}$ is. the liquid nozzle efficiency. 
The inlet stagnation pressure ratio is defined as

$$
\mathrm{B}=\mathrm{P}_{5} / \mathrm{P}_{1} \text {, }
$$

so that

$$
\mathrm{U}_{\mathrm{OL}}=\left[(2 \mathrm{~g})(0.144) \epsilon_{\mathrm{n} \ell} \frac{\mathrm{BP} \mathrm{P}_{1}-\mathrm{P}_{\mathrm{O}}}{\rho_{\mathrm{L}}}\right]^{1 / 2} .
$$

The area ratio at $O$ is determined from the continuity equation

$$
A_{r o}=\frac{A_{O L}}{A_{O V}}=\frac{W_{L} P_{O V} U_{O V}}{W_{V} \rho_{L} U_{O L}} .
$$

If we define the mass flow ratio as $\mathrm{w}_{\mathrm{L}} / \mathrm{W}_{\mathrm{v}}=\mathrm{R}$, then

$$
A_{\text {ro }}=R P_{\text {OV }} U_{O V} / \rho_{L} U_{O L}
$$

Referring to Fig. V-1, the momentum balance across the convergent mixing section of the injector (from $O$ to $x$ ), neglecting wall friction forces, is

$$
P_{o} A_{0}-P_{x} A_{x}-F_{P, o x}=M_{x}-M_{0}
$$

where $M$ is the momentum flux:

$$
\mathrm{M}=P U^{2} \mathrm{~A}=\mathrm{wU} \text {. }
$$

Since

$$
P_{x} A_{x}-P_{y} A_{y}=M_{y}-M_{x}
$$

Eq. $(V-15)$ bécomes

$$
P_{o} A_{o}-P_{y} A_{y}-F_{P} ; o x=M_{y}-M_{o} \text {. }
$$

The wall-pressure force term $F_{P \text {, ox }}$ for the assumed case in which $P$ is constant can be shown to reduce to

$$
F_{P, o x}=P_{o}\left(A_{o}-A_{X}\right) \text {. }
$$

Therefore,

$$
P_{o} A_{o}-P_{y} A_{y}-P_{o}\left(A_{o}-A_{x}\right)=M_{y}-M_{o}
$$


Since

$$
A_{y}=A_{x}
$$

Eq. $(V-20)$ reduces to

$$
P_{y} \Lambda_{x}=P_{o} A_{x}+M_{o}-M_{y}
$$

The momentum flux at position $O$ is

$$
\mathrm{M}_{\mathrm{O}}=\mathrm{W}_{\mathrm{OL}} \mathrm{U}_{\mathrm{OL}}+\mathrm{W}_{\mathrm{OV}} \mathrm{U}_{\mathrm{OV}}
$$

that at position $\mathrm{Y}$ is

$$
\mathrm{M}_{\mathrm{y} \cdot}=\left(\dot{\mathrm{w}}_{\mathrm{oL}}+\mathrm{w}_{\mathrm{ov}}\right) \mathrm{U}_{\mathrm{y}}
$$

Assuming the liquid state exists at $y$, we have

$$
M_{\mathrm{y}}=\rho_{\mathrm{L}} \mathrm{U}_{\mathrm{y}}^{2} \mathrm{~A}_{\mathrm{y}}=\rho_{\mathrm{L}} \mathrm{U}_{\mathrm{y}}^{2} \mathrm{~A}_{\mathrm{x}}
$$

Solution of Eq. $(\mathrm{V}-22)$ for $\mathrm{P}_{\mathrm{y}}$ gives

$$
P_{y}=P_{n}+\frac{M_{0}}{A_{x}}-\frac{M_{y}}{A_{x}}
$$

The total stagnation head at position. 2 is

$$
P_{2}=P_{y}+\frac{\rho_{L} U_{y}^{2}}{2}=\frac{\rho_{L} U_{y}^{2}}{2} \frac{A_{x}}{A_{x}}=P_{y}+\frac{M_{y}}{2 A_{x}} .
$$

Therefore,

$$
P_{2}=P_{0}+\frac{M_{0}}{A_{x}}-\frac{1}{2} \frac{M_{y}}{A_{x}} .
$$

From Eq. (V-28),

$$
M_{O}=\left(\rho_{L} U_{O L}^{2} \cdot \frac{A_{O L}}{A_{O}}+P_{O V} U_{O V}^{2} \cdot \frac{A_{O V}}{A_{O}}\right) A_{O}
$$

Noting that

$$
\frac{A_{O L}}{A_{O}}=\frac{A_{O L}}{A_{O V}+A_{O L}}=\frac{A_{O L} / A_{O V}}{1+\frac{A_{O L}}{A_{O V}}} \frac{A_{O L}}{A_{O}}=\frac{A_{\text {ro }}}{1+A_{\text {ro }}}
$$


and that

$$
\frac{A_{O V}}{A_{O}}=\frac{1}{1+\frac{A_{O L}}{A_{O V}}}=\frac{1}{1+A_{\text {ro }}}
$$

we have

$$
\frac{M_{O}}{A_{X}}=\left[\rho_{L} U_{o L}^{2} \frac{A_{r o}}{1+A_{r o}}+P_{o v} U_{o v}^{2} \frac{1}{1+A_{r o}}\right] \frac{A_{O}}{A_{x}}
$$

Similarily, it can be shown that

$$
\frac{M_{y}}{A_{x}}=\frac{1}{\rho_{L}}\left(P_{o v} U_{o v} \frac{1}{1+A_{r o}}+\rho_{L} U_{o L} \frac{A_{r o}}{1+A_{r o}}\right)^{2}\left(\frac{A_{o}}{A_{x}}\right)^{2}
$$

The quantity $A_{0} / A_{x}$ is generally referred to as the contraction ratio and is denoted by

$$
A=A_{0} / A_{x}
$$

The pressures at position $\mathrm{y}$ and 2 therefore are

$$
\begin{aligned}
P_{y} & =P_{O}+\left(\rho_{L} U_{O L}^{2} \frac{A_{r o}}{1+A_{r o}}+P_{O V} U_{O V}^{2} \frac{1}{1+A_{r o}}\right) A \\
& -\frac{1}{\rho_{L}}\left(P_{O V} U_{O V} \frac{1}{1+A_{r o}}+\rho_{L} U_{O L} \frac{A_{r o}}{1+A_{r o}}\right) A^{2}
\end{aligned}
$$

and

$$
\begin{aligned}
P_{2}= & P_{O}+\left(\rho_{L} U_{O L}^{2} \frac{A_{r o}}{1+A_{r o}}+P_{O V} U_{O V}^{2} \frac{1}{1+A_{r o}}\right) A \\
& \therefore \\
& -\frac{1}{2 \rho_{L}}\left(P_{O V} U_{O V} \frac{1}{1+A_{r o}}+\rho_{L} U_{O L} \frac{A_{r o}}{1+A_{r o}}\right) A^{2} .
\end{aligned}
$$

The total stagnation head at 2 is

$$
P_{2 T}=P_{2}+\left(\rho_{L} U_{2}^{2} / 2 g\right)
$$

To allow for real condensing-injector losses and nonideal diffuser performance, the calculated performance is reduced by a performance factor $\epsilon_{c}$. Therefore 


$$
P_{2}=\epsilon_{\mathrm{c} 2} P_{2 I}
$$

and

$$
\mathrm{U}_{\mathrm{y}}=\left[\frac{\left(\epsilon_{\mathrm{c} 2} \mathrm{P}_{2 \mathrm{I}}-\mathrm{P}_{\mathrm{y}}\right) 2 \mathrm{gc}}{\rho_{\mathrm{L}}} 0.144\right]^{1 / 2}
$$

The fluid state at the exit of the injector is obtained from an energy balance from position 0 to 2 . Assuming an adiabatic injector and utilizing the total stagnation pressure, we find for the energy balance that

$$
\begin{aligned}
& W_{V} h_{i v}+\left[E_{5 L}\left(T_{5}\right)+\frac{P_{5}}{J \rho_{L}}\right] W_{L}=\left(E_{2 L}\left(T_{2}\right)+\frac{P_{2}}{J \rho_{L}}\right)\left(W_{L}+W_{v}\right) \\
& h_{i v}+R\left[E_{5 L}\left(T_{5}\right)+\frac{P_{5}}{J \rho_{L}}\right]=(1+R)\left[E_{2 L}\left(T_{2}\right)+\frac{P_{2}}{J \rho_{L}}\right] .
\end{aligned}
$$

Simplifịcation yields

$$
E_{2 L}\left(T_{2}\right)=\frac{h_{i v}}{1+R}+\frac{R}{1+R}\left[E_{5 L}\left(T_{5}\right)+\frac{P_{5}}{J \rho_{L}}\right]-\frac{P_{2}}{J \rho_{L}} .
$$

From $E_{2} L\left(T_{2}\right)$ the temperature $T_{2}$ can be determined-from the tabulation of properties of the fluid.

The subcooling at the exit of the condensing injector is

$$
\Delta T_{\text {sub }}=T_{\text {sat }}\left(P_{2}\right)-T_{2} \text {. }
$$

The restraint of the second law of thermodynamics on the performance of the condensing injector requires that the entropy of this exit stream must be greater than the entropy of the entering vapor and liquid streams. Expressed mathematically,

$$
\left(\mathrm{w}_{L}+\mathrm{w}_{\mathrm{v}}\right) \mathrm{S}_{2}>\mathrm{w}_{\mathrm{L}} \mathrm{S}_{\mathrm{Lo}_{0}}+\mathrm{w}_{\mathrm{v}} \mathrm{S}_{\mathrm{vo}}
$$

or

$$
\Delta S=S_{2}-\frac{R}{1+R} S_{5}-\frac{1}{1+R} S_{1} \geq 0,
$$

where $S_{2}$ is evaluated at $T_{2}$. 
When the calculated performance of the condensing injector does not conform to this stipulation, the condition specified in the cycle and the cycle itself is rejected.

2. The MHD Generator:

An energy balance across the MHD generator from 2 to 3 yields

$Q-W=E_{2 L}\left(T_{2}\right)+\frac{P_{2}}{J \rho_{L}}-E_{3}\left(T_{3}\right)-\frac{P_{3}}{J \rho_{L}}$.

As shown previously, the energy extracted from the generator is

$W=\epsilon \frac{P_{2}-P_{3}}{J \rho_{L}}$.

Thus, for an adiabatic generator, Eq. (V-44) reduces to

$$
-\epsilon_{g} \frac{P_{2}-P_{3}}{J p_{L}}=E_{2 L}\left(T_{2}\right)+\frac{P_{2}}{J \rho_{L}}-E_{3 L}\left(T_{3}\right)-\frac{P_{3}}{J P_{3}}
$$

\section{The Heat Exchanger}

The heat exchanger is as sumed to operate with a specified log mean temperature difference $\Delta \mathrm{T}_{\ell \mathrm{n}}$ and reject heat to a fluid whose temperature $T_{S}$ remains constant. Therefore,

$$
\Delta T_{\ell n}=\frac{T_{3}-T_{5}}{\ln \frac{T_{3}-T_{S}}{T_{5}-T_{S}}}
$$

For the cycle analysis the log mean temperature drop was arbitrarily set equal to $100^{\circ} \mathrm{F}$.

The pressure drop across the heat exchanger was also arbitrarily fixed at $\Delta P_{H E}=10$ psi. Therefore,

$$
P_{3}=P_{5}+\Delta P_{H E}=P_{5}+10 \text { psi. }
$$

The heat rejected in the heat exchanger is

$$
\frac{Q_{R}}{W_{L}}=\left[E_{3}\left(T_{3}\right)+\frac{P_{3}}{\rho_{L}}\right]-\left[E_{5}\left(T_{5}\right)+\frac{P_{5}}{\rho_{L}}\right]
$$


Equations (V-40), (V-46), and (V-47), which represent the heat-exchanger equation, the energy equation across the injector, and the energy equation across the generator, contain three unkrowns: $T_{5}, T_{2}$, and $T_{3}$, and therefore must be solved simultaneously. It should be noted, however, that for large values of the log mean temperature differential and low values of $R, T_{5}$ approaches $T_{S}$ and, hence, for ease in computation, the following as sumption. may be made:

$$
\mathrm{T}_{5}=\mathrm{T}_{\mathrm{S}}+10^{\circ}
$$

With this additional stipulation $T_{2}$ and $T_{3}$ can readily be calculated.

\section{The Heat Source}

The pressure drop across the heat source, $\Delta P_{H S}$, was arbitrarily set equal to 10 psi. Therefore,

$$
P_{y}=P_{1}+\Delta P_{H S}
$$

If excess pressure must be dissipated between positions 3 and 4 before the fluid enters the heat source, it is rejected in a Joule-Thoms on process.

The heat added to the fluid i.e given by

$$
\frac{Q_{A}}{W_{V}}=-\left[E_{4}\left(T_{3}\right)+\frac{P_{4}}{J \rho_{L}}\right]+h_{1}\left(T_{1}\right) .
$$

5. The Cycle Efficiency

The cycle efficiency is given by

$$
\epsilon_{\mathrm{c}}=\frac{\mathrm{P}_{\mathrm{O}}}{\mathrm{P}_{\mathrm{R}}}=\left(\mathrm{W}_{\mathrm{V}}+\mathrm{W}_{\mathrm{L}}\right) \frac{\mathrm{P}_{2}-\mathrm{P}_{3}}{\rho_{\mathrm{L}} \mathrm{J}} \frac{144 \epsilon_{\mathrm{g}}}{\mathrm{W}_{\mathrm{v}}\left(\mathrm{h}_{1}-\mathrm{h}_{3}\right)}
$$

or

$$
\epsilon_{\mathrm{c}}=\frac{(1+\mathrm{R})\left(\mathrm{P}_{2}-\mathrm{P}_{3}\right)}{\mathrm{h}_{1}-\mathrm{h}_{3} \rho_{\mathrm{L}}^{\mathrm{J}}} \cdot 144 \epsilon_{\mathrm{g}}
$$

From Eq. $(V-40)$ it can' be shown that

$$
h_{1}-h_{3}=\frac{R}{l+R}\left(\dot{h}_{1}-h_{5}\right)
$$


Therefore,

$$
\epsilon_{c}=\frac{(1+R)^{2}(144)\left(P_{2}-P_{3}\right) \epsilon_{g}}{R(778) \rho_{L}\left(h_{1}-h_{5}\right)} .
$$

Several criteria are considered to establish the validity of $\epsilon_{c}$ as calculated above. They are:

a. The entropy must increase across the injector:

$$
\Delta S=S_{2}-\left(\frac{1}{1+R} S_{i v}+\frac{R}{1+R} S_{5 L}\right) \geq 0
$$

conditions for which $\Delta S<0$ are inadmissible.

b. The subcooling at the condensing-injector exit must be positive. The saturation temperature corresponding to $P_{2}$ is calculated as.

$$
\mathrm{T}_{\text {sub 2 }}=\mathrm{T}_{\mathrm{S}_{2}}-\mathrm{T}_{\mathbf{2}}
$$

The condition $\mathrm{T}_{\text {sub }}<0$ implies the assumption of existence of a liquid state at (2) is not true.

c. The subcooling at the generator exit is also checked. The saturation temperature at $P_{3}$ is $T_{S_{3}}$. Then

$$
\mathrm{T}_{\text {sub } 3}=\mathrm{T}_{\mathrm{S}_{3}}-\mathrm{T}_{3}
$$

The condition $\mathrm{T}_{\text {sub } 3}<0$ implies the fluid has flashed to vapor in the generator. This is not allowed in this cycle.

d. The value of $\mathrm{P}_{2}$ can become negative; for this case calculations are also rejected.

e. The value of $P_{y}$ can become negative. This situation is not admittedisince it is doubtful that the injector would operate.

The working fluids studied in this cycle were cesium, potassium, sodium, and mercury.

B. Discussion of Results

Typical results of the cycle analysis for the four liquid metals studied are shown in Figs. V-3 to V-22. For illustrative purposes, detailed data are presented for the cesium cycle. The cycle efficiency, total stagnation heat at 2 , stagnation head at $y$, and exit subcooling at 3 are plotted against percent of the maximum contraction ratio, which is calculated from the arbitrary stipulation that

$$
A_{x}=A_{O} \cdot L \cdot
$$



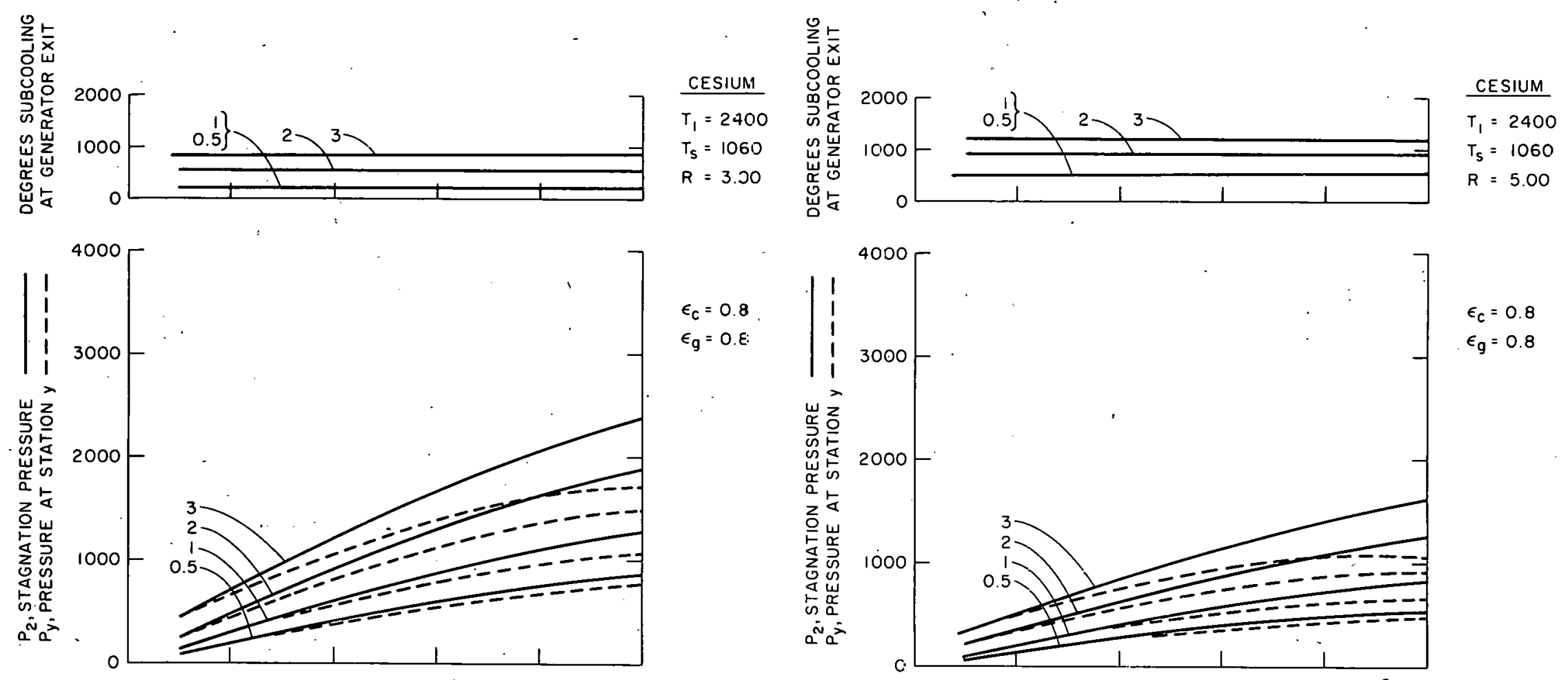

$\epsilon_{\mathrm{c}}=0.8$

$\epsilon_{\mathrm{g}}=0.8$

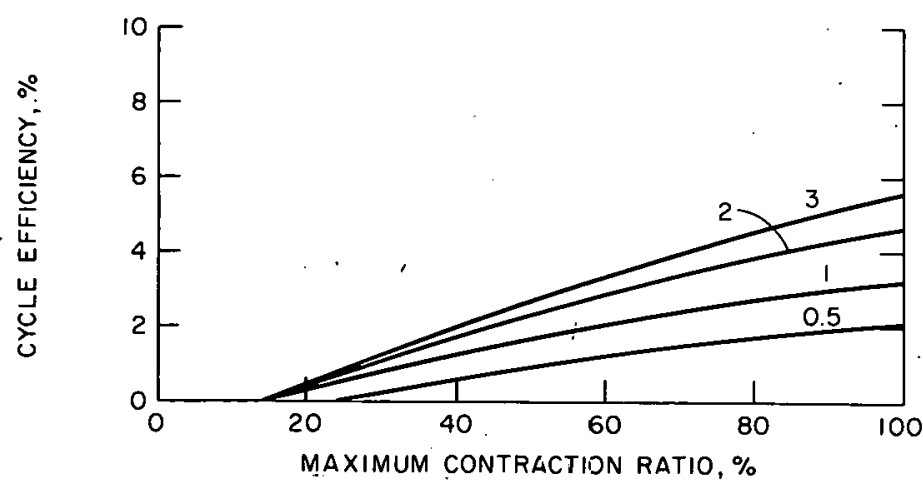

\begin{tabular}{cc}
$\underline{\beta}$ & $\frac{\alpha_{m}}{16.7}$ \\
\hline 0.5 & $\cdot 16.7$ \\
1 & 24.6 \\
2 & 34.1 \\
3 & 41.7 \\
&
\end{tabular}

Fig. V-3. Calculated Performance Data for the Condensinginjector Cycle Operating with Cesium for $\mathrm{T}_{1}=$ $2400^{\circ} \mathrm{R}, \mathrm{T}_{\mathrm{S}}=1060^{\circ} \mathrm{R}$, and $\mathrm{R}=3.00$

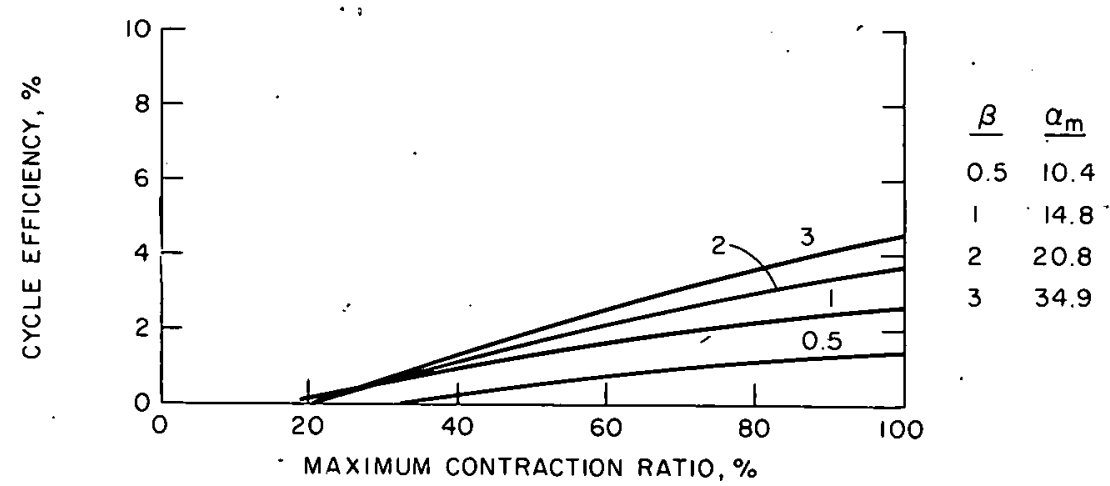

Fig. V-4. Calculated Performance Data for the Condensinginjector Cycle Operating with Cesium for $\mathrm{T}_{1}=$ $2400^{\circ} \mathrm{R}, \mathrm{T}_{\mathrm{S}}=1060^{\circ} \mathrm{R}$, and $\mathrm{R}=5.00$ 

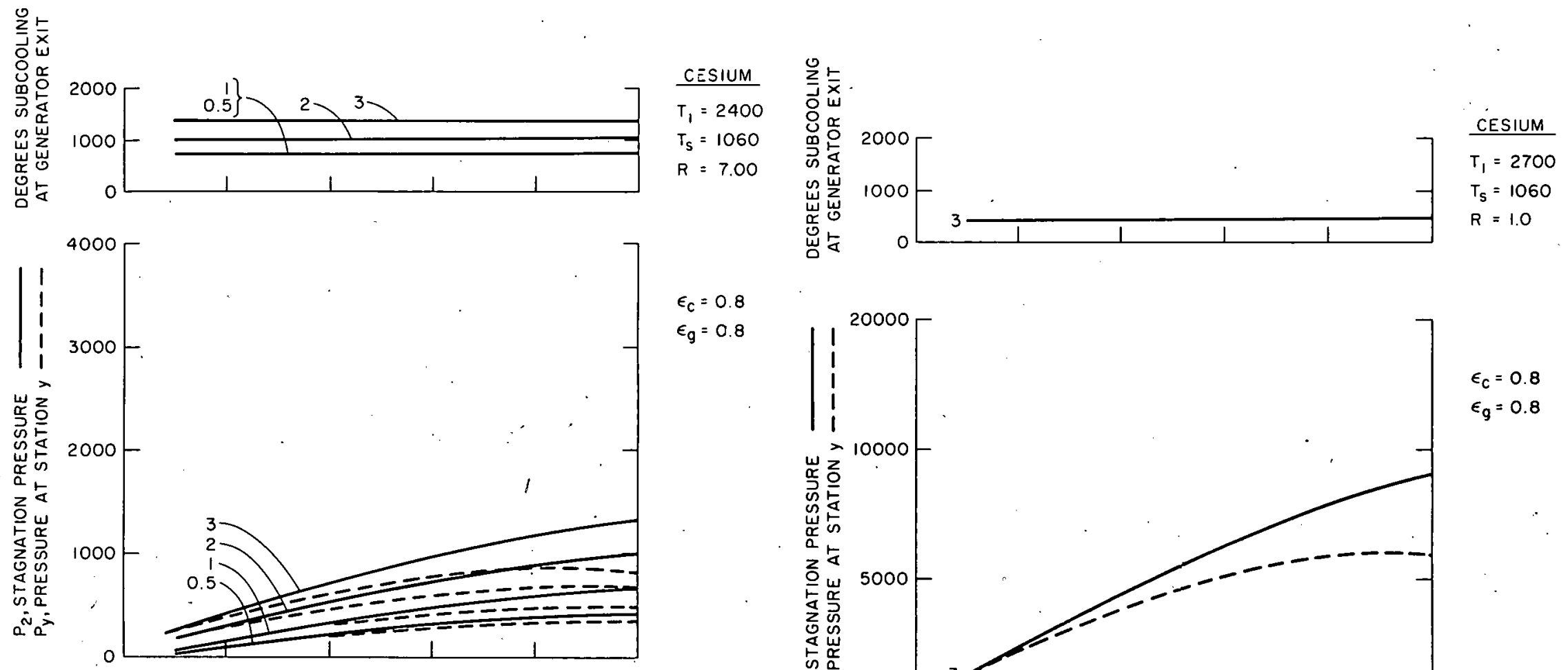

$\epsilon_{\mathrm{c}}=0.8$
$\epsilon_{\mathrm{g}}=0.8$
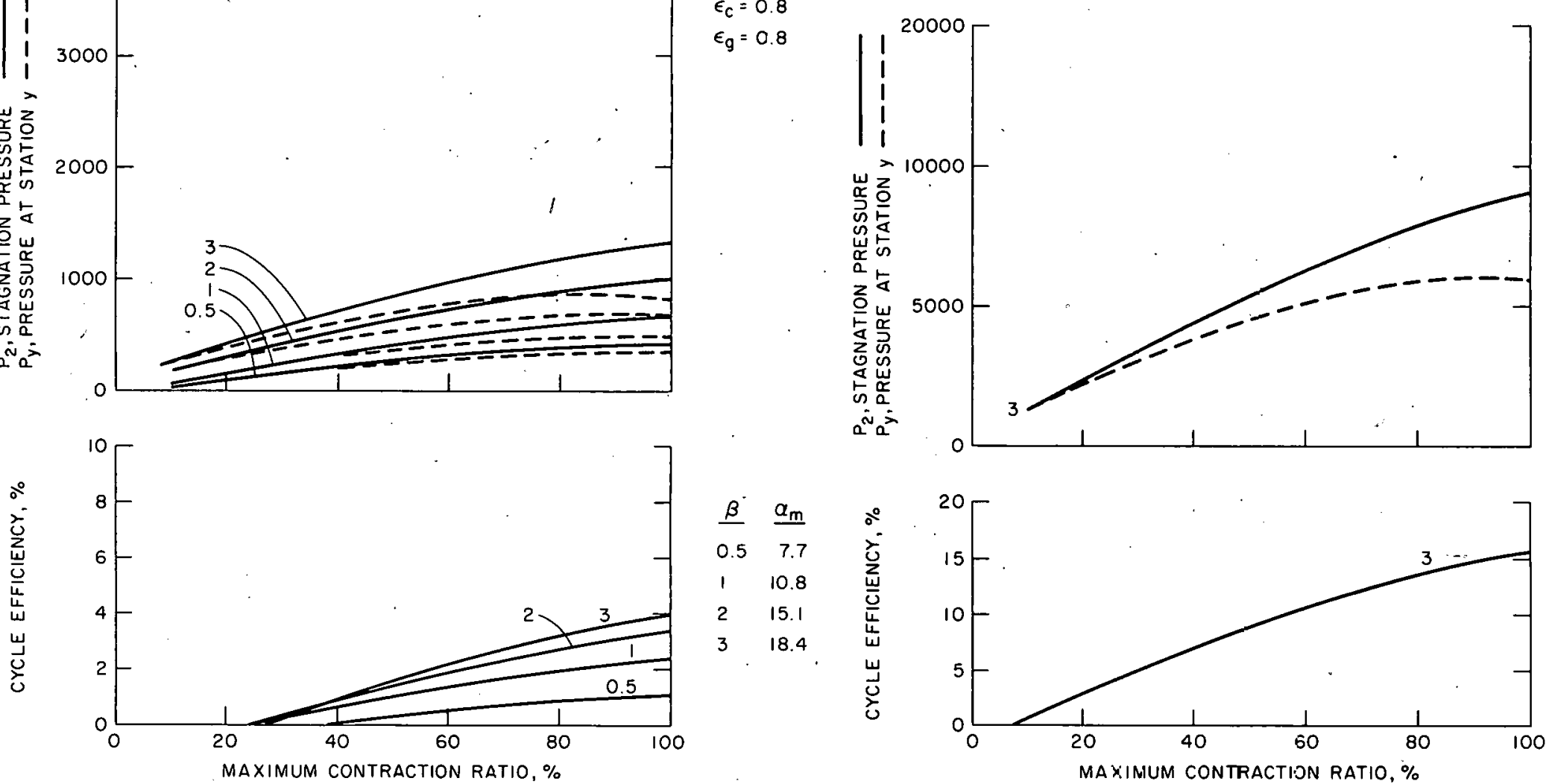

$\underline{\beta} \quad \underline{\alpha_{m}}$

$3 \quad 145.9$

Fig. V -5 . Calculated Performance Data for the Condensing injector Cycle Operating with Cesium for $\mathrm{T}_{1}=$ $2400{ }^{\circ} \mathrm{R}, \mathrm{T}_{\mathrm{s}}=1060^{\circ} \mathrm{R}$, and $\mathrm{R}=7.00$

Fig. V-6. Calculated Performance Data for the Condensing in jector Cycle Operating with Cesium for $T_{1}=$ $2700^{\circ} \mathrm{R}, \mathrm{T}_{\mathrm{S}}=1060^{\circ} \mathrm{R}$, and $\mathrm{R}=10.0$ 
吾

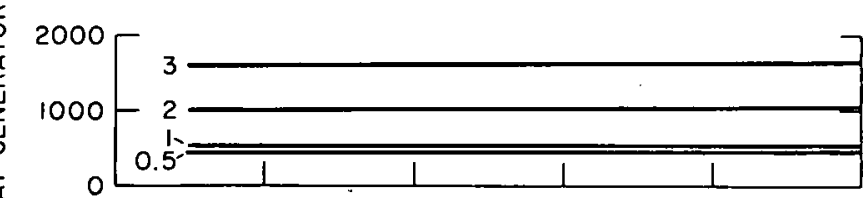

CESIUM

$T_{1}=270 \mathrm{C}$

$T_{\mathrm{S}}=1060$

$R=3.00$

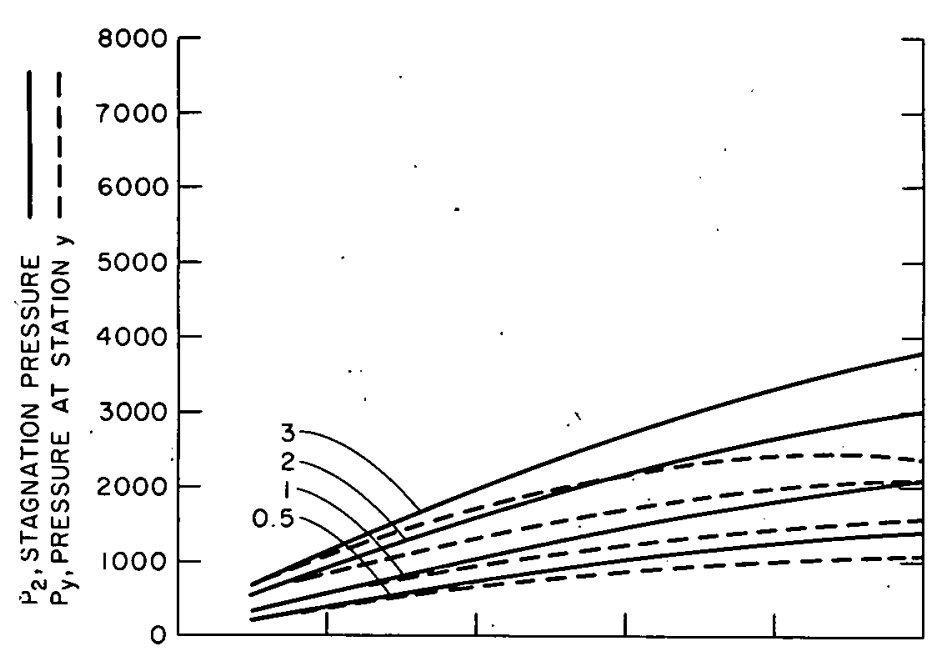

$\epsilon_{\mathrm{c}}=0.8$

$\epsilon_{\mathrm{g}}=0.8$

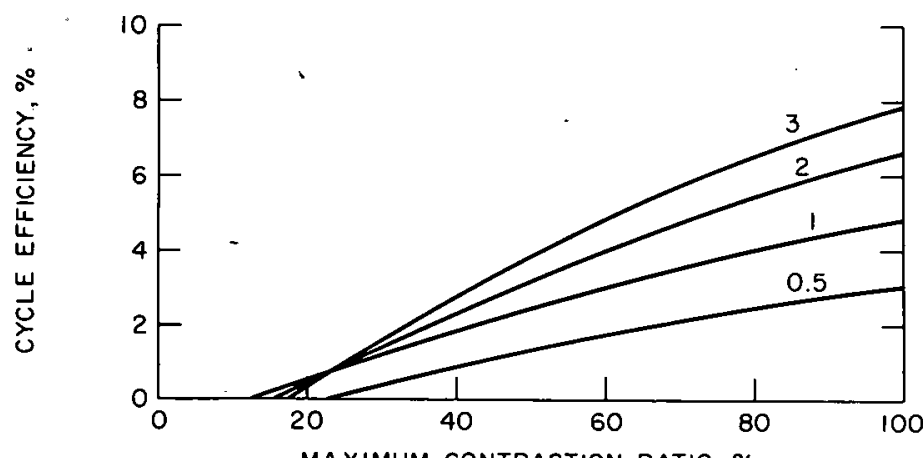

$\underline{\beta} \quad \underline{\alpha_{m}}$

$0.5 \quad 20.2$

$1 \quad 28.6$

240.3

349.3

MAXIMUM CONTRACTION RATIO, \%

Fig. V-7. Calculated Performance Data for the Condensinginjector Cycle Operating with Cesium for $\mathrm{T}_{1}=$ $2700^{\circ} \mathrm{R}, \mathrm{T}_{\mathrm{S}}=1060^{\circ} \mathrm{R}$, and $\mathrm{R}=3.00$
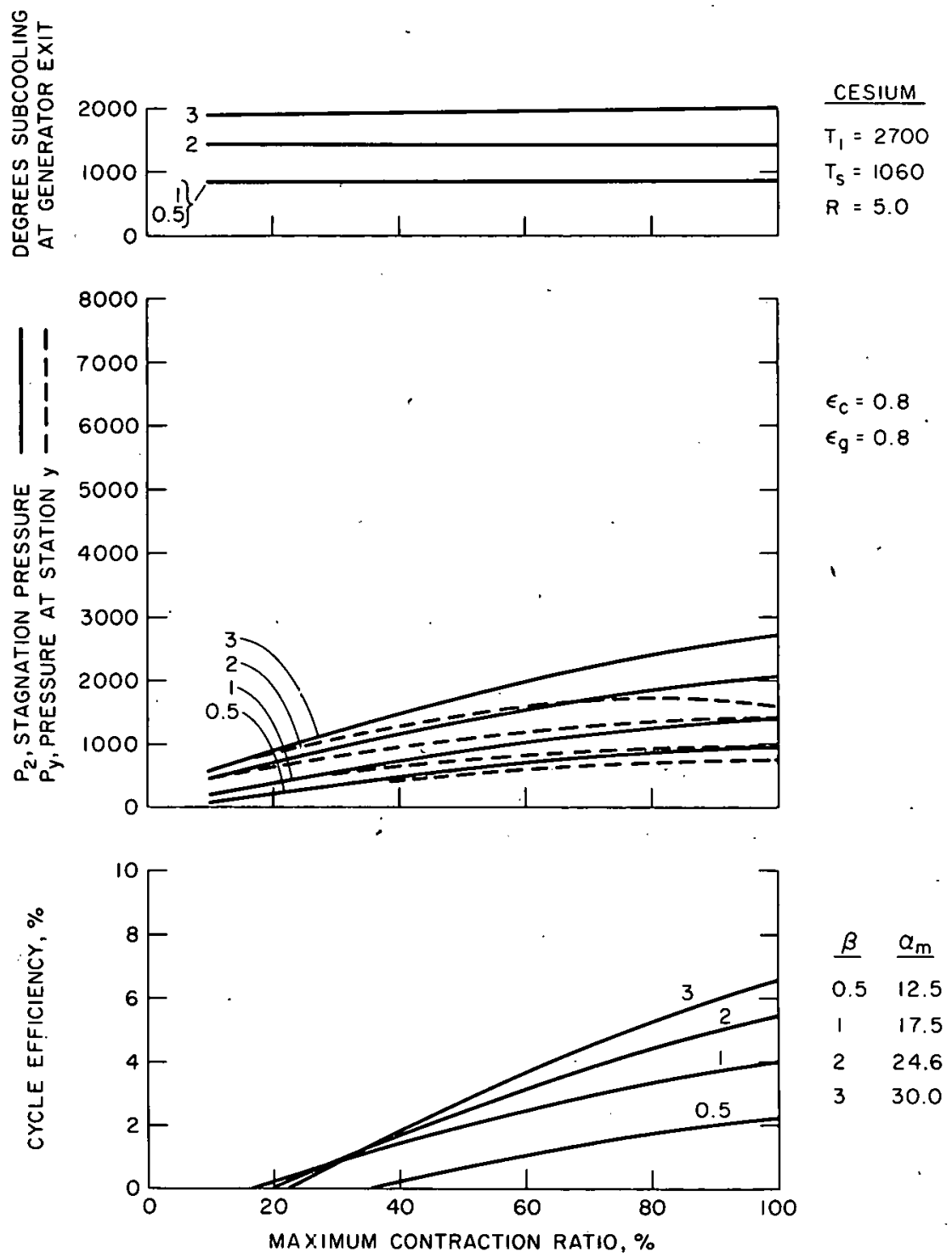

Fig. V-8. Calculated Performance Data for the Condensinginjector Cyclè Operating with Cesium for $\mathrm{T}_{1}=$ $2700^{\circ} \mathrm{R}, \mathrm{T}_{\mathrm{s}}=1060^{\circ} \mathrm{R}$, and $\mathrm{R}=5.0$ 

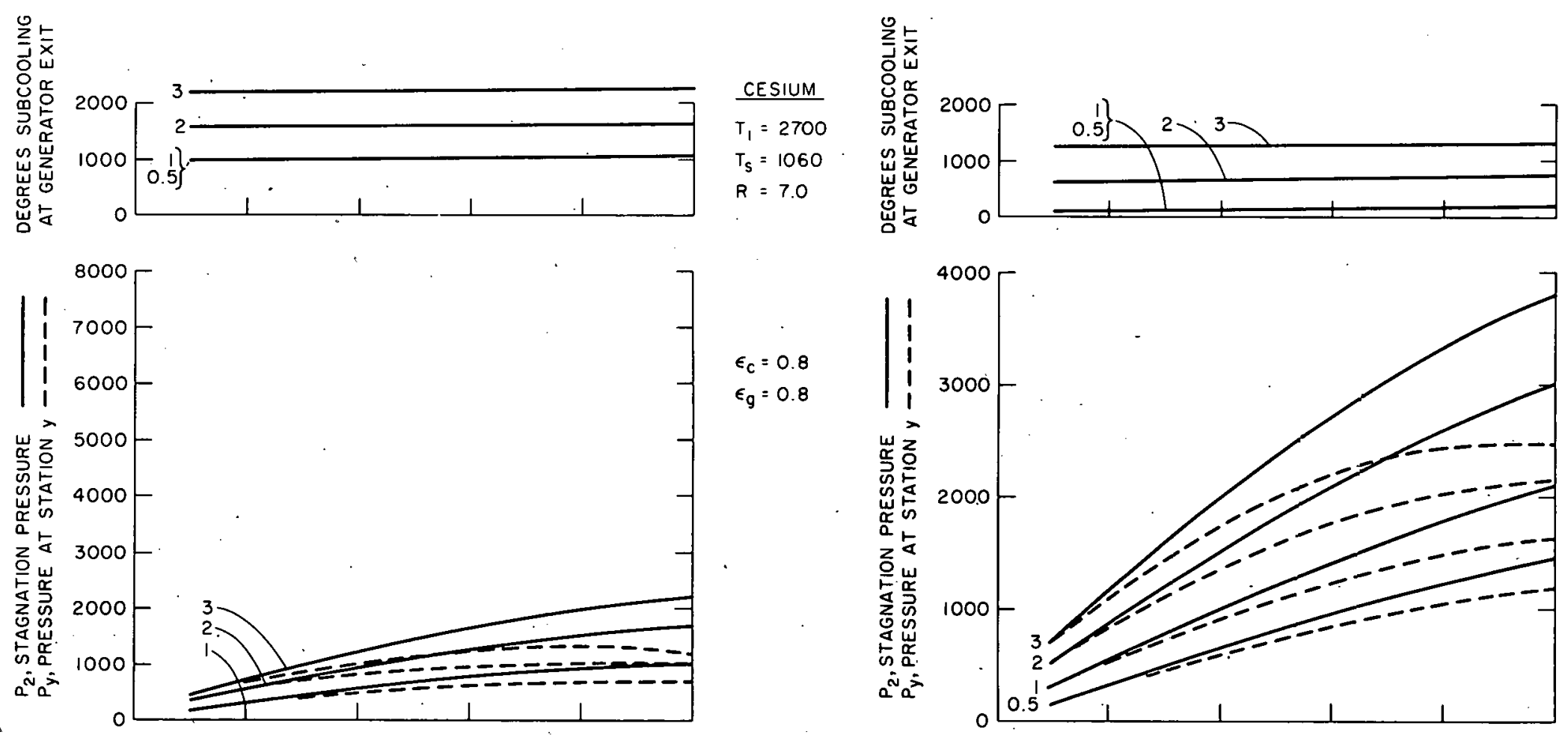

$$
\begin{aligned}
& \text { CESIUM } \\
& T_{1}=2700 \\
& T_{S}=1510 \\
& R=3.00
\end{aligned}
$$

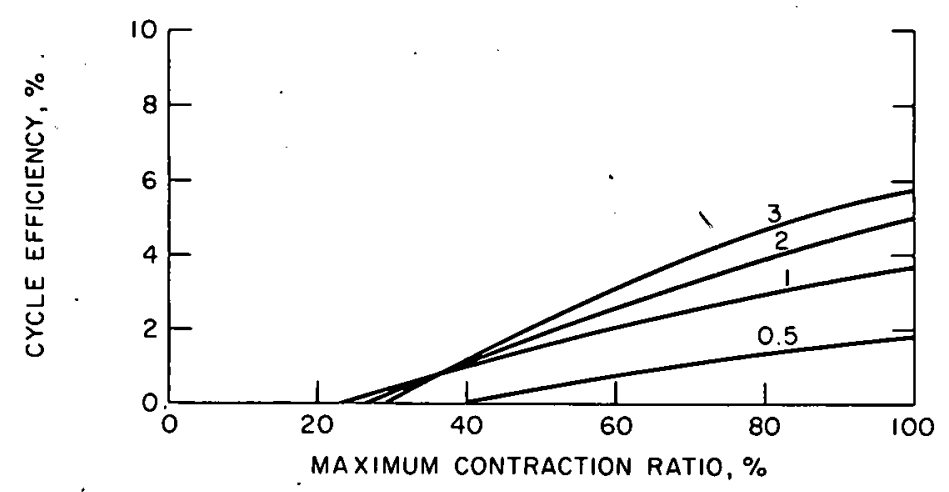

$\underline{\beta} \quad \dot{\alpha}_{m}$

$0.5 \quad 9.2$

$\begin{array}{ll}1 & 12.8\end{array}$

$\begin{array}{ll}2 & 17.8 \\ 3 & 3.7\end{array}$

$\begin{array}{ll}3 & 21.7\end{array}$

Fig. V-9. Calculated Performance Data for the Condensingin jector Cycle Operating with Cesium for $T_{1}=$ $2700^{\circ} \mathrm{R}, \mathrm{T}_{\mathrm{S}}=1060^{\circ} \mathrm{R}$, and $\mathrm{R}=7.0$

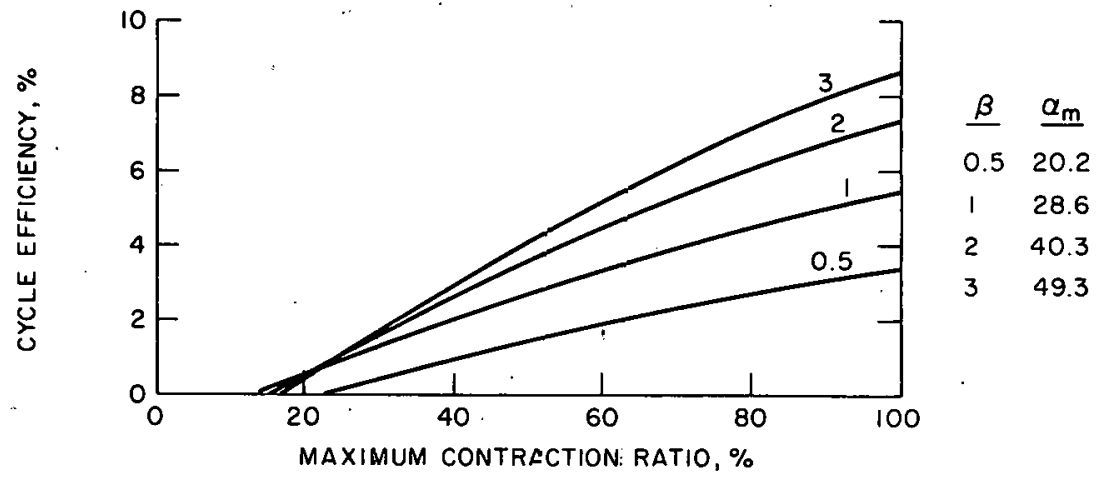

Fig. V-10. Calculated Performance. Data for the Condensing injector Cycle Operating with Cesium for $\mathrm{T}_{1}=$ $2700^{\circ} \mathrm{R}, \mathrm{T}_{\mathrm{s}}=1510^{\circ} \mathrm{R}$, and $\mathrm{R}=3.00$ 
竞
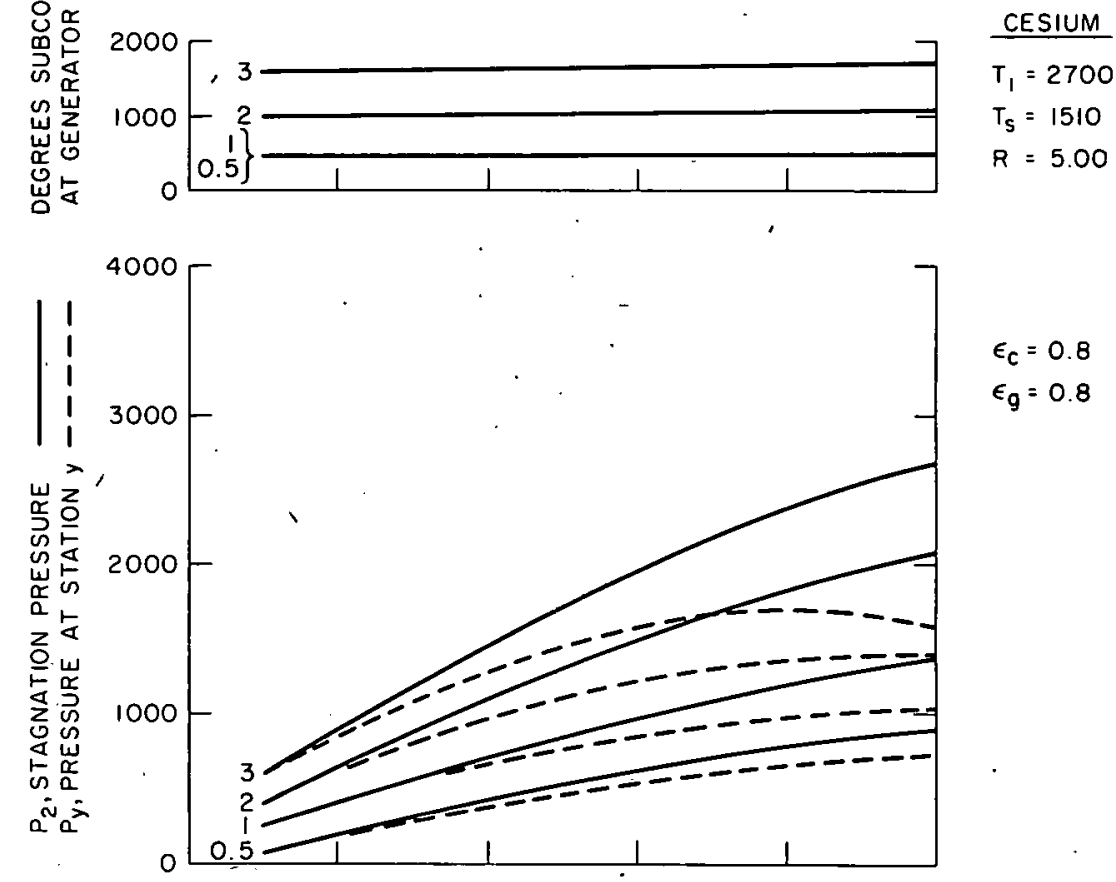

$\epsilon_{\mathrm{c}}=0.8$

$\epsilon_{\mathrm{g}}=0.8$

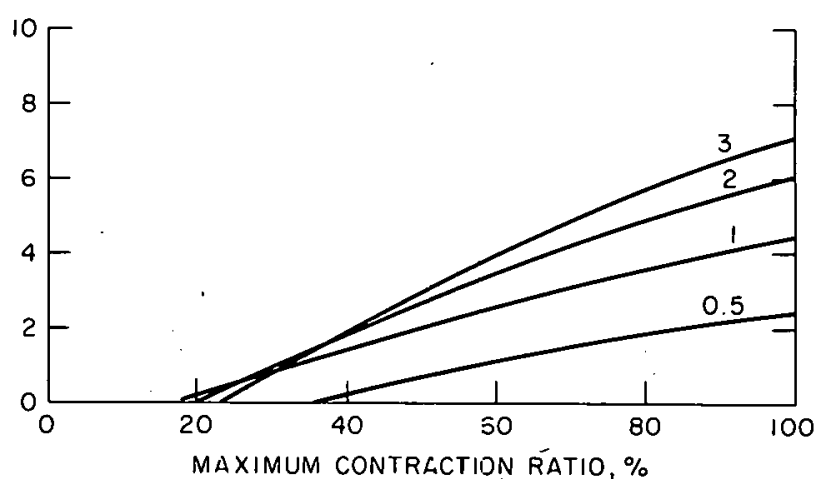

Fig. V-11. Calculated Performance Data for the Condensinginjector Cycle Operating with Cesium for $\mathrm{T}_{1}=$ $2700^{\circ} \mathrm{R}, \mathrm{T}_{\mathrm{S}}=1510^{\circ} \mathrm{R}$, and $\mathrm{R}=5.00$
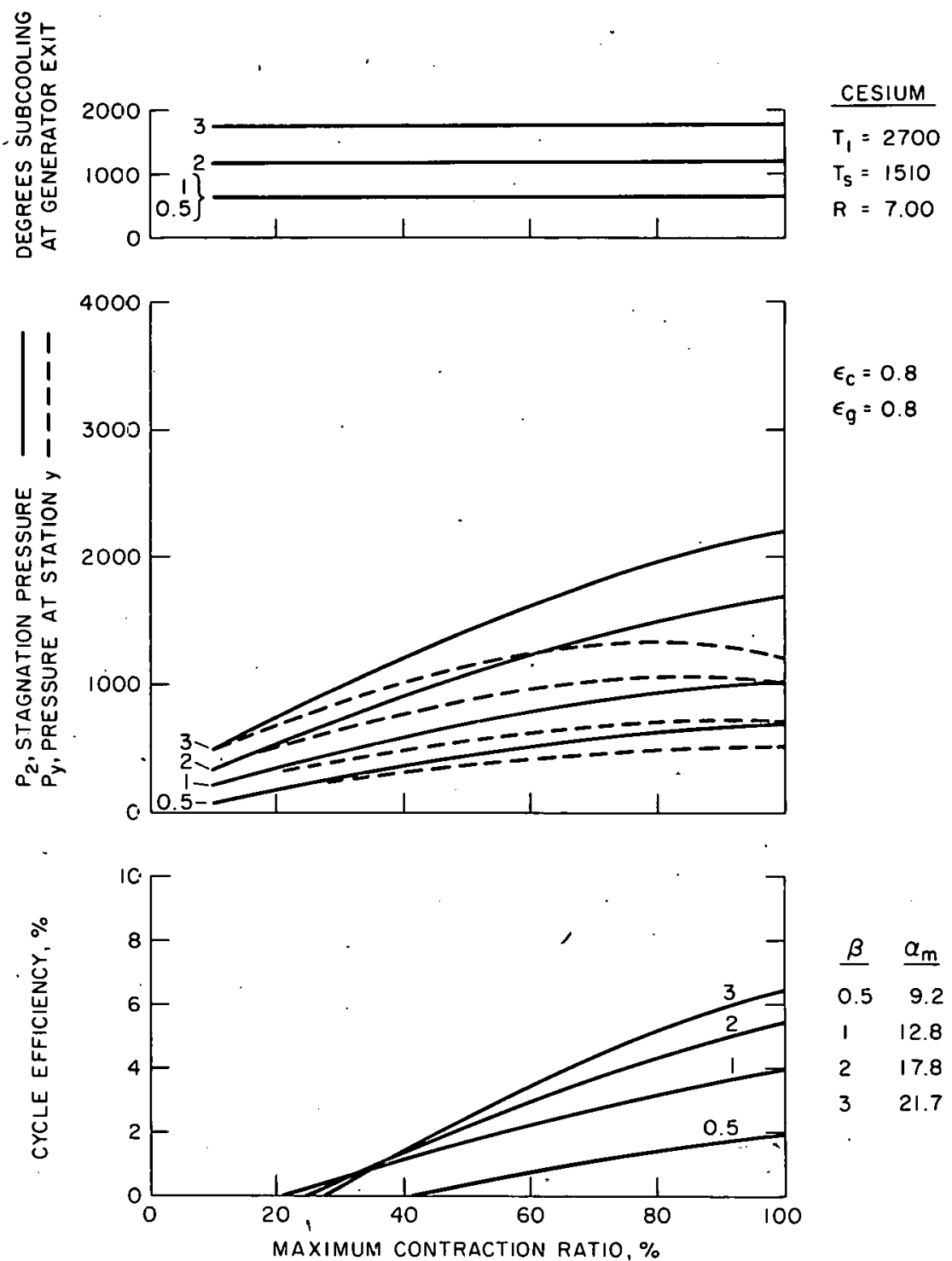

Fig. V-12. Calculated Performance Data for the Condensing injector Cycle Operating with Cesium for $\mathrm{T}_{1}=$ $2700^{\circ} \mathrm{R}, \mathrm{T}_{\mathrm{S}}=1510^{\circ} \mathrm{R}$, and $\mathrm{R}=7.00$ 
势
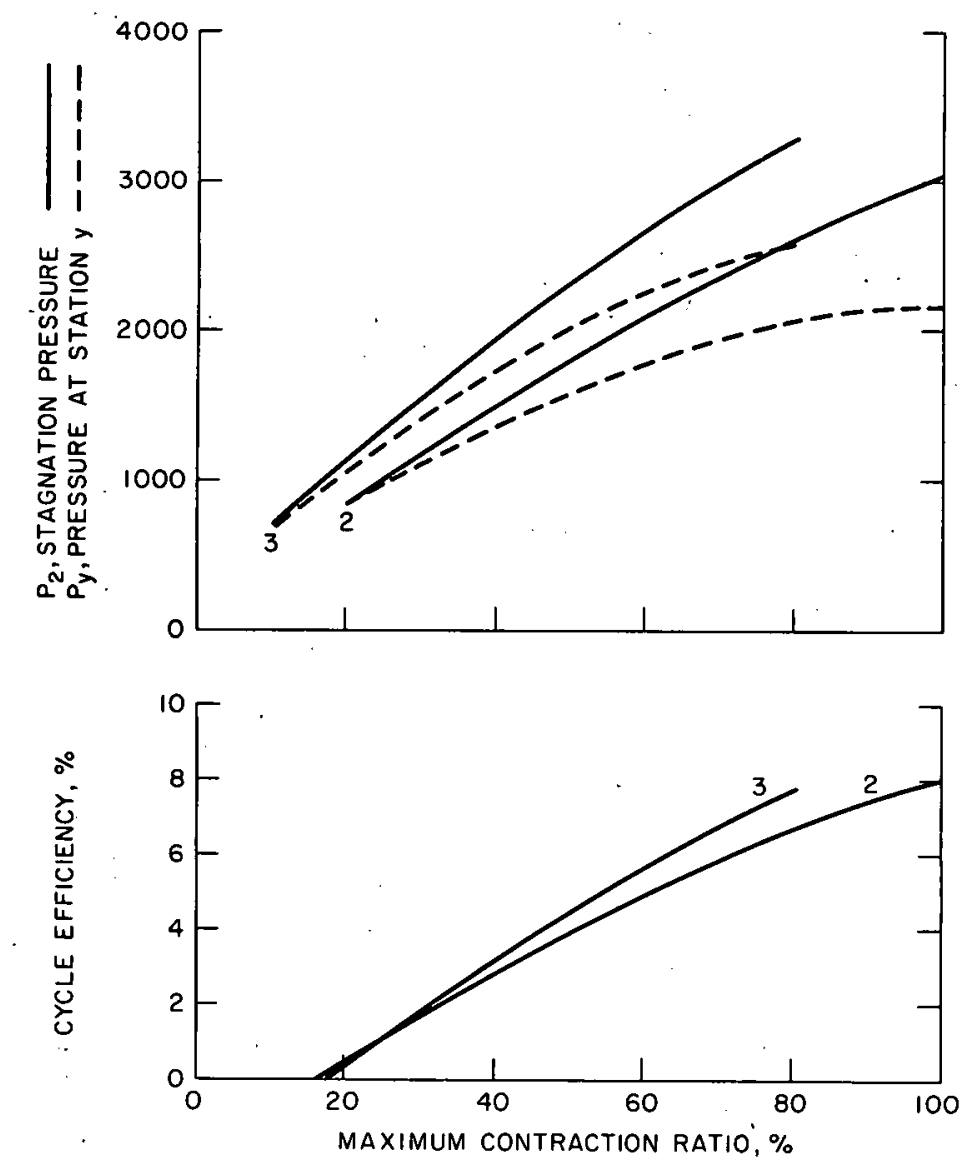

Fig. V-13. Calculated Performance Data for the Condensinginjector Cycle Operating with Cesium for $T_{1}=$ $2700^{\circ} \mathrm{R}, \mathrm{T}_{\mathrm{s}}=1860^{\circ} \mathrm{R}$, and $\mathrm{R}=3.00$
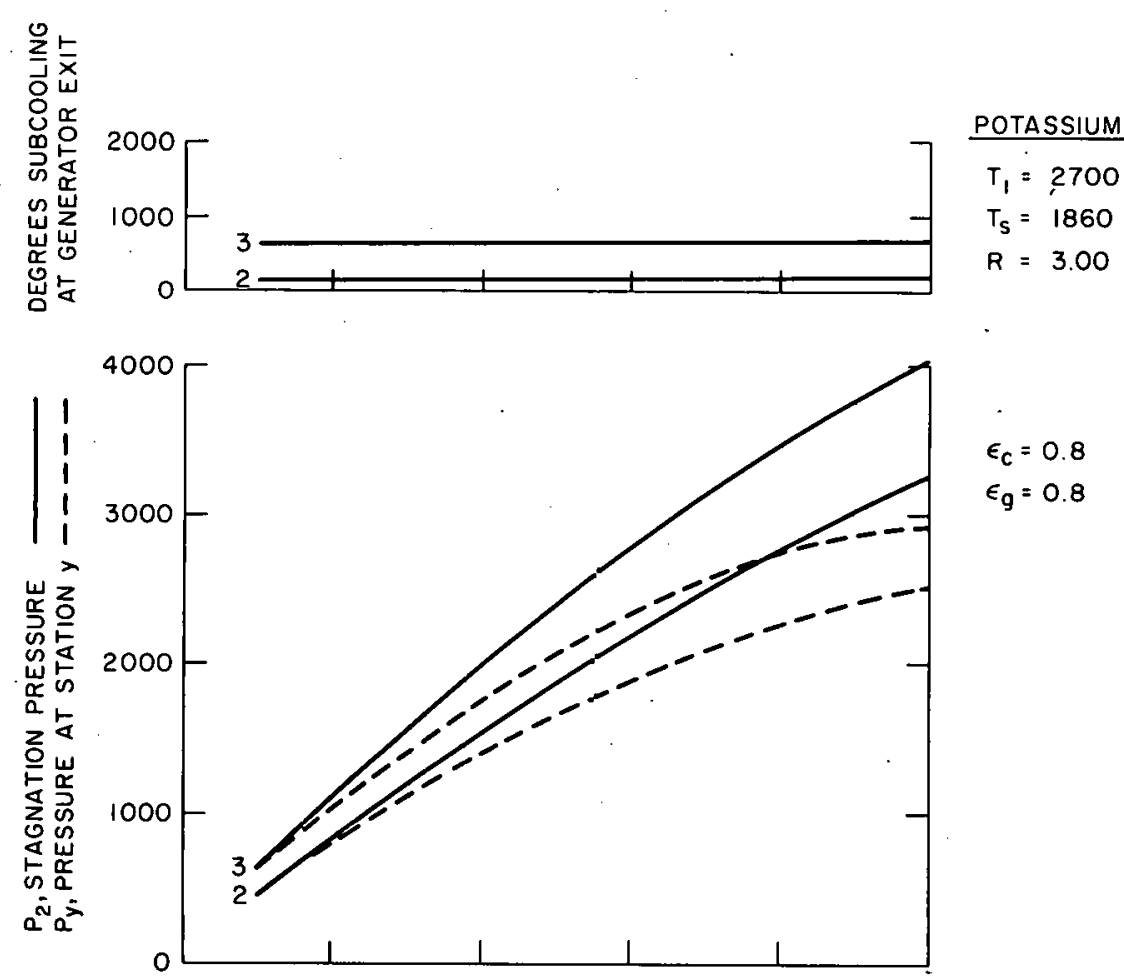

$\epsilon_{\mathrm{c}}=0.8$

$\epsilon_{\mathrm{g}}=0.8$

$\underline{\beta} \underline{\alpha_{m}}$

- -

240.3

$3 \quad 49.3$

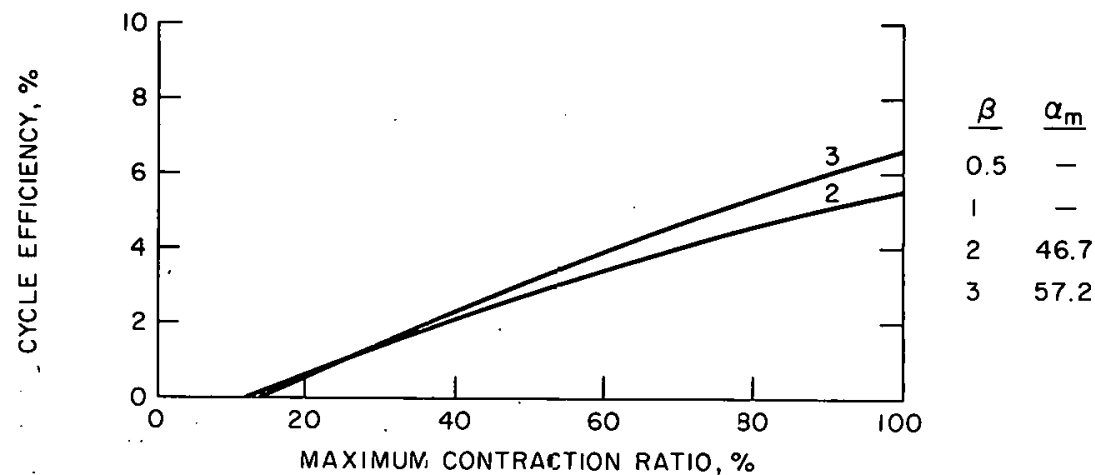

Fig. V-14. Calculated Performance Data for the Condensing injector Cycle Operating with Potassium for $\mathrm{T}_{1}=$ $2700^{\circ} \mathrm{K}, \mathrm{T}_{\mathrm{S}}=1860^{\circ} \mathrm{R}$, and $\mathrm{R}=3.00$ 


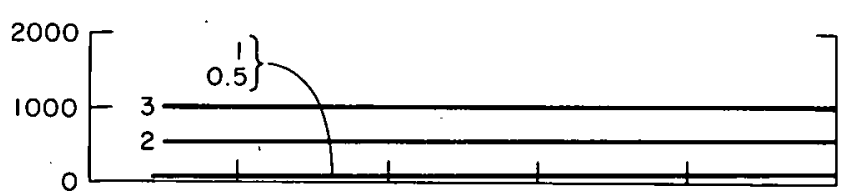

$T_{1}=2700$

$T_{s}=1860$

$R=5.60$

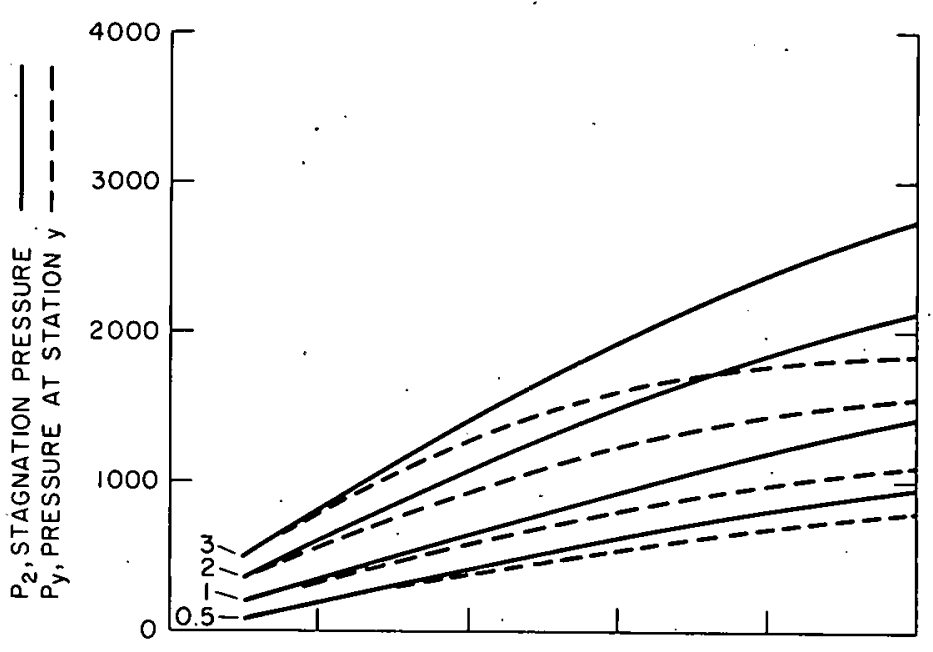

$\epsilon_{\mathrm{c}}=0.8$

$\epsilon_{\mathrm{g}}=0.8$

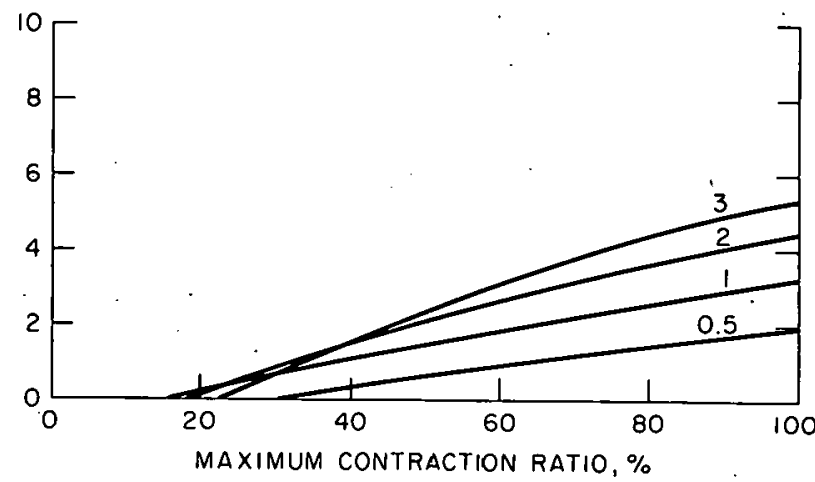

Fig. V-15. Calculated Performance Data for the Condensinginjector Cycle Operating with Potassium for $\mathrm{T}_{1}=$ $2700^{\circ} \mathrm{R}, \mathrm{T}_{\mathrm{S}}=1860^{\circ} \mathrm{R}$, and $\mathrm{R}=5.00$
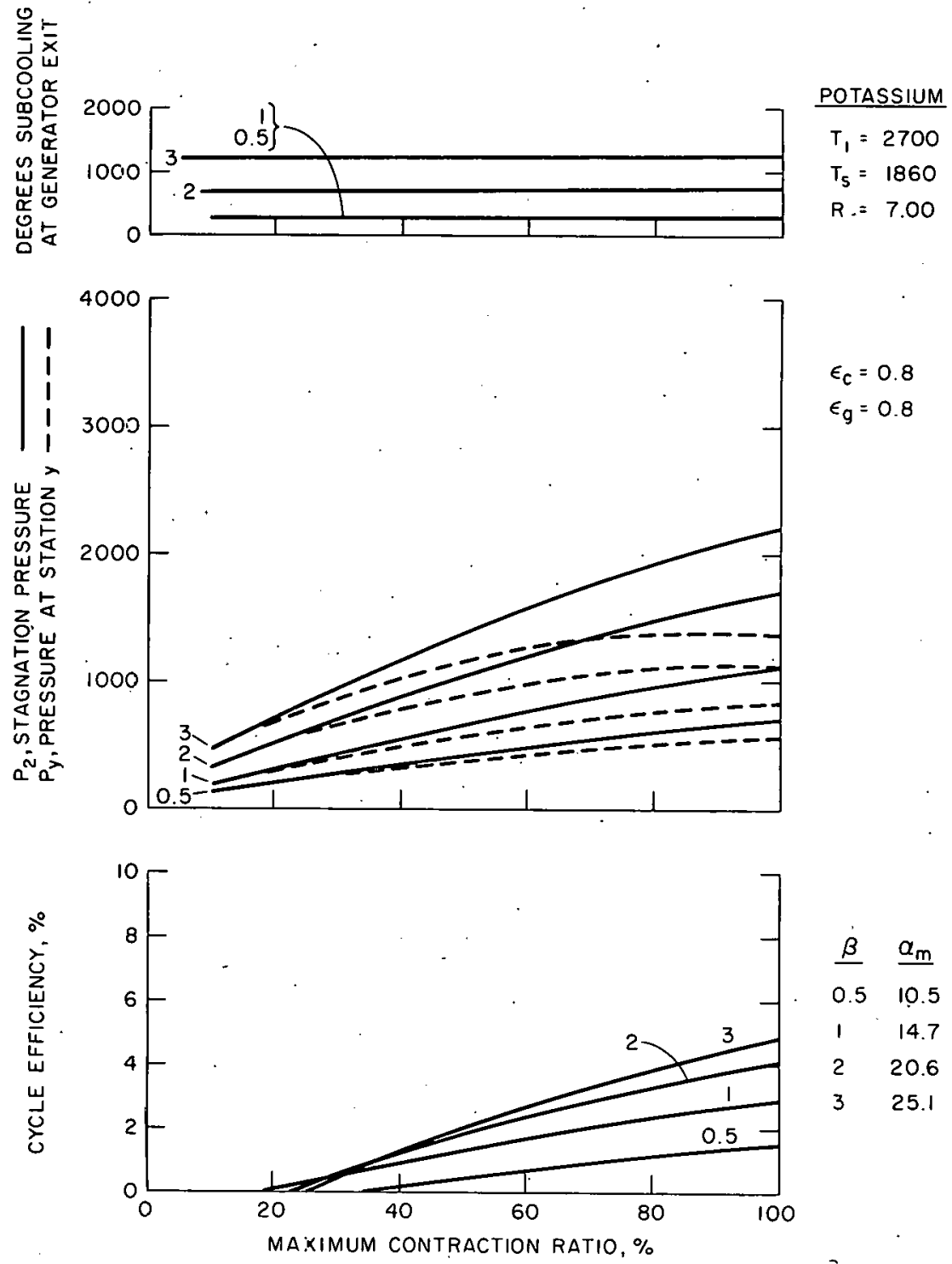

Fig. V-16. Calculated Performance Data for the Condensinginjector Cycle Operating with Potassium for $\mathrm{T}_{1}=$ $2700^{\circ} \mathrm{R}, \mathrm{T}_{\mathrm{S}}=1860^{\circ} \mathrm{R}$, and $\mathrm{R}=.7 .00$ 

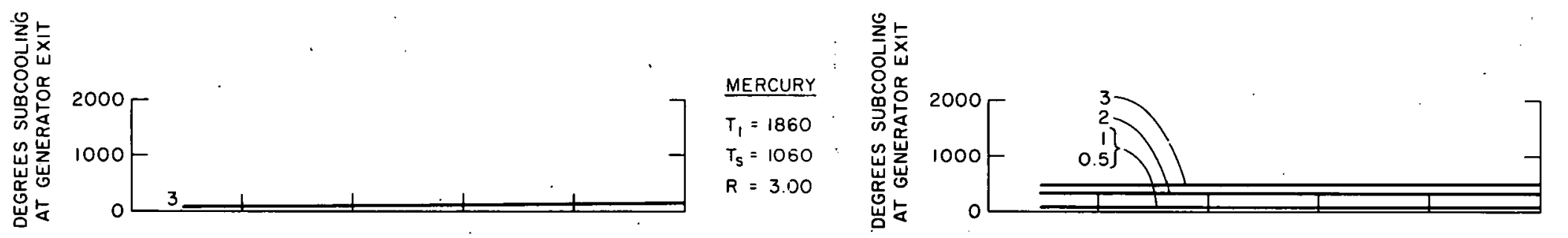

MERCURY

$T_{1}=1860$

$T_{S}=1060$

$R=5.00$

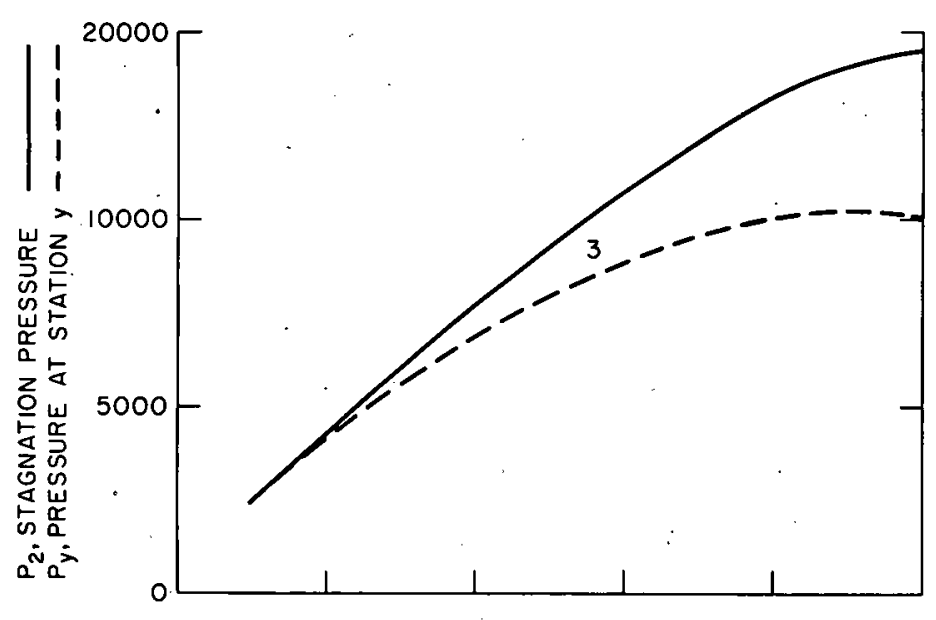

$\epsilon_{\mathrm{c}}=0.8$

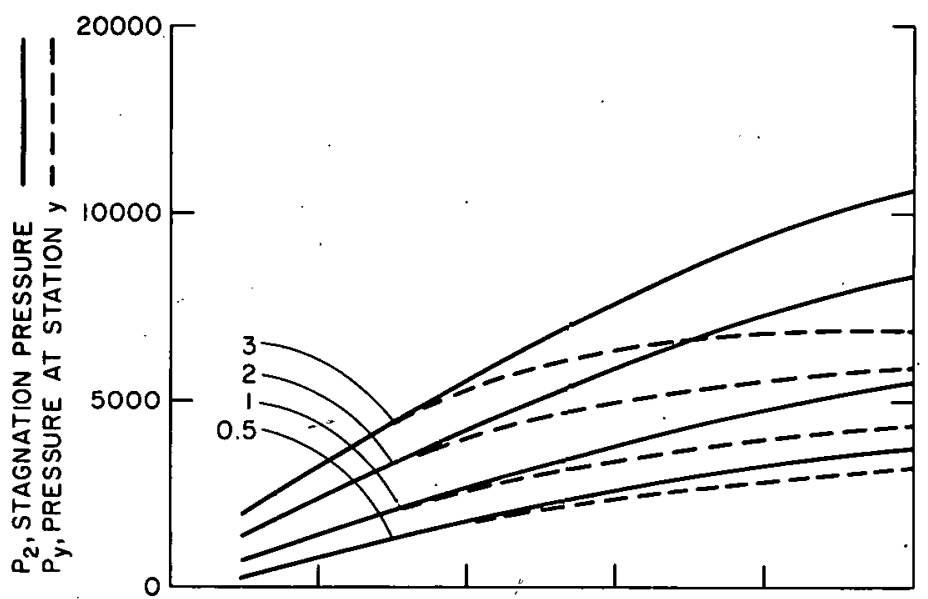

$\epsilon_{\mathrm{c}}=0.8$

$\epsilon_{9}=0.8$

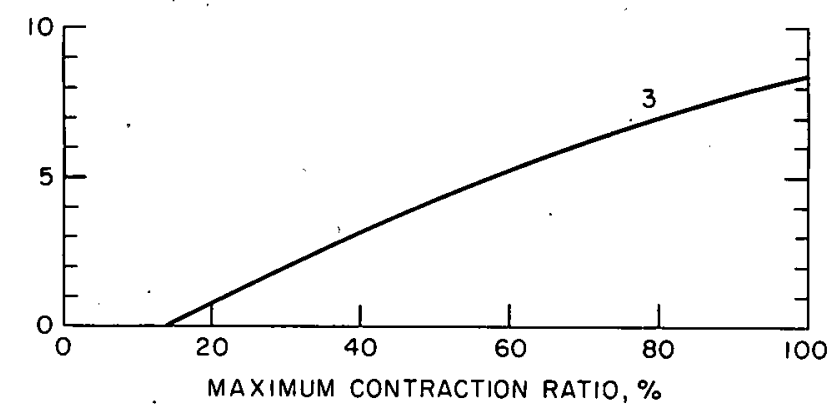

$\underline{\beta} \quad \underline{\alpha_{m}}$

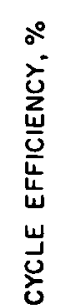

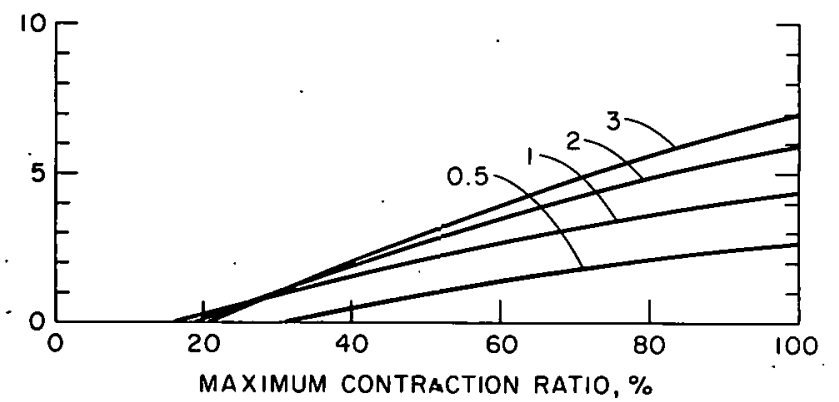

$\underline{\beta} \quad \underline{\alpha_{m}}$

Fig. V-17. Calculated Performance Data for the Condensinginjector Cycle Operating with Mercury for $\mathrm{T}_{1}=$ $1860^{\circ} \mathrm{R}, \mathrm{T}_{\mathrm{S}}=1060^{\circ} \mathrm{R}$, and $\mathrm{R}=3.00$

Fig. V-18. Calculated Performance Data for the Condensinginjector Cycle Operating with Mercury for $\mathrm{T}_{1}=$ $1860^{\circ} \mathrm{R}, \mathrm{T}_{\mathrm{S}}=10 \mathrm{E} 0^{\circ} \mathrm{R}$, and $\mathrm{R}=5.00$ 


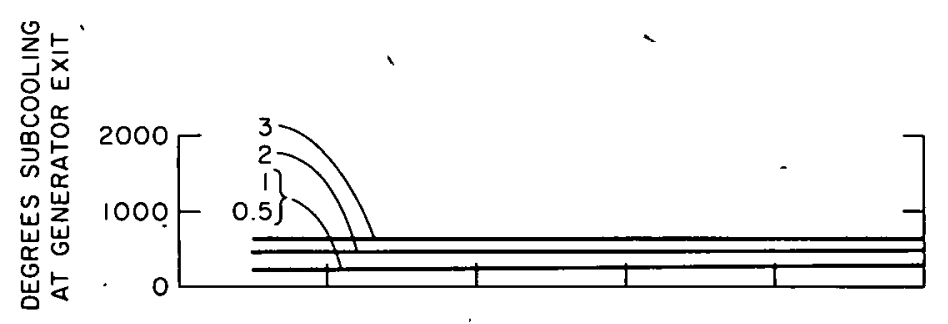

MERCURY

$T_{1}=1850$

$T_{s}=1050$

$R=7 . D$

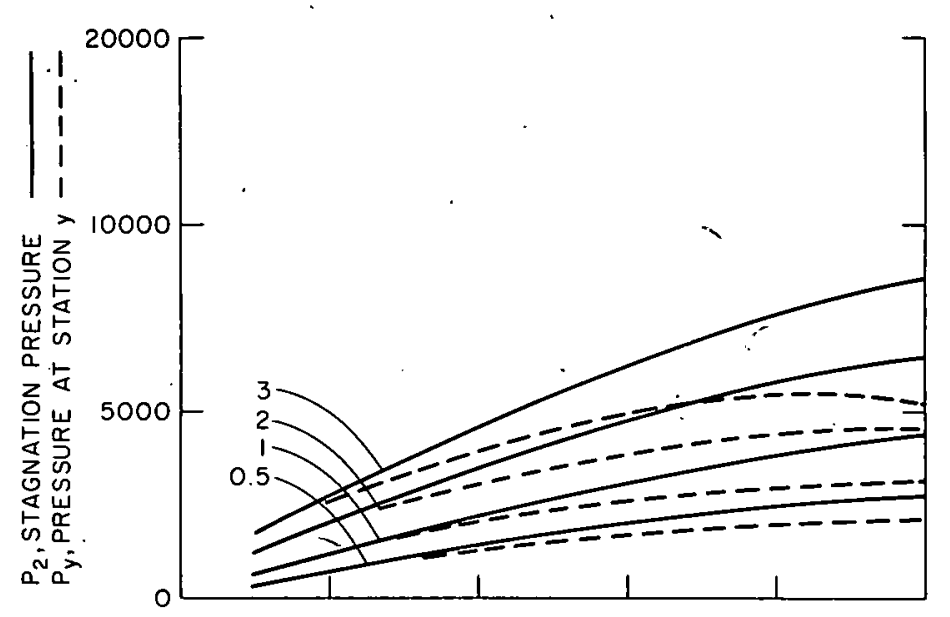

$\because$

$\epsilon_{g}=0.8$

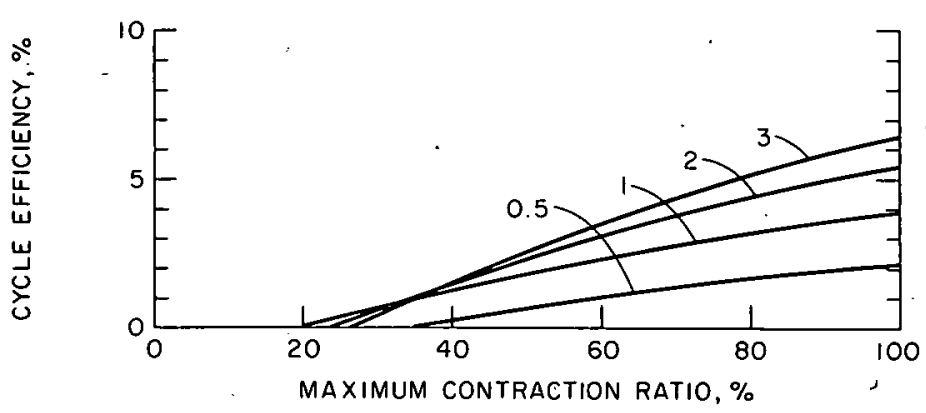

$\underline{\beta} \quad \underline{\alpha_{m}}$

0.525 .2

35.4

49.8

$3 \quad 60.8$

Fig. V-19. Calculated Performance Data for the Condensinginjector Cycle Operating with Mercury for $\mathrm{T}_{1}=$ $1860^{\circ} \mathrm{R}, \mathrm{T}_{\mathrm{S}}=1060^{\circ} \mathrm{R}$, and $\mathrm{R}=7.0$
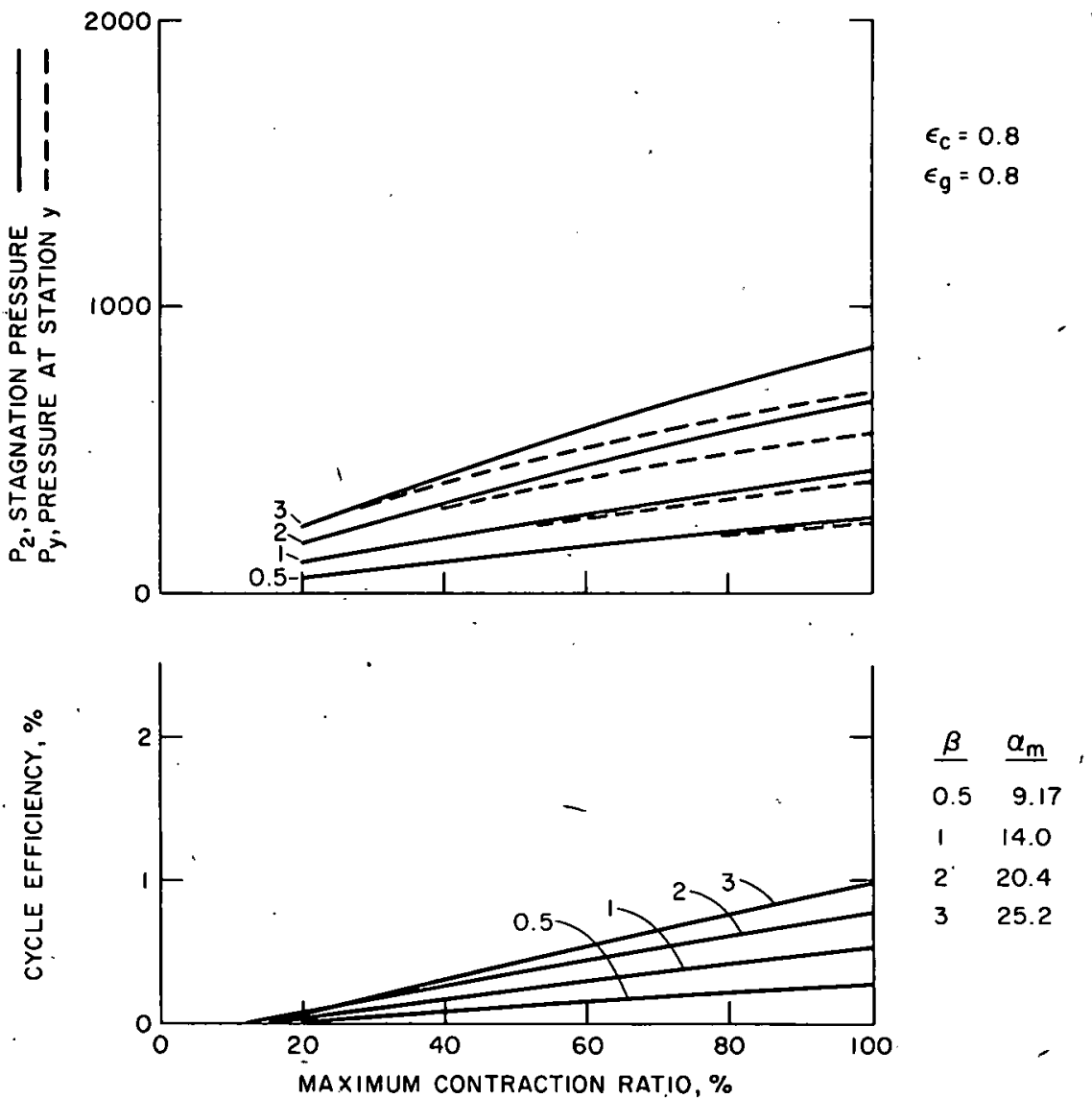

Fig. V.-20. Calculated Performance Data for the Condensinginjector Cycle Operating with Sodium for $\mathrm{T}_{1}=$ $2400^{\circ} \mathrm{R}, \mathrm{T}_{\mathrm{s}}=1060^{\circ} \mathrm{R}$, and $\mathrm{R}=7.0$ 


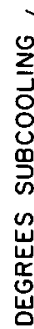

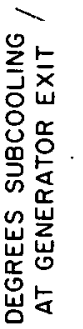

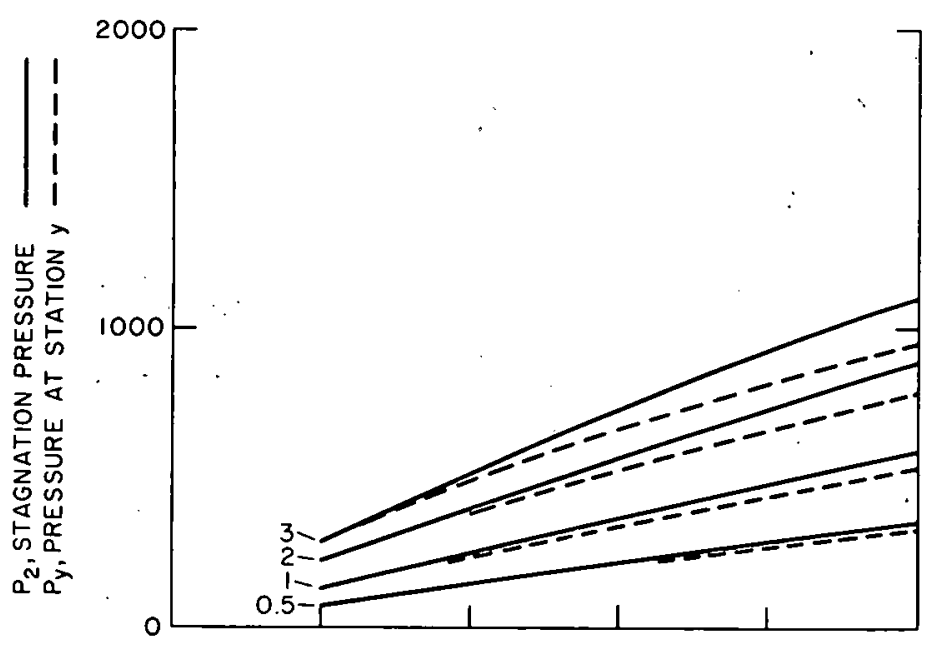

$\underline{\text { SODIUM }}$

$T_{1}=2400$

$T_{S}=1060$

$R=5.0$
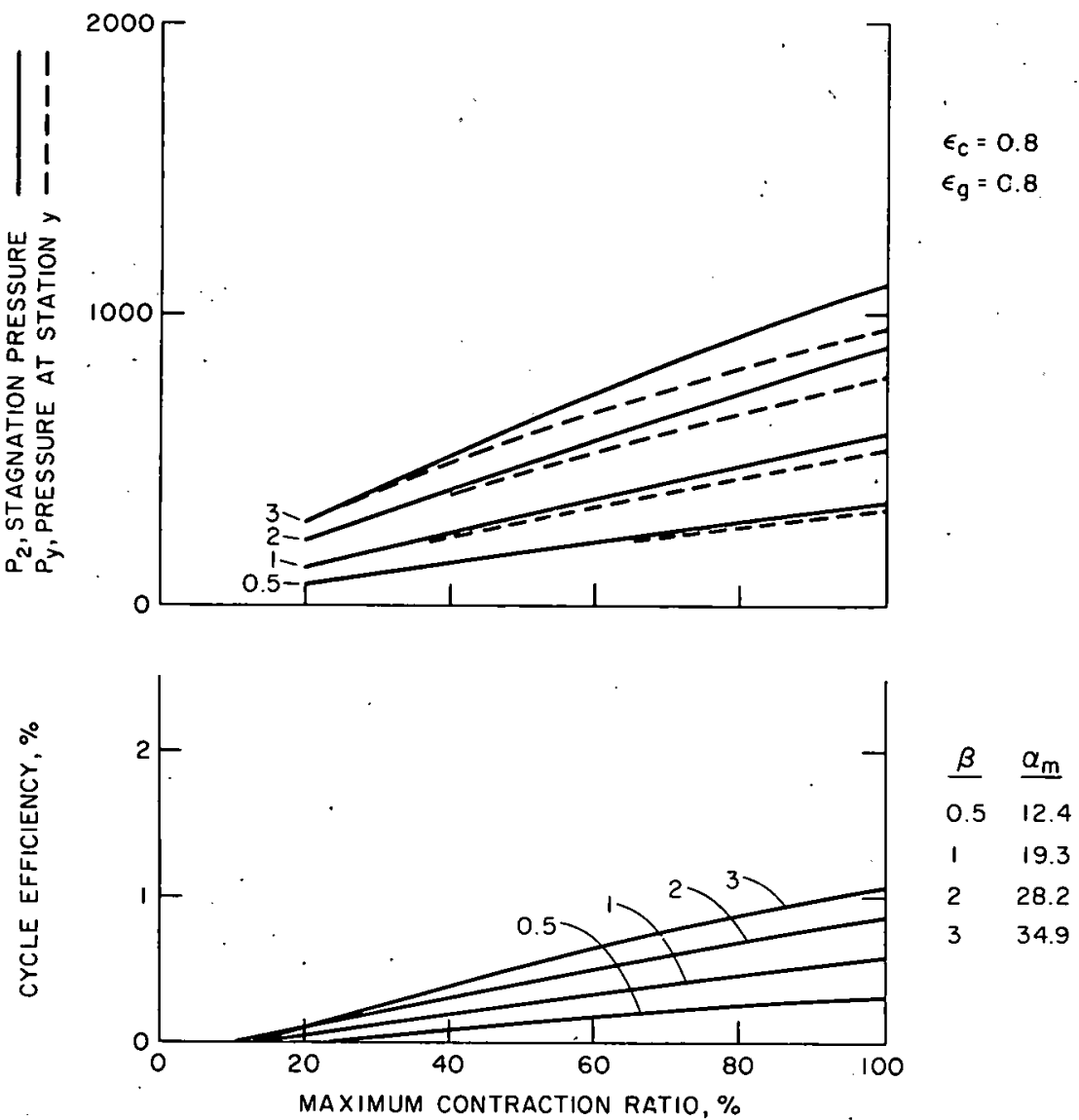

Fig. V-21. Calculated Performance Data for the Condensinginjector Cycle Operating with Sodium for $\mathrm{T}_{1}=$ $2400^{\circ} \mathrm{R}, \mathrm{T}_{\mathrm{S}}=1060^{\circ} \mathrm{R}$, and $\mathrm{R}=5.0$
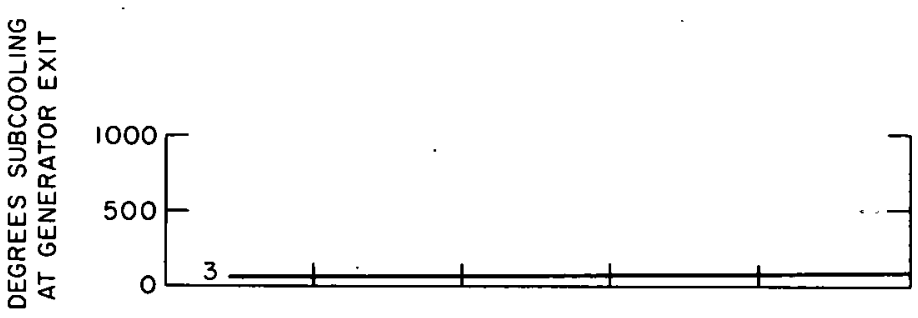

SODIUM

$T_{1}=2400$

$T_{\mathrm{S}}=1060$

$R=3.0$

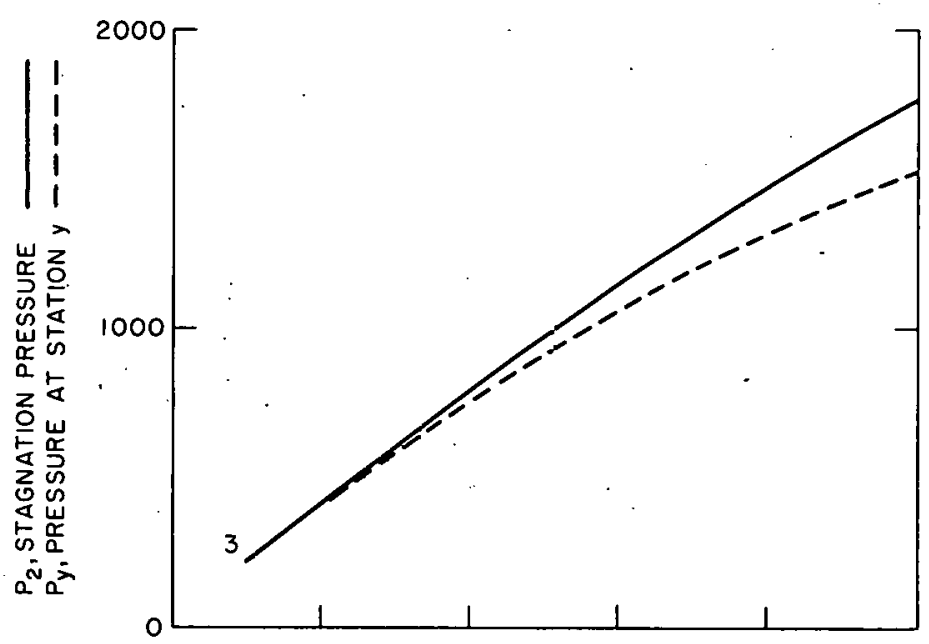

$\epsilon_{\mathrm{g}}=0.8$

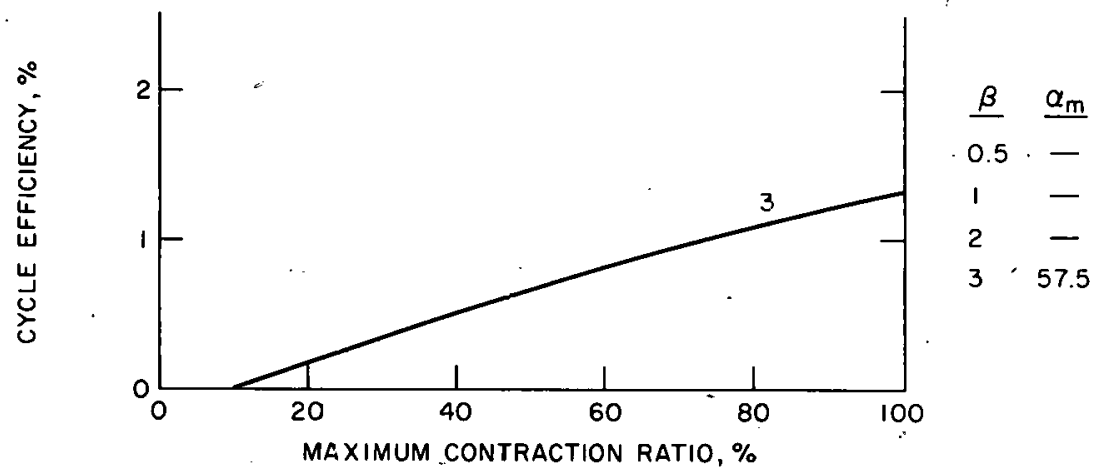

Fig. V-22. Calculated Performance Data for the Condensing injector Cycle Dperating with Sodium for $\mathrm{T}_{1}=$ $2400^{\circ} \mathrm{R}, \mathrm{T}_{\mathrm{S}}=1060^{\circ} \mathrm{R}$, and $\mathrm{R}=3.0$ 
This criterion was set because of the probable performance limitations of the condensing injector as discussed previously. Therefore

$$
A_{\text {r max }}=\frac{A_{v o}+A_{L o}}{A_{L o}}=\frac{1+\left(A_{L o} / A_{v o}\right)}{A_{L o} / A_{v o}}
$$

or

$$
A_{\text {max }}=\left(1+A R_{0}\right) / A R_{0}
$$

The decision to plot the calculated performance data against the percent of maximum contraction ratio was based on the fact that the contraction ratio is perhaps the most important variable affecting the performance of the condensing injector, and hence the cycle efficiency. Other important independent parameters shown on the curves are: inlet pressure ratio $B$, mass flow ratio $R$, and source and sink temperatures. For all the computations the assumptions were made that the MHD generator is $80 \%$ efficient and that the performance factor of the condensing injector is 0.8 .

The maximum cycle efficiencies of the condensing-injector cycle are essentially comparable with the maximum efficiency of the two-phase, two-component cycle.

The maximum cycle efficiencieo for the four liquid metals studied are listed in Table $\mathrm{V}-1$. These are approximate values (within $\pm 5 \%$ ) that have been taken from Figs. V-3 to V-22. It can be seen that the maximum cycle efficiency increases slightly with a decreasing flowrate ratio $R$. The ratio of the cycle efficiency to Carnot efficiency is in the range from 0.17 to 0.25 , which again is comparable with the ratio from the two-phase, twocomponent cycle.

Referring to Table $\mathrm{V}-1$, it is seen that mercury as a working fluid in the condensing-injector cycle produces the highest cycle effciency (10\%), followed closely by cesium at $8 \%$. Sodium as a working fluid shows the lowest performance potential.

The performance data for a cesium cycle are shown in Figs. V-3 to $\mathrm{V}-13$. This cycle was analyzed extensively to study the effects of various parameters. Some interesting trends that are apparently typical and noteworthy are:

1. Cycle efficiency increases with increasing contraction ratio. 
2. The cycle efficiency, increases with increasing inlet stagnation pressure ratio $B$, all other conditions being held constant. However, at higher values of $B$ the second law is violated at lower contraction ratios. Thus considerations of the second law limit the cycle-operating parameters.

3. As the flowrate ratio $\mathrm{R}$ is increased, the cycle efficiency tends to decrease slowly. As $R$ is decreased below a value of $\sim 3$, the smallest value presented in the figures, the efficiency continues to rise until a performance limit is again reached. The calculations show that as $R$ decreases $(R \leq 2)$ complete condensation of the vapor does not take place, as is indicated by a negative subcooling at the injector exit.

Table V-l

MAXIMUM CYCLE EFFICIENCIES

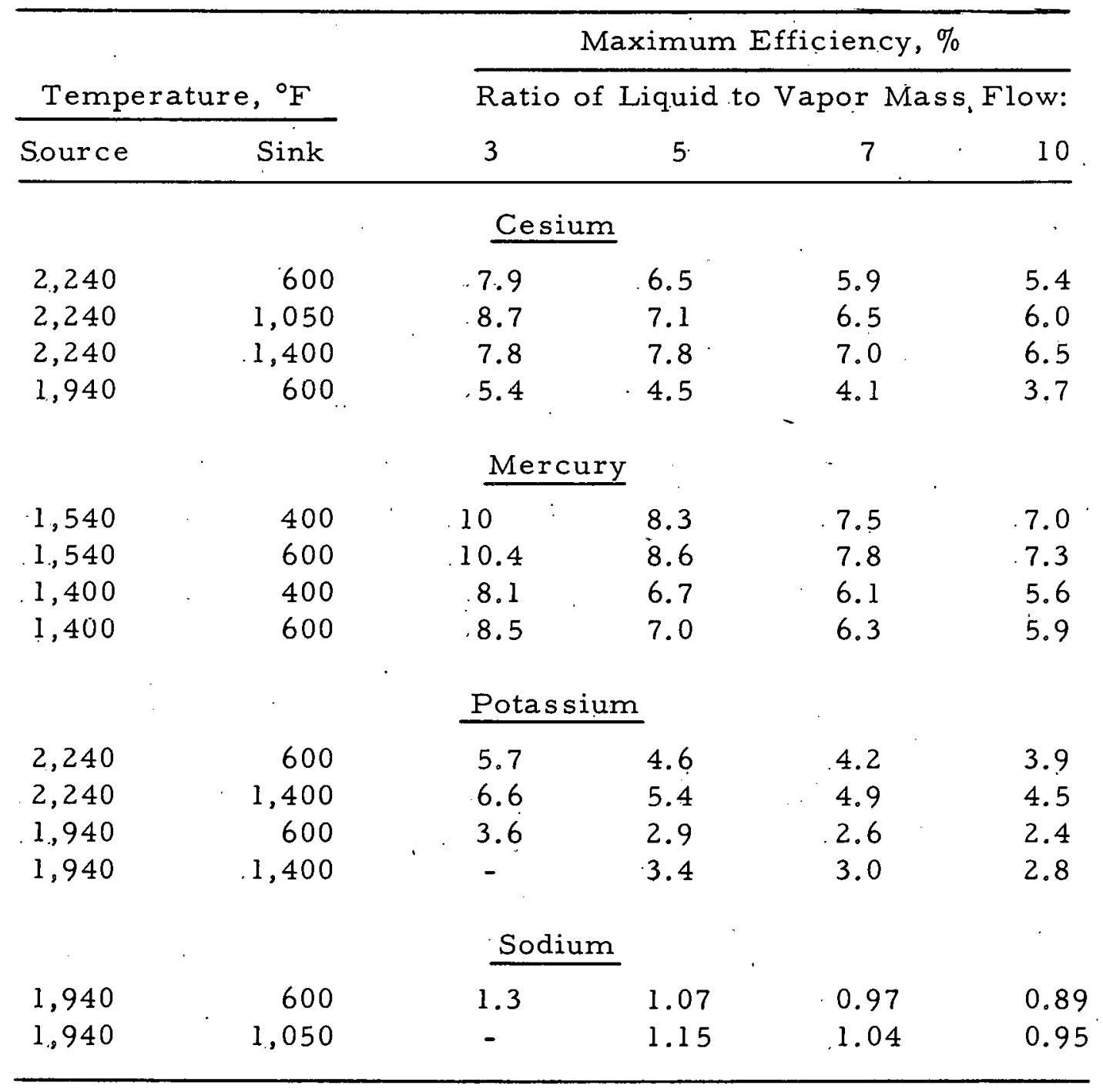


The variation of the cycle efficiency with the flowrate ratio $R$ can be illustrated analytically as follows. Referring to Eq. (V-53), the cycle efficiency is

$$
\epsilon_{c}=\frac{(1+R)\left(P_{2}-P_{3}\right) 144}{\rho_{L}\left(h_{1}-h_{3}\right) 778} .
$$

It can be shown that

$$
h_{1}-h_{3}=\frac{R}{1+R}\left(h_{1}-h_{5}\right)
$$

and

$$
P_{2}=P_{0}+\frac{W_{o}^{\prime}}{g A_{y}}\left[R V_{o}^{\prime \prime}+V_{o}^{\prime}-\frac{144 W_{o}^{\prime}(1+R)^{2}}{2 \rho_{L} A_{y}}\right] .
$$

If the mixing section area is specified as

$$
A_{y}=K A_{0}^{\prime \prime} \frac{K W_{0}^{\prime \prime}(144)}{\rho_{L} V_{0}^{\prime \prime}}
$$

Eq. (V - 58) becomes

$$
P_{2}=P_{O}+\frac{\rho_{L} V_{O}^{\prime \prime}}{144 g K}\left[V_{O}^{\prime \prime}+\frac{V_{O}^{\prime}}{R}-\frac{V_{O}^{\prime \prime}(1+R)^{2}}{2 K R^{2}}\right] .
$$

The above equations can be combined to give, after extensive algebraic manipulation,

$\frac{1}{\epsilon_{c}}=\frac{\frac{778 R}{144(1+R)^{2}}\left(h_{1 V}-h_{f_{5}}\right)+\frac{P_{1}}{\rho_{L}(1+R)^{2}}\{R(2 B-1)+B-1\}+\frac{\Delta P_{H E}-\Delta P_{H S}}{\rho_{L}(1+R)}}{\frac{\epsilon_{g} N_{c} V_{O L}}{144 g K}\left[\frac{V_{O V}}{R}+V_{O L}\left\{1-\frac{(1+R)^{2}}{2 K R^{2}}\right\}\right]+\epsilon_{g} N_{c} \frac{P_{O}}{\rho_{L}}-\epsilon_{g} \frac{B P_{1}+\Delta P_{H E}}{\rho_{L}}}+\frac{1}{1+R}$,

where

$$
V_{O L}=\left[(2 \mathrm{~g}) \overline{1} 44 \mathrm{~N}_{\mathrm{L}} \frac{\mathrm{BP} \mathrm{P}_{1}-\mathrm{P}_{\mathrm{O}}}{\rho_{\mathrm{L}}}\right]^{1 / 2}
$$

and

$$
V_{O V}=\left[2 g J\left(h_{1 V}-h_{O V}\right)\right]^{1 / 2}
$$


The above gives an expression for the cycle efficiency in terms of the basic independent parameters añd arbitrarily fixed quantities. It can be seen that for the cycle in question

$$
\frac{\Delta \mathrm{P}_{\mathrm{HE}}-\Delta \mathrm{P}_{\mathrm{HS}}}{\rho_{\mathrm{L}}(1+\mathrm{R})}=0 .
$$

For the particular case of a cesium cycle operating between $\mathrm{T}_{1}=2400^{\circ} \mathrm{R}$ and $\mathrm{T}_{\mathrm{s}}=1060^{\circ} \mathrm{R}$, with $\mathrm{B}=3, \mathrm{P}_{\mathrm{o}}=10 \mathrm{psi}$, and $\mathrm{K}=1\left(\mathrm{~A}_{\mathrm{y}}=\mathrm{A}_{\mathrm{o}}^{\prime \prime}\right)$, the cycle efficiency becomes

,

$$
\epsilon_{\mathrm{C}}=\frac{(1+\mathrm{R})\left[9.7+\frac{87.9}{\mathrm{R}}-5.1\left(\frac{1+\mathrm{R}}{\mathrm{R}}\right)^{2}\right]}{11.4+258.7 \frac{\mathrm{R}}{1+\mathrm{R}}+\frac{97.7}{\mathrm{R}}-5.7\left(\frac{1+\mathrm{R}}{\mathrm{R}}\right)^{2}} .
$$

The variation of $\epsilon_{c}$ vs $R$ is shown in Fig. V-23.

4. The cycle efficiency increases slightly with increasing sink temperature, that is, for specified parameters of $B, R$, and a given geometry which do not, violate the second law, the

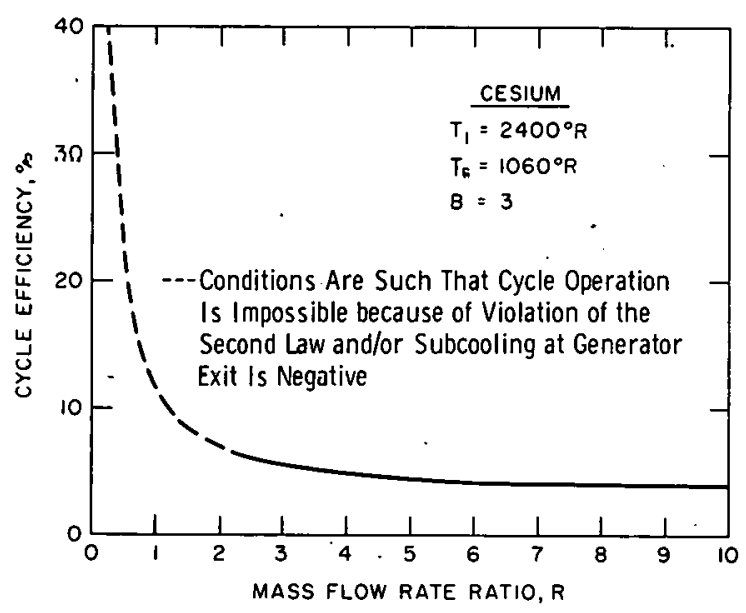

Fig. V-23. Variation of Cycle Efficiency vs Flowrate Ratio ( $R$ ) at Maximum Contraction Ratio, cycle efficiency is higher at the higher sink temperature. This effect is due to the fact that the heat input $Q_{a}$ to the vapor loop is decreased, and also the stagnation pressure generated in the condensing injector is virtually unaffected by the increased temperature of the liquid loop.

5. The subcooling at the exit of the MHD generator decreases as the mass flow ratio $R$ decreases, and this fact imposes another limitation on the potential cycle performance.

6. As the source temperature is lowered, the cycle efficiency drops substantially. This is due to the fact that the energy input into the condens ing injector is lowered, which reduces the stagnation pressure delivered into the generator. More precisely, the vapor yelocity at station $O$ is determined by the inlet vapor conditions for a fixed $P_{0}$. Thus, the decrease in source temperature reduces the enthalpy change across the vapor nozzle, which results in lower vapor velocity at position $O$. The vapor velocity at position $O$ has a rather strong effect on the pressure performance of the condensing injector. 
7. In order to achieve conditions at the exit of the condensing injector where the greatest percentage of the total stagnation head is due to the kinetic head at position $y$, the geometry of the injector must have a contraction ratio which is greater than $50 \%$ of the maximum contraction ratio. Conditions of high kinetic head and low static pressure are desirable from the considerations of both injector and MHD generator design. If a substantial portion of the total stagnation head.is kinetic head, the MHD generator may: be of the variable-area.type and thus be designed for much.lower pressures.

Similar.trends as discussed above are apparent in Figs. V-14 to $\mathrm{V}-22$ on which are plotted the performance characteristics of the condensing injector cycles for potassium, mercury, and sodium. 


\section{POTENTIAL OF LIQUID.METAL MHD CYCLES FOR COMMERCIAL APPLICATION}

From a thermodynamic viewpoint, steam is a poor working fluid since it absorbs too small a fraction of the heat input at the maximum cycle temperature. However, no other single fluid has been found which is superior to steam'when all pertinent factors are considered. A logical extension of the technology, therefore, is the combination of several working fluids into a binary cycle. The advantages of such a cycle have long been recognized, and a substantial effort has already been made in this direction with the development of the mercury-steam turbo-electric cycle. The acceptance of this concept has been delayed because of the serious problems which were encountered during its introduction. Many of these problems have been resolved, but the highest temperature of the system has been kept below $1000^{\circ} \mathrm{F}$.

The introduction of a topping cycle above $1000^{\circ} \mathrm{F}$ will create additional problems that will have to be resolved. These are concerned with special design problems arising from the ultra-high temperatures and material limitations as they effect component fabrication, cost, reliability, and, most importantly, longevity. The lifetime of power equipment vs the maximum operating temperature is shown in Fig. VI-1. The figure was taken from a recent evaluation of the SNAP program (20) and depicts typical experience gained from commercial rotating equipment, ducted gases, and reactors. Also shown on the figure are the goals of the more ambitious AEC programs. It appears that the turbo-electric topping cycle

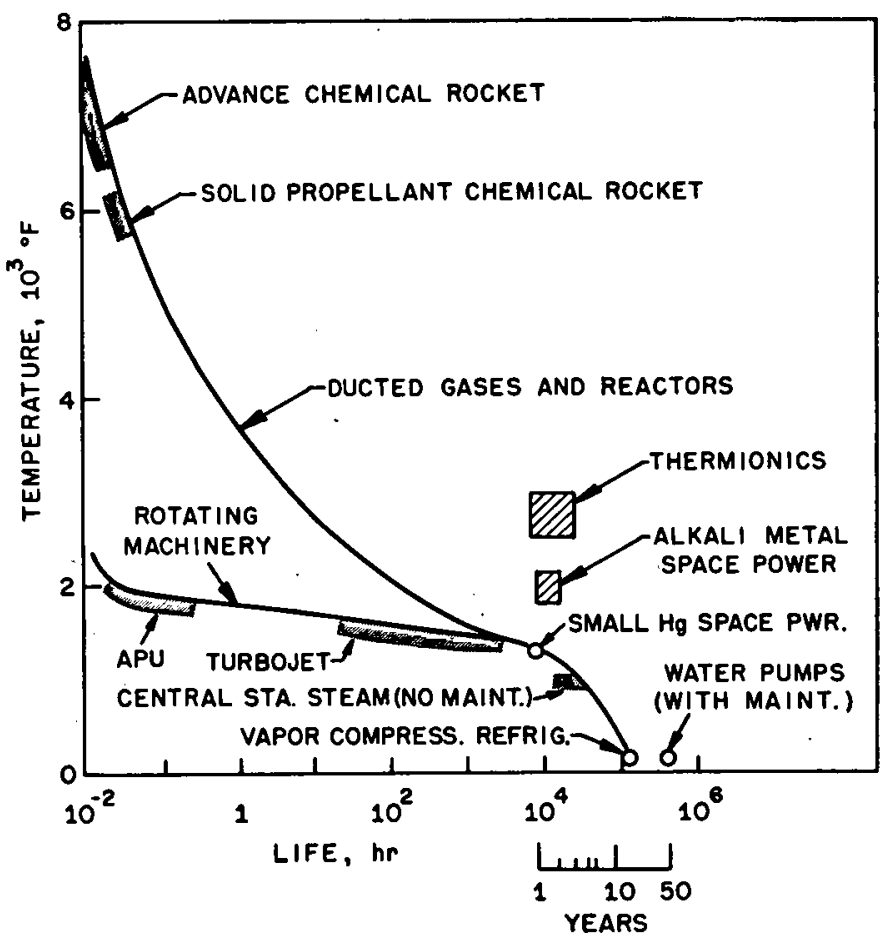

Fig. VI-1

Lifetime of Power Equipment vs Maximum Operating Temperature Tubes (from Ref. 20) 
may very well be limited to the medium-temperature range $\left(900-1400^{\circ} \mathrm{F}\right)$ because of the very serious problems that are encountered beyond this range in turbine design and in other system components, such as valving and pumps. The liquid-metal MHD topping cycle, on the other hand, shows great promise for being developed as an efficient power system which is capable of operating in the medium-temperature range (up to $2000^{\circ} \mathrm{F}$ ), as denoted by the alkali-metal space-power goals in Fig. VI-1. Unlike the conventional turbo-electric generator, the MHD generator contains no moving solid parts that are subject to extreme temperature and dynamic stress or require close machine tolerances. As a result, the MHD generator can operate under conditions of high temperatures, highly corrosive and errosive atmospheres, and temperatures where conventional energyconversion devices could not operate for prolonged periods of time.

The MHD topping cycle is a much simpler system than the turboelectric system and, therefore, more easily adaptable to high-temperature operation. The MHD generator coupled with the heat source forms one single closed loop which has no moving or rotating parts, and has a minimum of valving, etc. The MHD loop can virtually be welded shut. The working fluid is moved by the conversion of thermal to kinetic energy. It appears that the efficiency of the MHD electrical generator can be made to approach that of the turbine-generator. However, the ratio of the actual efficiency to the Carnot efficiency of the MHD topping cycle may be lower than that achieved.with a turbo-electric cycle,because of the additional losses which occur in the componento suilı ds nozzles and inverters.

\section{A. Overall Efficiencies. of Binary Cycles}

The overall efficiency and potential of a central-station power systern employing a liquid-metal MHD topping cycle are excellent. The system mentioned previously consists of a reactor heat source, MHD loop, and the normal steam plant which functions as the sink or bottoming cycle. It should be noted that a fossil-fuel-fired boiler using a liquid-metal coolant can also be utilized as the heat source. The heat transfer characteristics of the liquid metal are superior to water, and the boiler would operate at the highest cycle temperature with a low vapor pressure.

The overall efficiencies of a binary power cycle using a MHD topping cycle were computed by combining the efficiencies of the topping cycle with steam-plant efficiencies in the following manner:

$$
\epsilon_{\mathrm{C}}=\epsilon_{\mathrm{MHD}}+\left(1-\epsilon_{\mathrm{MHD}}\right) \epsilon_{\mathrm{SC}}
$$

where $\epsilon_{M H D}$ is the efficiency of the topping cycle and $\epsilon_{\mathrm{SC}}$ the efficiency of the steam bottoming cycle. 
The overall cycle efficiency, percentage increase of the cycle efficiency, and the percent of the total power generated by the MHD topping cycle are shown in Fig. VI- 2 as a function of the topping cycle efficiency and the base steam-plant efficiency. From Eq. (VI-l) it is apparent that the overall efficiency of the binary cycle increases with increasing efficiency of the topping cycle, and efficiencies greater than $50 \%$ are readily obtained when the base steam-plant efficiency $\epsilon_{S C}$ is equal or greater than $40 \%$ and the topping cycle efficiency becomes $15 \%$ or greater. The maximum overall cycle efficiency is generally reached when the secondary steam cycle is operated at maximum allowable temperature conditions. As the sink temperature is raised, the decrease in the efficiency of the topping cycle is more than offset by the increase in the steam cycle efficiency which results in a maximization of the vverall gycle. Ry combining Eq. (VI-l) with the topping-cycle data, discussed in the previous sections, the following results can be deduced:

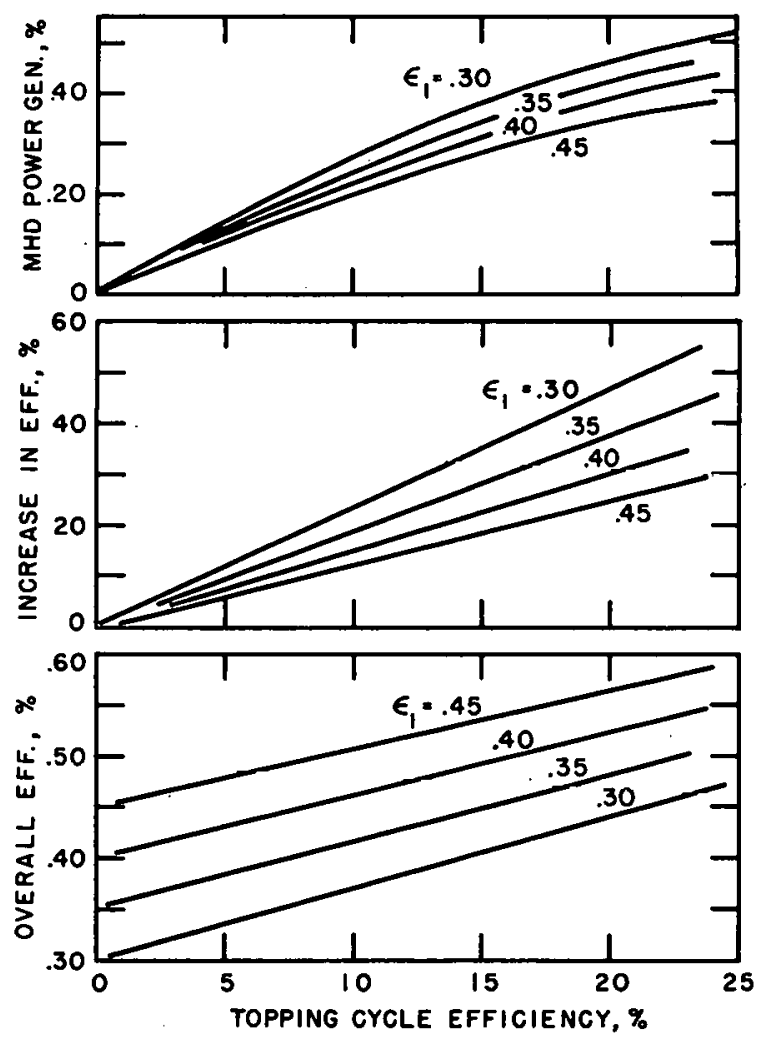

Fig. VI-2. Overall Cycle Efficiency, Percentage Increase of Cycle Efficiency, and Percent of Total Power Generated by MHD Topping Cycle vs Topping Cycle Efficiency and Steam Plant Efficiency
1. If an älkali metal is specified as the working fluid, the maximum potential efficiency of the overall cycle which is attainable ranges between $55 \%$ and $60 \%$, and results from either a potassiumor cesium-steam binary cycle. The liquid-metal topping cycle operates between a temperature range of 2240 and $1100^{\circ} \mathrm{F}$, and produces $35 \%$ of the total power. The bottoming steam plant is assumed to be the equivalent of a modern supercritical plant, such as the Eddystone unit operating at 4000 psi and $1050^{\circ} \mathrm{F}$. The efficiency of such a plant was as sumed to be $\sim 0.45$ after upgrading the published Eddystone efficiency of 0.407 . The upgrading résults from the elimination of boiler inefficiency and stack losses.

\section{The maximum potential} efficiency of the mercury-steam binary cycle is $\sim 56 \%$ and is slightly lower than that for the cesium- or potassium-steam binary cycle. This is based on a source temperature of $1540^{\circ} \mathrm{F}$ and a condenser temperature of $1100^{\circ} \mathrm{F}$. If the sink temperature

is dropped to $440^{\circ} \mathrm{F}$, the overall cycle efficiency drops to $\sim 47 \%$, even though the efficiency of the topping cycle increases substantially. From a 
thermodynamic viewpoint, mercury is the superior working fluid. It has several major drawbacks, however. The principal drawback is its rapidly rising vapor pressure at high temperature. Other drawbacks are (a) poor wettability and heat transfer characteristics which requires the use of additives; this tends to increase operational problems considerably; (b) limited availability and.(c) relatively high cost. The feasibility of the high-pressure mercury system is questionable.

3. For the medium temperature range (1100-1600\% $\mathrm{F})$, mercurypotassium alloy and potassium appear to be the most promising working fluids for the liquid-metal cycle. Overall cycle efficiencies up to $50 \%$ appear possible. The MHD topping cycle can have an efficiency as high as $15 \%$ and its maximum working pressure would be below 75 psi.

4. The working fluid most suitable for a pure MHD power cycle appears to be mercury. Mercury is súperior from a thermodynamic viewpoint, as has'been pointed out previously, and can operate in the lowest temperature range. The maximum efficiency of such a pure MHD cycle ranges between 0.20 and 0.30 , and depends upon the maximum pressure that could be tolerated in the system and the type of cycle. The feasibility of the cycle must, of course, be dictated by strictly economic considerations, which remain to be explored. The attractiveness of such a cycle is the major simplification that could be achieved in the overall plant and its components.

\section{B. Econurntc Considerations}

The attractiveness of the calculated cycle efficiencies is apparent. The incentive for development of the cycle therefore must be dictated by strictly economic considerations. Although no detailed economic studies have been made, the results of a preliminary study tend to indicate a favorable economic argument.

The rudimentary study was made for a 1000-MWe plant operating with a load factor of 0.90 . In the analysis it was assumed that operational. and maintenance costs would be unaffected by changes in the plant efficiency for a fixed plant size. Therefore, the two major areas in which a dollar savings could accrue from the introduction of a topping cycle would be (a) reduction in capital costs for the steam bottoming plant, since its capacity is reduced in proportion to the power generated in the MHD topping cycle, and (b) reduction in fuel costs arising from the increased efficiency. The dollar differential which results from these can then be considered as the amount available for converting the ordinary steam plant to the binary cycle. Any excess monies are regarded as the profit incentive. No attempt was made in this preliminary study to estimate the cost for upgrading the heat source to the elevated temperatures and for introducing the MHD topping cycle. As a result, only the total dollar differential figures are cited. 
From Fig. VI-2 it is apparent that rather modest topping cycle efficiencies can produce substantial increases (percentagewise) in the overall cycle efficiency. As an example, the introduction of a topping cycle with an efficiency of 0.15 into a modern steam plant whose efficiency $\epsilon$ is 0.38 results in an increase of $25 \%$ in the overall cycle efficiency.

Figure VI-3 shows the dollar differential which results from reduced fuel costs. The dollar savings, plotted vs the percentage increase in cycle efficiency, are based on an assumed capitalization charge of $14.7 \%$. The capitalization charge transfers the annual fuel savings to an equivalent captial expenditure. The curves shown bracket fuel costs and plant efficiencies of $\$ 0.20$ to $\$ 0.30$ per $10^{6} \mathrm{Btu}$ and $\epsilon=0.35-0.40$, respectively. These parameters are representative of current fuel costs and steam-plant technology. It can be seen that small percentage increases in plant efficiency produces very substantial dollar savings.

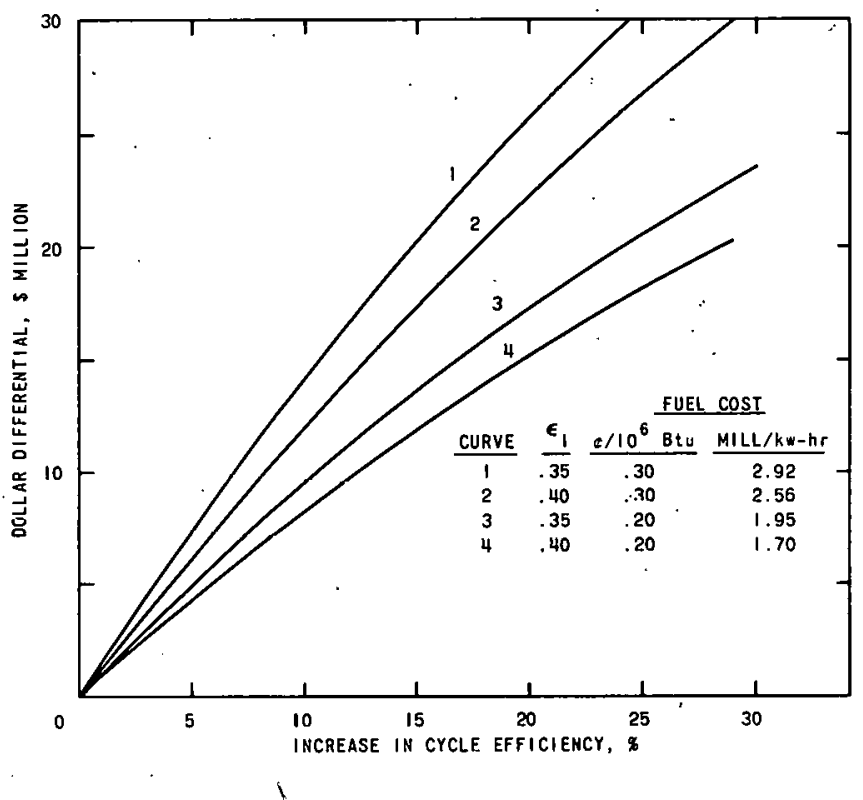

Fig. VI-3

Dollar Differential Resulting from Reduced Fuel Costs as a/Function of Increase in Cycle Efficiency

The savings accruing from the reduction in the size of the steam plant are shown in Fig. VI-4, as a function of the percentage increase in

\section{Fig. VI-4}

Dollar Differential Resulting from Reduced Steam-plant Size as a Function of Increase in Cycle Efficiency

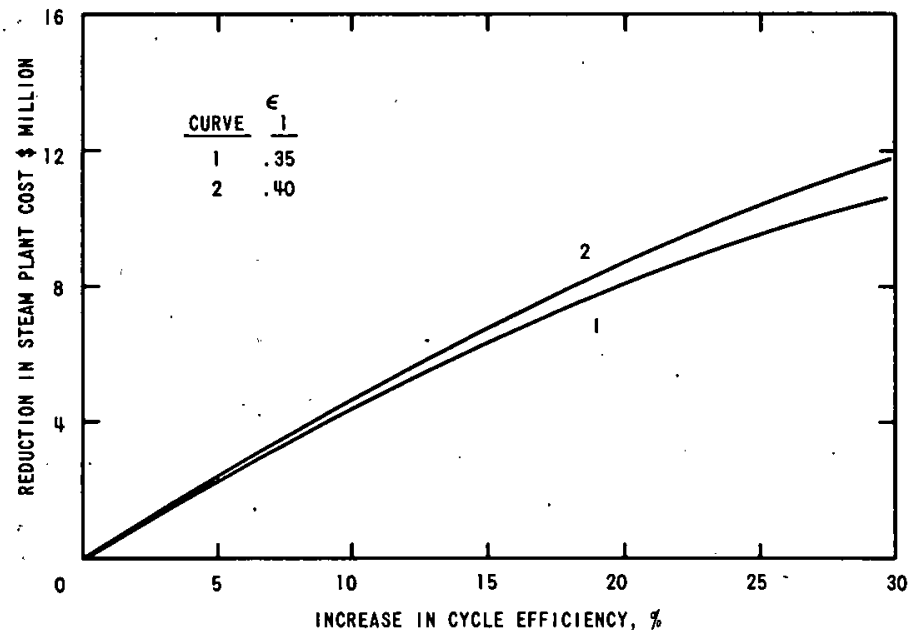


cycle efficiency. The assumed cost for the steam-turbine plant was $\$ 30 / \mathrm{kW}$. The figure is believed to be a realistic one. It is apparent that the capital cost savings are also quite important.

The total dollar differential, obtained by combining Figs. VI- 3 and VI-4, is shown in Fig. VI-5. As an illustrative example of the economic incentive involved in the addition of a MHD topping cycle, consider a base steam plant whose efficiency is 0.35 and which operates with a fuel cost of $\$ 0.20 / 10^{6} \mathrm{Btu}$. Reference to Fig. VI- 5 shows that the gross dollar differential or breakeven point is approximately $\$ 25,000,000$ for a $20 \%$. increase in cycle efficiency. From Fig. VI- 2 it can be seen that the increase in the cycle efficiency can be achieved by a MHD topping cycle whose efficiency is 0.125 . Based on the "state of the art" this efficiency. appears realistically attainable at a maximum cycle temperature of about $1600^{\circ} \mathrm{F}$.

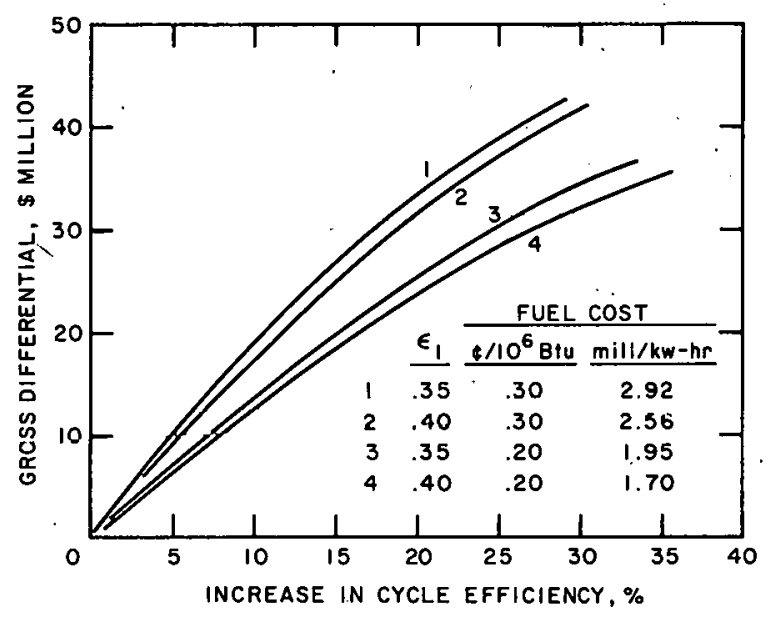

Fig. VI-5

Total Dollar Differential as a Function of Percent Increase in Cycle Efficiency

It is apparent that detailed design studies are needed to establish the economic incentive more accurately.

\section{ACKNOW LEDGMENTS}

The authors wish to express their appreciation to Michael Grolmes who performed the major portion of the calculations for the condensinginjector cycle. 


\section{REFERENCES}

1. D. G. Elliott, Two-fluid Magnetohydrodynamic Cycle for NuclearElectric Power Conversion, ARS Journal 32, No. 6 (1962). "

2. W. D. Jackson and G.. A. Brown, Liquid Metal Magnetohydrodynamic Power Generator Utilizing the Condensing Ejector, Patent Disclosure, M.I.T., Cambridge, Mass. (Oct 1962).

3. Michael Petrick and Kung-You Lee, Performance Characteristics of a Liquid Metal MHD Generator, ANL-6870 (July 1964).

4. J. P. Penhune, Energy Conversion in Laminar MHD Channel Flow, ASDTR 61-294 (1961).

5. G. W. Sutton, The Theory of Magnetohydrodynamics Power Generators, Space Science Laboratory R62SD990 (1962).

6. A. Sherman, Exact Solutions for Magnetohydrodynamic Channel Flows, Space Science Laboratory R62SD991 (1962).

7. W. D. Jackson, Magnetohydrodynamic Channel Flow (unpublished

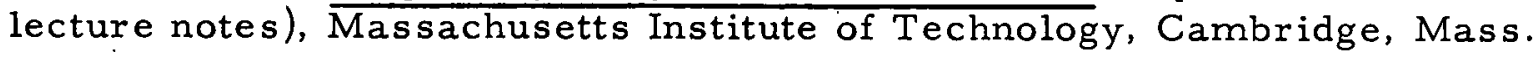

8. Michael Petrick and Kung-You Lee, Performance Characteristics of a Liquid Metal MHD Generator, International Symposium on Magnetohydrodynamic Electric Power Generation, Paris, France, Paper 62, (July 1964).

9. G. W. Sutton, H. Hurwitz, Jr., and H. Poritsky, Electrical and Pressure Losses in a Magnetohydrodynamic Channel Due to End Current Loops, Trans. AIEE, I (Commun. and Electronics No. 58) (1962).

10. M. Kh. Kbragimov, Ye. V. Nomofilov, and V. I. Subbotin, Heat 'Transfer and Hydraulic Resistance During Helical Flow of a Fluid in a Tube, Trans. FTD-TT-62-315-1+2+4, Teploenergetika, No. 7, 57-60 (1961).

11. D. G. Elliott, D. J. Cerini, and E. Weinberg, Investigation of Liquid Metal MHD Power Conversion, Third Biennial Aerospace Power Sys tems Conference, AIAA Paper No. 64-760, Philadelphia, Penn. (Sept 1964).

12. W. F. Wade and M. B. Moffett, The Bubble-flow Magnetofluid Mechanical Energy Conversion System for Space Power, ER-5978 (May 1964).

13. J. C. Maxwell, A Treatise on Electricity and Magnetism, Oxford University Press, Vol. 1, 3rd Edition (1904).

14. W. D. Weatherford, J. C. Tyler and P. M. Ku, Properties of Inorganic Energy-Conversion for Heat-Transfer Fluids for Space Application, WADD TR-61-96 (Nov 1961).

15. A. Roeder and W. Morawietz, Investigation on the Occurrence of Compound Molecules in Vapor of Potassium Amalgam Melts.

Z. Elektrochem. 60, 431-454 (1956). 
16. - G. A. Brow11, An Analysis of Performance Data from the NUOS Condensuctor $\bar{T}$ est Facility with a New Theory for the Variable-area Condensuctor, Joseph Kay and Co., Inc., Cambridge, Mass., Report 44, (1961).

17. J.. Miguel and G. A. Brown, An Analytical and Experimental Investigation of a Condensing Ejector with a Condensable Vapor, lst AIAA Annual Meeting, Paper No. 64-469 (June-July 1964).

18. Lance Hays, Investigation of Condensers Applicable to Space Power Systems, Part II, Jet Condensers, Electrical Optical Systems, Report 1588-Final II (Nov 1962).

19. R. P. Rose, Steam Jet Pump Analysis and Experiments, Bettis Atomic Power Laboratory, WAPD-TM-227 (June 1960).

20. An Evaluation of Systems for Nuclear Auxiliary Power, U. S. Atomic Energy Commission; TID-20079 (Jan 1964). 